\title{
Power, Media and Development: A study of the Solomon Islands
}

By

\section{Adele Broadbent}

2012

A thesis submitted to Victoria University of Wellington in partial fulfilment of requirements for the degree of Master of Development Studies

School of Geography, Environment and Earth Sciences Victoria University of Wellington 



\section{ACKNOWLEDGMENTS}

First of all I would like to thank those in the Solomon Islands who contributed to this research. You were so generous with your time, thoughts and analysis.

I would like to sincerely thank my partner and my boys who allowed me to be an 'overage pikinini' (Pidgin for mature student), and who encouraged me with love and undying faith throughout.

I want to acknowledge the love and support of the other Masters students especially Renee and Morgan. You are a constant inspiration.

And finally my supervisor, John Overton, whose unfailing enthusiasm and openness was a joy to work alongside. 


\section{ABSTRACT}

Development donors spend millions of dollars a year on Media Development. Supporting the growth of a free and pluralistic media is being heralded as an integral part of working towards good governance and democracy in developing countries. It is seen as a technology transfer, apolitical and worthy. This research seeks to explore development donors' use of Media Development as part of an overall state-building strategy. It has investigated this by looking at the history and contemporary experience of the growing Media Development sector. It has uncovered growing unease around the priorities of the programmes used in this area. There are charges that its religious adherence to the commercialised neoliberal model of media threatens to marginalise the poor. There are concerns that Media Development is seen by donors as a way of training the 'watchdog' to oversee the funds that they no longer have control over in the new aid modality.

This research is grounded in the Solomon Islands where a relatively new local media is the subject of a Media Development programme. This is a country that wears the labels of a 'least developed nation' and, in the recent past, a 'post-conflict country' and a 'failed state'. The thesis is an attempt to get a snapshot of the Solomon Islands' media and its relationship with aid donors by exploring these ideas with journalists, civil society, the main media assistance programme, commentators, and villagers living outside of the capital of Honiara.

While the majority of the contributors see a Western model of media as inevitable with globalisation, there would appear to be an appetite for conversations around a more indigenised media that engages more fully with the local reality. There is an identifiable gap in research in this area of Media Development as a donor tool. 


\section{LIST OF ACRONYMS}

$\begin{array}{ll}\text { ABC } & \text { Australian Broadcasting Corporation } \\ \text { ADB } & \text { Asian Development Bank } \\ \text { AuSAID } & \text { Australian Agency for International Development } \\ \text { BBC } & \text { British Broadcasting Corporation } \\ \text { CIESPAL } & \text { Centro Internacional de Estudios Superiores de Comunicación para } \\ & \text { América Latina) } \\ \text { CPI } & \text { Consumer Price Index } \\ \text { CPJ } & \text { Committee to Protect Journalists } \\ \text { DAC } & \text { Development Assistance Committee } \\ \text { DFID } & \text { U.K. Department for International Development } \\ \text { EU } & \text { European Union } \\ \text { FIA } & \text { Freedom of Information Act } \\ \text { GDP } & \text { Gross Domestic Product } \\ \text { ICT } & \text { Information and Communication Technology } \\ \text { IDG } & \text { International Development Group (MFAT) } \\ \text { IMF } & \text { International Monetary Fund } \\ \text { INGO } & \text { International Non Government Organisation } \\ \text { MASI } & \text { Media Association of Solomon Islands } \\ \text { MDGs } & \text { Millennium Development Goals } \\ \text { MEF } & \text { Malaitan Eagle Force } \\ \text { MIRAB } & \text { Migration Remittances Aid and Bureaucracy } \\ \text { NGO } & \text { Non Government Organisation } \\ \text { NZAID } & \text { New Zealand Agency for International Development } \\ \text { ODA } & \text { Official Development Assistance } \\ \text { OTI } & \text { Office of Transitional Institutions } \\ \text { PasiMA } & \text { Pasifika Media Association } \\ \text { PINA } & \text { Pacific Island News Association } \\ \text { RAMSI } & \text { Regional Assistance Mission to the Solomon Islands } \\ \text { RNZ } & \text { Radio New Zealand } \\ \text { ROC } & \text { Republic of China Taiwan } \\ \text { SOLMAS } & \text { Solomon Island Media Assistance Scheme } \\ \text { TPA } & \text { Townsville Peace Agreement } \\ \text { TA } & \text { Technical Assistance } \\ \text { UN } & \text { United Nations } \\ \text { UNDP } & \text { United Nations Development Programme } \\ \text { UNESCO } & \text { United Nations Educational, Scientific and Cultural Organization } \\ \text { USAID } & \text { United States Agency for International Development } \\ \text { WAN } & \text { World Association of Newspapers } \\ \text { WHO } & \text { World Health Organisation } \\ & \end{array}$




\section{CONTENTS}

1.1 INTRODUCTION

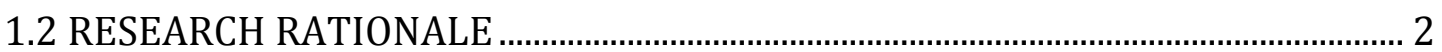

1.3 RESEARCH AIMS AND OBJECTIVES ............................................................................. 4

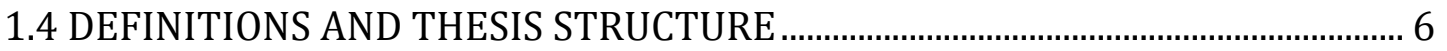

2.1 INTRODUCTION

2.2 THE EVOLUTION OF MEDIA DEVELOPMENT ….................................................... 10

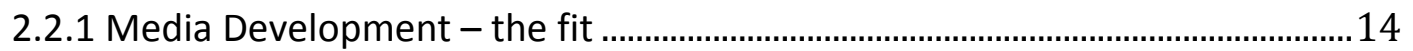

2.3 MEDIA DEVELOPMENT - A HETEROGENEITY OF INTENTIONS ........................16

2.3.1 A minor case study - Media Development Afghanistan .....................................20

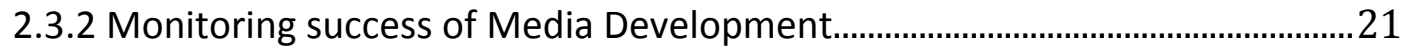

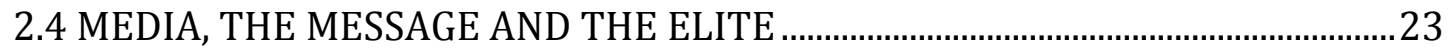

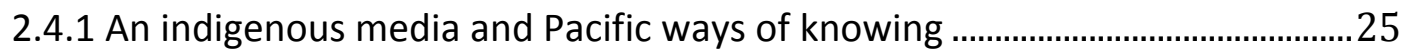

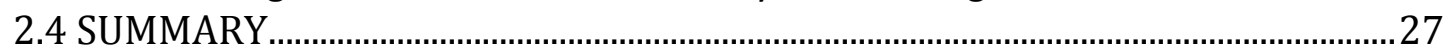

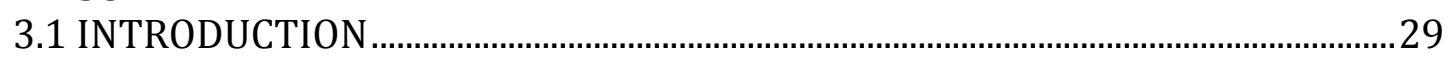

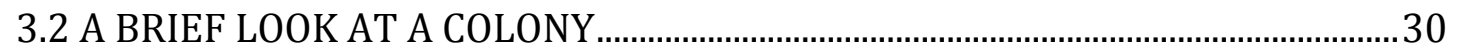

3.3 INDEPENDENCE AND THE LANGUAGE OF FAILURE .............................................3

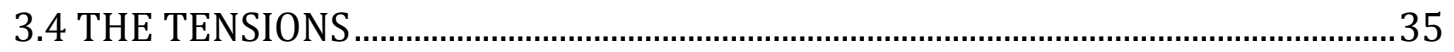

3.5 A 'FAILED STATE': THE LANGUAGE OF THE INTERVENTION .............................36

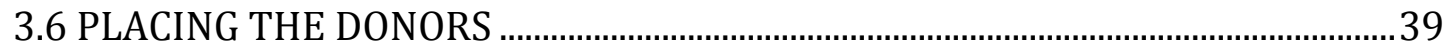

3.7 THE PARALLEL HISTORY OF THE MEDIA …….....................................................4

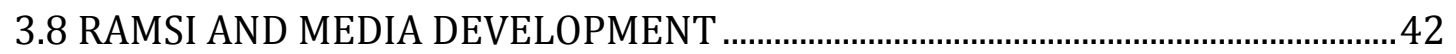

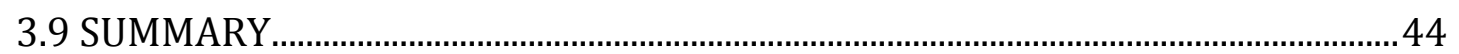

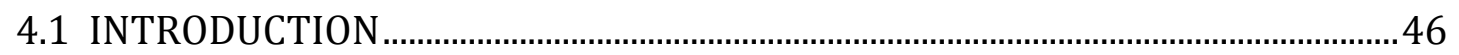

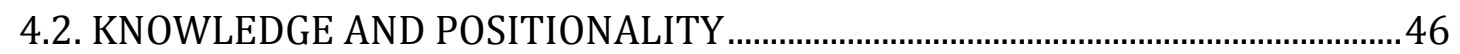

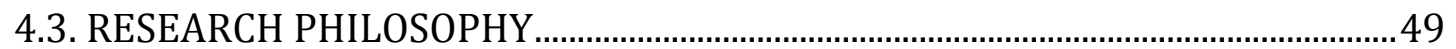

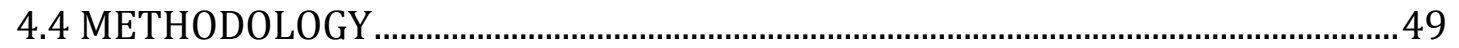

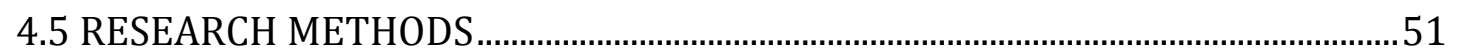

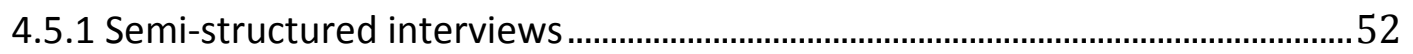

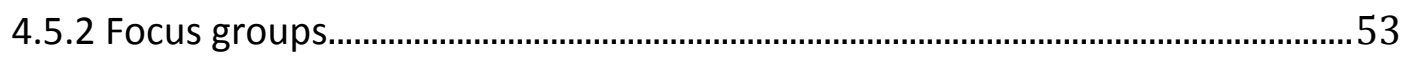

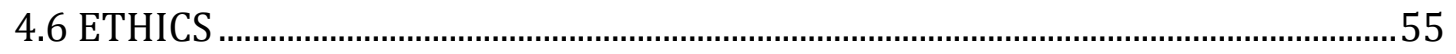

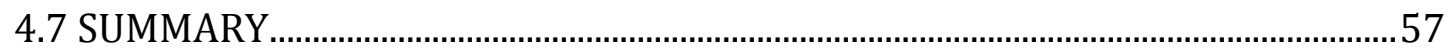

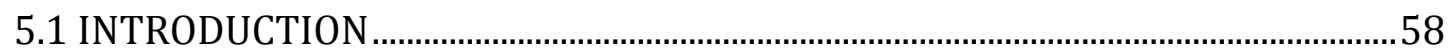

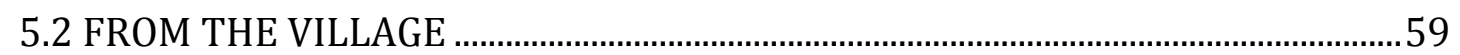

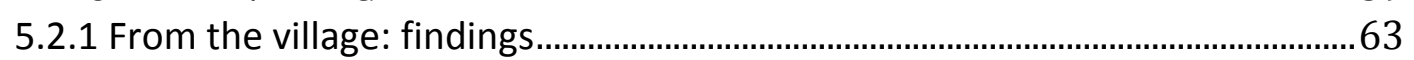

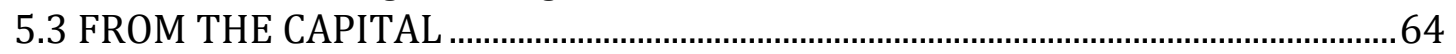

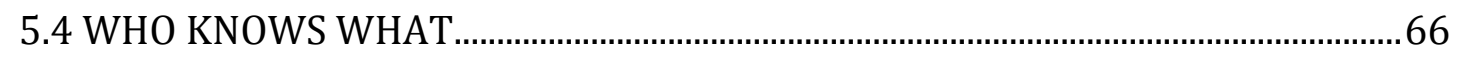

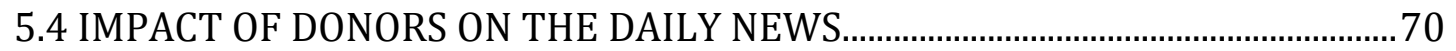

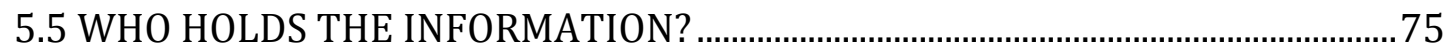

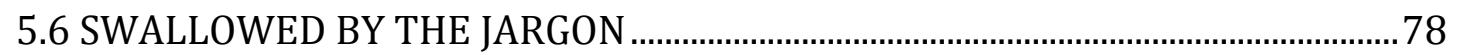

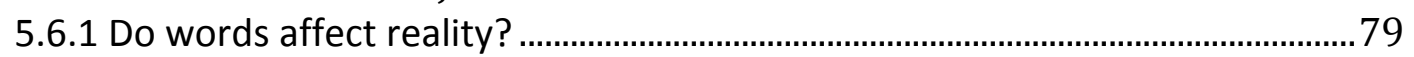

5.7 THE ‘CORRUPTION’ AND 'GOOD GOVERNANCE’ STORY ........................................

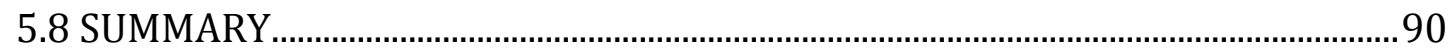

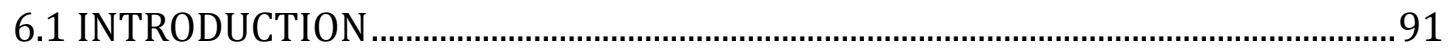

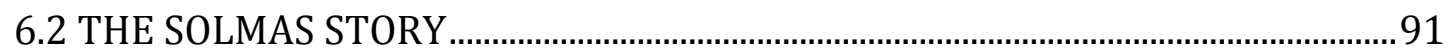

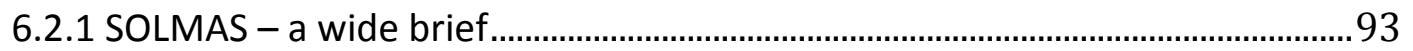

6.3 A CULTURE CLASH …........................................................................................... 98 
6.3.1 Adapting to the wantok 102

6.3.2 A place for Pidgin 105

6.4 AN ALTERNATIVE MEDIA MODEL? .................................................................... 107

6.5 SUMMARY 110

7.1 INTRODUCTION 112

\section{LIST OF FIGURES}

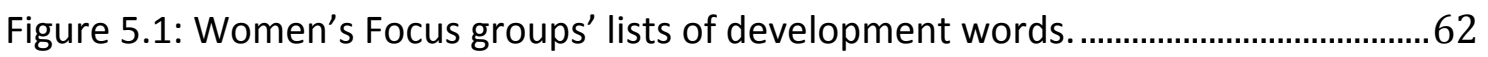

Figure 5.2 Men's focus groups' lists of development words..............................................63

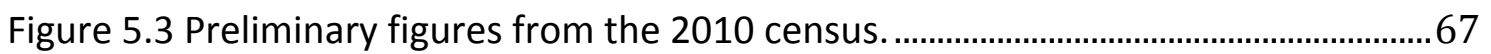

Figure 5.4. Examples of donor's policy language around corruption in the Solomon Islands. 


\section{CHAPTER ONE: INTRODUCTION, AIMS AND OBJECTIVES}

Development

Big word

Lotsa meanings

Staka dollar

Magnetic circle

Entices me

Urban drift

Empty villages

Customs forgotten

Loose living

Rat race

Dollar talks

Values change

Wantoks ignored

Every man for himself

I want to develop too!

Jully Sipolo ${ }^{1}$

\subsection{INTRODUCTION}

This research considers the use of Media Development by development donors working under a state-building mandate in the contemporary aid modality. It looks at how worldviews in developing countries can be changed and shaped by the direct and indirect influence of development donors on local news media ${ }^{2}$. By concentrating on Media Development ${ }^{3}$ as a development tool, this research looks at the motivation and understandings of the Western donor-funded trainers, the trainees and the consumers. It asks can this donor initiative successfully be a 'one size fits all' model across different cultures and contexts, and is the agenda as clear-cut as it professes?

This chapter briefly outlines the overarching theories that have coalesced to inform the research. It looks at the research questions and objectives, and it lays out the terminology used and the structure of the thesis.

1 (Sipolo, 1986, p. 13) Jully Sipolo [Makini] was interviewed as part of this research.

2 See 1.4 for definitions of terms used in this research.

3 Use of capitals and labels explained in 1.4 


\subsection{RESEARCH RATIONALE}

Media Development is still a largely ill-researched area of development. Most media and donor professionals view Media Development as a top down technological transfer - worthy, apolitical and unquestionable. A measure of this perhaps is revealed in the title 'Media Missionaries' (Hume, 2004), a research publication looking at successes and failures in the field.

The idea of growing a free media as the watchdog of newly formed states grew out of the desire to rehabilitate 'transitioning nations' at the end of the Cold War. It soon moved to being seen as a crucial part of shepherding faltering democracies in postcolonial countries, then as an essential tool to state-building post 9/11 as the security and anti-terrorism agenda took hold. It was cemented into place by the new aid modalities of the last decade that moved from project-based funding to policy-based funding of the developing country's government. Donors are increasingly dependent on recipient countries' citizens holding their governments accountable for donor funding (Groves \& Hinton, 2005). A strong news media is seen as crucial to this.

So Media Development has expanded into a multi-billion dollar sector (Howard, 2003; Becker, Vlad, \& Nuseer, 2007) and gained legitimacy as part of the good governance/democracy development discourse. There are more than 500 organisations working in over 100 countries on Media Development programmes and projects (GFMD, 2012) ${ }^{4}$ with the majority of the funding coming from Western donors. The programmes are weighted towards 'traditional' news media, in an image Western donors associate with in their own democratic and economic ideals (Berger, 2010; Howard, 2003; Nyamnjoh, 2005; Wasserman, 2006).

As it is seen as a pragmatic tool for development, Media Development has seemingly been untouched by challenges to the development project. Post Development writers

\footnotetext{
${ }^{4}$ Retrieved from gfmd.info/index.php/about_gfmd
} 
such as Sachs (1992) and Escobar $(1992,1995)$ labeled development hegemonic and a myth (Tucker, 1992 as cited in Pieterse, 1999). They described development, through the height of the neoliberal decades, as a "neocolonial enterprise ... through which Western economic rationalities and cultural and political forms are imposed and embodied" (McKinnon, Gibson, \& Malam, 2008, p. 275). In the 21st century there are those who believe the words have changed, but the emphasis on globalising, marketled policies by donors, remains; neoliberalism by a different name (Overton \& Murray, 2011; Rosser, 2008; Slatter, 2006).

As Dinnen puts it, Media Development falls neatly into "the latest wave of international state-building" (2007, p. 259). It fits into this paradigm in the Pacific as concerns over increasing tensions gave birth to the concept of the so called "arc of instability" (Barbara, 2008a, p. 141) which fed into the discourse over failed states and the risk of terrorism that became prevalent after 9/11 (Connell, 2007b; Dinnen, 2011; Rosser, 2008). The imperatives of building good governance and strengthening democracy sit well with the state-building model but, as Connell points out, the underlying agenda is more to do with subsuming the countries into the modernity model. "The inevitable mix of economic determinism, remarkably applied here in its most extreme neoliberal form, means that such concerns remain minor considerations compared with an overriding commitment to unrestrained economic growth" (Connell, p. 5, 2007b).

Donor-funded Media Development programmes are based on the transfer of knowledge around a Western system of news media to grow a free and pluralistic media. They generally concentrate on funding journalism training and increasingly are focusing on investigative reporting to strengthen the 'watchdog' role of the media. However donor funds have also gone to building infrastructure for the proliferation of private media organisations, and cross cutting programmes targeting legislative barriers to freedom of speech. Donors have also been involved in training justice professionals on media law and funding media freedom campaigners (Howard, 2003). 
This democratisation and modernity tool appears to be a part of development where there is adherence to principles of knowledge being a "one-way commodity ... a NorthSouth operation" (Dragon, 2006, p. 593). But more than that it is predicated on the belief that the Western media model being transferred is based on global principles that cannot be challenged; it is seemingly above politics - an altruistic endeavour. As Miller (2009) puts it:

It is hardly contentious; it is, instead, a gift, from the developed West to the 'transitional' or developing Rest. Similarly, media assistance NGOs - creative implementers of donor projects - view themselves as being, on the one hand, uniquely autonomous humanitarians and, on the other, apolitical technicians with a valuable skill to impart ( $p$ 10).

Some would argue that the Western model of media that is being transplanted in developing countries is flawed (Herman \& Chomsky, 2006). Running parallel to the development discourse is one on the mass media and its 'capture' by certain sectors of the world increasingly connected by globalisation. As Hviding points out, "Oceania has been globalized before by such diverse forces as colonialism, trade, missions, and aid" (2003, p. 49), therefore could Media Development, under the Aid umbrella, be facilitating a globalisation of truth and ways of knowing?

The sphere of this research is the Pacific, primarily the Solomon Islands, where the prominent bilateral partners are Australia and New Zealand. The radical change to New Zealand overseas development assistance agenda in 2009/10 from favouring poverty alleviation to economic development and private enterprise is seen by some commentators as returning to "the modernist phase with strong elements of neoliberalism" (Banks et al, 2011, p. 26). Rosser (2008) also argues that Australia has never escaped neoliberalism driven by powerful business interests that block more participatory aid modalities.

\subsection{RESEARCH AIMS AND OBJECTIVES}


This research seeks to explore development donors' use of Media Development as part of an overall state-building strategy.

The Solomon Islands was chosen as the field of study as it is a so-called post conflict country dominated by development donors and with a relatively new and inexperienced media that is the recipient of a donor-driven Media Development programme.

By looking at the way journalists are responding to the volume of donor media releases and also how they are framing the language used by those donors, this research extrapolates how that might influence the understandings of the consumers of news, the people of a nation. While the donor-heavy economy of the country investigated means there is a constant indirect influence on the news media, the main vehicle for the direct influence is a Media Development programme. This is instigated and funded by donors to grow a free and pluralistic media. This thesis seeks to understand the motivation behind that programme and how the journalists and civil society perceive it. It looks at whether Media Development as a development tool successfully crosses cultural boundaries, and where it fits in the development discourse.

The central question of this thesis is: how do Media Development programmes contribute to effective and appropriate development.

In order to answer the central research question this thesis looks for answers to the following questions:

1. What challenges do the news media face in an economy and environment dominated by development donors?

2. How are the worldviews of the journalists, civil society and the rural majority consuming the news shaped by the use of the donor rhetoric around democracy, anticorruption and good governance? 
3. What is the motivation behind the funding of Media Development programmes and how that is viewed by the news media?

4. How do a selection of the people on the periphery hear and interpret the news they are receiving?

The overarching objectives of this research are:

1. To examine the complex relationship amongst donors, the news media, and the public of the Solomon Islands.

2. To contextualise these relationships by addressing the concepts of good governance and democracy and the role of media.

3. To question the assumptions around Media Development as a technological transfer of knowledge or a political tool.

4. To open up the discussion on an indigenous way of 'doing' news that may be organically developing - or needs room to develop.

\subsection{DEFINITIONS AND THESIS STRUCTURE}

The use of the term media in this thesis refers to the 'traditional' news media comprised of what is referred to mainstream print (newspapers and magazines) and broadcast (radio and television) journalism. Minimal access to the Internet in the Solomon Islands has meant this has been largely left out of this research.

Media Development is capitalised in this thesis to place it apart from other development communication tools. Media Development refers to active donor involvement, or intervention, in media. Howard (2003) asserts that donors using this method of development aim to build an independent media and, more often than not, in a post conflict society.

\footnotetext{
"An independent media is one in which the media is genuinely independent from interference by owners, state authority or powerful interests which prejudice the news gathering and presentation process..." (Howard, 2003, p. 13).
} 
Media assistance in this research refers to the programmes that come under the Media Development umbrella. These are primarily journalism training through the provision of resources and trainers. However increasing resources are going into financing the building of infrastructure, tools of the trade, and cultivating market research skills to create sustainable private media.

Chapter Two explores the theories and beliefs that sit as an umbrella to the relationship between the news media in developing countries and development donors. It looks at the historical impetus for the growth of Media Development to aid democratisation and modernity, and how the rhetoric that has grown around its efficacy as an instrument of good governance and anti corruption, has become, although unsubstantiated, widely accepted as fact.

Chapter Three places the research firmly in the Solomon Islands, exploring the history of colonisation as a backdrop to an uncomfortable relationship with postcolonial political structures and beliefs that prevail today. It describes the present donordominated economic environment. It looks at the crisis that led to the intervention of the Regional Assistance Mission (RAMSI), its mandate for Media Development and the tensions that may exist because of it. This chapter also touches on how the Solomon Islands media itself has grown throughout its pre and postcolonial history.

In Chapter Four the philosophy that underpins this research is investigated. I place myself in the research and discuss the methodological theories that have informed it. This chapter details the methods used in the research and the restrictions of the Masters thesis.

Chapter Five looks at the accessibility and importance of the news from the perspective of the majority of Solomon Islanders living semi subsistence existences in often-isolated villages. It explores how the rural and urban areas are inextricably linked by wantok, yet worlds apart in language and worldview from the donor community. The chapter also investigates issues over the interpretation of the donors' media 
releases and donor-emphasis on good governance and anti corruption issues.

Chapter Six gives voice to the part donor-funded Media Development programme, SOLMAS, its supporters and its critics, and how the commercial model of media may adapt to issues in the local reality such as language and kastom. It touches on whether it is feasible for a media model to evolve that is more suited to the country.

Finally Chapter Seven summarises the research, its findings, its limitations, and the questions that are left unanswered. 


\section{CHAPTER TWO: MEDIA DEVELOPMENT - THE GLOBAL PICTURE}

While smoking he reads the news of the day, imprinted in characters invented by the ancient Semites upon a material invented in China by a process invented in Germany. As he absorbs the accounts of foreign troubles he will, if he is a good conservative citizen, thank a Hebrew deity in an Indo-European language that he is 100 per cent American (Linton, 1936, p. 329).

\subsection{INTRODUCTION}

Chapter One outlined the research aims and objectives of this thesis. However before situating Media Development in the Solomon Islands it is important to place this research in a global and theoretical context. This chapter will look at the overarching theories and beliefs that have been shaped by the evolving development discourses, and form an umbrella to the relationship between the news media and the donors in developing countries.

It begins by outlining the literature around the growth of Media Development initially as part of the post WWII Western modernisation toolkit and the "Cold War phenomenon" (Miller, 2009, p. 10). It looks at how Media Development began gaining more traction and attracting more funding in the 1990s alongside the push for democratisation in former Eastern bloc nations. Then it investigates the rhetoric around the strengthening of media post 9/11 to today where 'state-building' intervention has reinforced the attraction of Media Development as a means to stabilise countries.

This chapter examines the contemporary aid regime's use of pervasive rhetoric such as 'a free, independent, pluralistic media ${ }^{5}$ leads to good governance, democracy, and a strong, more empowered civil society'. This investigation of literature is brought together finally by looking at the power of the media to change worldviews and ideas around the emergence of indigenous media that may be more suited to local realities.

\footnotetext{
${ }^{5}$ As defined by the UNESCO Declarations of Windhoek, Santiago de Chile, Almaty, Sana'a and Sofia.
} 


\subsection{THE EVOLUTION OF MEDIA DEVELOPMENT}

"No substantial famine has ever occurred in any independent country with a democratic form of government and a relatively free press" (Sen, 1999, p. 152).

To introduce a relatively new and unexplored sector of international development called Media Development is to open the door to one of the most enduring questions around development. This is to do with the efficacy and the relevance of introducing Western values into developing countries. While the development project of the $1950 \mathrm{~s}$ and 60s was driven by the belief that modernisation-by way of imitation of Western industrialisation-would solve poverty, media has been seen as one of the essential technological tools of success. The influential economist Walter Rostow, adviser to both US Presidents Kennedy and Johnson, highlighted media platforms and Information and Communication Technology (ICT) as essential components to modernity in his famous development tome, 'The Stages of Economic Growth: A NonCommunist Manifesto' (1971).

Pye (1963) in his book investigating the role of communications in political development argued that in Western notions of development, the 'stages of civilization', were constructed purely in terms of economic progress. Gradually linkages to "world views ... stability and effectiveness of government" (p. 15) were made. At this point there was a push to disseminate a scientific and technological-based urban, industrial, and democratic world culture (Pye, 1963, p. 19). This was the ideology at the birth of donors' involvement with media interventions in developing countries and it remains very strong today.

But it was the end of the Cold War that propelled Media Development firmly into the political consciousness of the international development sector. Growing independent media was seen as a conduit to democracy following the fall of the Berlin Wall in 1989. Donors supported a non-state media as it was hoped to provide a way of reforming the countries of Eastern Europe, the 'transition societies', from within (Arsenault \& Powers, 2010; Coronel, 2008). 
Browne argues that the failure of donors to aid the transition of Eastern Europe and the former Soviet Union during the 90s was because of their religious adherence to the three tenets of change, "statehood, market and democracy" (2006, p. 35). They ignored the local realities of the countries and saw the economies retract by half over that time. Yet 'good governance', which was the catchphrase then, remains as tightly aligned today to traditional Western notions of democracy, and ways of promoting it are "strikingly similar to those used to promote economic reform" (Santiso, 2001 as quoted in Browne, 2006, p. 37).

Aligning a free media as part of human rights may have muddied the arguments around Media Development even further. Sen (1999) added his voice to liberal theorists from Milton to Mills by arguing that democracy and the right of freedom of expression are facilitated by a free press which strengthens the way governments respond to, and also their accountability to their people.

All these ideas were brought squarely into the donor world by the President of the World Bank in the late 90s when he said:

A free press is not a luxury. A free press is at the absolute core of equitable development, because if you cannot enfranchise poor people, if they do not have a right to expression, if there is no searchlight on corruption and inequitable practices, you cannot build the public consensus needed to bring about change (Wolfensohn, 1999, p A 39).

Statements such as; "[p]lural media support informed decision-making, increased accountability, responsiveness and contribute to anti-corruption efforts" (Locksley, 2008, p. 6), have peppered the literature ever since. Warren Feek of the Communications Initiative (Feek, 2006) argues that history is full of examples where the media has generated debate, analysis and dialogue affecting all major social movements of the 20th century.

Berger (2010) in his detailed analysis of the use of the term Media Development and how it has entered the development vocabulary recounts how UNESCO established its 
credibility finally in 2008. UNESCO published a complex series of indicators described as a 'diagnostic tool' for donors to use to decide when and where money should be spent. He outlines the plethora of organisations that have grown from the sector and questions the blurring of the lines between different projects around media in developing countries.

While these Media Development threads continue through the changing discourses, there were other steps to today's reality. There were further transitions of thought and theory as the world lurched through the neoliberal phase of deregulation and state privatisation. It was instituted in the 70s under the Chicago School of Economics, with its ideology of monetarism, and led to the "wave of generalised neoliberalism" (Pieterse, 2009, p. 43). Developing economies needed to be subsumed by market-led economics because "poor countries are poor mainly because of mismanagement" (Pieterse, 2009, p. 43). The debt crisis of the 1980s brought about the imposition of structural adjustment programmes wiping out state ownership and crippling a number of developing countries as the 'market rules' mentality gained credence across the globe.

A growing clamour around the negative impact of the 'fundamental neoliberal approach' on the poor and underprivileged saw a recognition that governments had a place in development and by the mid 90s the vocabulary of ownership, good governance, capacity building and empowerment had begun to dominate (Storey et al, 2005; Overton \& Murray, 2011; Pieterse, 2007). The Millennium Development Goals (MDGs) in 2000 and the Paris Declaration (2005) cemented in the new aid modality. At this point Pieterse's judgment, referred to above, becomes 'poor governments create poor nations mainly because of mismanagement'.

Meanwhile, Overton and Murray argue that despite the rhetoric in the Paris Declaration, the new aid regime is just providing a more palatable "middle road to globalization" (2011, p. 310). Their premise is that the current aid modality has taken on the social responsibility mantra of neostructualism that endears it to the left-wing political critics, while never having dropped the ultimate goal of "open regionalism and 
free market allocation" (p. 317). The donors, they attest, have turned their attention on growing a strong state in developing countries that can support an economy ripe to take part in global trade - a state in the image of the donors themselves.

To achieve this, once again, there is a constant emphasis on 'good governance'. This is a term sprinkled liberally through the development discourse alongside such terms such as participation, civil society and democracy. UNDP says good governance is "... among other things participatory, transparent and accountable. It is also effective and equitable. And it promotes the rule of law" (1994). UNESCO (2005) acknowledges good governance has more recently been associated with public sector reform. Others such as Fry and Kabutaulaka (2008) and Firth (2006) suggest the concept is being understood and interpreted only on Western terms to aid free market reforms or as a form of a "globalising the message preached by aid donors and international institutions" (Firth, 2006, p. 2). Media Development could be seen as a tool to this effect.

With the good governance discourse comes an emphasis on anti-corruption and a strong civil society. Media Development has found a home amongst this discussion as a way of encouraging post conflict countries to tidy up their houses by strengthening the media's 'watchdog' role. The new aid modality, moving away from projects to policy-based funding of recipient governments, has left donors searching for ways of monitoring the money flow. It means "donors must rely more on the recipient country's citizens to hold their government accountable for donor funds " (Groves \& Hinton, 2005, p. 173).

Media Development therefore becomes an even more attractive option, as it is a relatively acceptable way for the West to exercise its influence on developing nations. This isn't to say there isn't tension in this role. Barbara maintains there is a "myth of apolitical intervention" (2008, p. 125) in the state-building development scenarios where Media Development is prevalent:

These pressures-the simultaneous need to allay the sovereign anxieties of local 
political communities at the same time as meeting the transformative goals of the good governance agenda asserted as necessary by the broader international community of states-constitutes a form of two-level game (Barbara, 2008, $p$. 125).

As the neoliberal approach attempted to replicate markets in developing countries, Media Development is charged with reproducing a model of news media in struggling economies; a media the donors understand. It is also a media that can be trained to understand the imperatives of the global market. Examples of this can be found on the websites of government donors such as New Zealand.

\footnotetext{
"The technical capacity programme be opened, also, to PACNEWS member journalists in order to assist (in a neutral way) with increased and better-informed coverage of international trade and of national trade policy issues (Gallagher, Gounder \& Lee, 2009, p. 31)".
}

The terms free and pluralistic are, to some extent, a flashback to the donor-driven liberalisation programmes of the 1980s and 90s although they are very much in the conversation today. By encouraging a strong, independent and private media the developing community is adding a fundamental building block for economic growth and democracy (Putzel \& van der Zwan, 2005). However analysis of Media Development programmes has begun to reveal flaws in the logic. Cautionary tales of failure and divisiveness in post-war states where donors are working under a statebuilding mandate have revealed that privatised media may even damage peace building when there is no legal and judicial environment to oversee it. Putzel \& van der Zwan's (2007) report, 'Why templates for media development do not work in a crisis state', is an example of research around this issue. It contains recommendations on customising programmes to their context, and recognising that "the development of an open and free environment, like other liberal projects, requires the presence of a strong state" (Putzel \& van der Zwan, 2007, p. 2).

2.2.1 Media Development - the fit 
Different arms of development called 'communication for development' or 'media for development', and even 'development journalism', have concentrated on disseminating the development messages such as HIV and AIDS education. But these have come under the microscope of the critics who question the discourse. As early as 1978 CIESPAL (Centro Internacional de Estudios Superiores de Comunicación para América Latina) sponsored the first Latin American seminar on Participatory Communication. This brought together academics who collectively agreed there was a slippery slope around development communications, which could see the interests of the elite being forced on the poor. It was more top-down neoliberalism, they and many others argued (Rogers, 2006).

A debate has ensued over how communications in development should be used (the two theoretical frameworks being the diffusion/mechanistic model and the participatory/organic model ${ }^{6}$. However the role of news media has apparently escaped the same scrutiny. While recognising the function the media has to play in empowering populations, a voice to the voiceless (Hudock, 2003), Rogers talks about the market model of media possibly disenfranchising the very people donors are trying to reach:

[W] hile most journalists feel a need to report on news wherever it be found, there is mounting evidence that, as competition amongst various media outlets intensifies, content is being increasingly shaped by the demands of advertisers and sponsors ... often leaving out any coverage of issues affecting the rural and urban poor (Rogers, 2006, p.184).

A 2006 DFID paper alluded to the explosion of media around the globe and especially in developing countries over the preceding decade. While the paper highlights the opportunities, such as greater debate and freedom of expression that such growth can encourage, it also sounds a note of caution.

Commercial media has increasingly focused on urban, consumer audiences who attract advertisers. Marginalised and poor populations have been left poorly

\footnotetext{
6 Rogers (2006) goes into the pros and cons of these two models in great depth. However this thesis is concentrating on Media Development which has evolved separately but parallel to these concepts.
} 
served as a consequence (DFID, 2006, p. 6).

Berger (2010) argues the term is restricted to meaning intervention from outside developing countries and therefore ignores Media Development that is driven internally and successfully in those countries. It is this 'disconnect', such as ignoring the rise of Al Jazeera in Qatar as Media Development because it was initiated internally, not externally from donors, that Berger says, "limits the utility of the concept" (Berger, 2010, p. 550).

It is Miller (2009) who questions the ideology and lack of critical analysis that donors bring to their use of Media Development to achieve modernisation and democratisation. Miller argues that Media Development is seen as a type of "suprapolitical, even altruistic transfer" and "hardly contentious" when it is in his view “inescapably political” (p. 10).

\subsection{MEDIA DEVELOPMENT - A HETEROGENEITY OF INTENTIONS}

Media Development is sometimes referred to as media assistance, which Berger points out is a "less ideologically tinted phrase" (2010/11, p. 550). He argues the different terms could be interpreted as 'media manipulation' or 'media meddling' and are confusing a 'process' with a 'state'.

Over the 30 to 40 years that the term Media Development has slipped into the development lexicon, it has been championed by diverse organisations. There are a number of interventions that fall under this heading ranging form training journalists, facilitating law changes to support freedom of expression or access to official information, to setting up international media loans with the prime aim of supporting the infrastructure of private newspapers and radio stations. UNESCO set the standard for journalism training in developing countries emphasising the function of the media.

The basic goal of most journalists ... is to serve society by informing the public, scrutinizing the way power is exercised, stimulating democratic debate, and in those ways aiding political, economic, social and cultural development (UNESCO, 2007). 
The World Association of Newspapers (WAN) was launched after WWII by about a dozen European and United States newspaper publishers to push for a guarantee of freedom of expression in the new world order. Now more than 73 national newspaper publishers are associated. In 2006 WAN's then director of communications, Larry Kilman advocated "nothing short of a Marshall Plan" $(2006$, p. 3) for the press in developing countries as he pitched for donors to become part of the Media Development Loan Fund (MDLF).

\begin{abstract}
Newspapers and other media throughout the developing world desperately need outside support if they are to survive, prosper, and contribute to the development of their societies. Put another way: Programmes to tackle the economic and social problems of developing and transitional countries cannot be fully effective, and are indeed often condemned to failure, without open, fair and well-managed government (Kilman, 2006, p. 3).
\end{abstract}

And so the message has formed almost like a 'truth'. It has entered the collective consciousness of the donor world, and had weight added to it by way of Media Development professionals and media experts eager to see more done to support a free and pluralistic media in the developing world.

However a survey of the literature shows confusion over how to rate the success of this form of aid (see below 2.3.2 Monitoring success of Media Development). This is because donors have not labelled and isolated Media Development in their programmes in a systematic way until the last few years. This has created difficulties for academics, donors and their monitoring and evaluation specialists struggling to gain an accurate picture of the landscape.

Hume (2006) explains that the major donors have put Media Development work under the heading of 'democracy-building' or they have seen training of local journalists as part of communicating their own particular message. She points out that it wasn't until 2005 that "the funding and development community acknowledged the media sector had emerged as a distinct area of development" (Hume, p. 194). 
Hume is one of the 31 specialists who has given a contemporary overview of the Media Development landscape in a downloadable resource. 'Media Matters; Perspectives on Advancing Governance \& Development' is published by Internews Europe on behalf of the World Bank sponsored Global Fund on Media Development (Harvey, 2006). It combines the research of leading academics, and the arguments of media professionals from both the North and the South working in Media Development. It is a comprehensive resource with an overarching aim to encourage more understanding and debate around the impact of media towards international development targets.

In Paris in 2010 UNESCO hosted the third in a series of a meetings aimed at harmonising media support and coordinating the many international organisations involved around the world. The report identifies interventions in countries facing breaches of press freedom but concludes the impact has been 'ad hoc' with a multitude of motivations.

"[T]he heterogeneity of intentions by donors and implementing organisations in the field of media has resulted in a variety of priorities and outputs, some without any sustainable or long-term perspective in place and without any anchor in the local medias' agenda for development" (IMS, 2011). ${ }^{7}$

Others researching the Media Development landscape have echoed this analysis. Allen \& Stremlau (2005) raise concerns about the use of experts from the donor countries setting standards for 'truth' and 'justice' while ignoring local realities. Drawing parallels with former colonial powers' mistrust of the local, they say media training offers an alternative trusteeship, meaning under Media Development programmes "viable local alternatives were not explored or tolerated because they may possibly contradict some of the expectations or standards of rich countries" (2005, p. 13). Nyamnjoh (2005) says marrying media and democracy ignores how profit-driven media marginalise cultural diversity.

\footnotetext{
7 International Media Support (IMS) is a non-profit organisation working to support local media in countries affected by armed conflict, human insecurity and political transition. http://www.i-m-s.dk/article/international-partnerships-progress-new-report
} 
Culturally the media are victims of an imposed hierarchy of national and world cultures, and also of the cultural industries that have opted for routinisation, standardisation and homogenisation of media content. This has occasioned the exclusion or marginalisation of entire world-views and cultures that do not guarantee profitability (Nyamnjoh, 2005, p. 2).

The sector continues to grow with multilateral, bilateral and philanthropic giants like the World Bank, UNESCO, USAID, the Bill and Melinda Gates Foundation and many others pouring in millions of dollars. A Seattle Times article (Doughton, 2011) raises unease around the "blurring of the lines" by having private interests such as the Microsoft billionaires placing their stamp and their culture on media in the developing world. The newspaper reports that it has tracked nearly US\$70 million from the Gates Foundation in support of direct grants to media organisations, media training, and media research.

The foundation sits alongside the many donors supporting the setting up of private newspapers and radio stations throughout Africa, Asia and Eastern Europe, as well as training journalists, setting up a media loan fund, and supporting infrastructure of media outlets.

These projects are increasingly found under the titles of good governance, anticorruption and strengthening civil society. ${ }^{8}$ A University of Georgia survey found that at least 70 organisations in 25 donor countries outside the United States of America were involved in media assistance projects totalling an estimated one billion dollars annually (Becker, Vlad, \& Nusser, 2007). A more recent study has suggested that with the moving world order, media support for developing nations from countries such as China may be driven by a desire for influence, and self-interest could be a significant issue (Myers, 2009).

\footnotetext{
8 NZAID WEBSITE - PRIORITIES: "provide media training and the promotion of information for the public good." RAMSI [peacekeeping force in the Solomon Islands] under the heading of media strengthening says; RAMSI will provide assistance to the Solomon Islands media to: Strengthen the capacity of commercial and community-based media. Strengthen Solomon Islands Broadcasting Corporation's effectiveness, and its role as the national public broadcaster. Maintain a close partnership with the Ministry of Communications and Aviation and the Telecommunications Commission regarding media legislation and broadcasting issues.
} 
Yet a survey of policy opinion conducted for the BBC World Service Trust, a leading deliverer of Media Development in Asia, Africa, Europe, Latin America and the Middle East, reveals there is a gap between the importance "ascribed to media in relation to governance, and its reflection in policy, research or programmatic action" (Lines, 2009, p. 4). While the majority of policy people interviewed supported the role of media as a tool to promote good governance, the research revealed another side. Leading development experts highlighted China's huge economic expansion: "the fastest in human history, manifestly without a free press" (William Orme at the UNDP as quoted in Lines, 2009, p. 9).

\subsubsection{A minor case study - Media Development Afghanistan}

One Media Development so-called 'success' story is Afghanistan where the international community has been active in 'assisting the media sector' for the last nine years. The big donors involved are USAID/OTI (Office of Transitional Institutions), DFID in the UK, and the European Commission (EC). There has been an explosion of private media outlets. Under the Taliban, television was outlawed and only one radio station broadcast. Since late 2001 and the fall of the Taliban the media landscape has exploded with 75 television channels, $175 \mathrm{FM}$ radio stations and 800 publications (Altai Consulting, 2010). The main company working on Media Development in Afghanistan boasts this has been achieved by using more donors and substantially less money than was present in supporting the sector in Iraq, investing in independent media as opposed to concentrating on reforming state media, and by instituting market policies.

The idea of starving outlets [of funding] from the beginning as a condition of making them sustainable in the long run (John West, former Director of Internews), has resulted in success, considering that a number of small radio stations created with very small amounts (less than $\$ 20,000$ in start-up costs) are still broadcasting today. (Altai Consulting, 2010, p. 31).

\footnotetext{
9 Michael Barker points out that the difference in media development funding between Iraq and Afghanistan has more to do with 'geostrategic value' where "oil rich Iraq received 20 times more American media assistance per year than war-ravaged Afghanistan, one of the poorest nations on earth' (Rohde, 2005, p. 29 as quoted in Barker, 2008, p.124).
} 
However, after conducting a major attitudinal survey in Afghanistan, the consultants working on the media evaluation uncovered an intriguing loyalty to the state-run broadcaster, RTA, which is seen as supporting national unity.

Disrespect of Afghan culture and religion is a common reproach of commercial media and divisive politics is an issue for political/religious media. Overall, media is generally viewed by Afghans as a positive force in society, celebrated for addressing key issues-economy, crime, and corruption-and is seen as a way to open minds and education (Altai consulting, 2010, p. 2).

In investigating US-funded media developments in Afghanistan and Iraq post 9/11, Barker (2008) questions the motivation of USAID/OTI spending on this area of development. He points out one of the stated media goals of the mission is to create a 'Western-style media law' (USAID/OTI, 2005, p. 29 as quoted in Barker, 2008) which, he says, "[t]ypifies the polyarchic strategies commonly employed in 'democracy promoting' projects, which sees the wholesale transplant of liberal democratic (or more often neoliberal) policies overseas" (2008, p. 114).

And on another OTI goal to support, 'the first truly independent radio stations in Afghanistan', Barker says,

Here it seems that the US is not promoting truly independent media (in an autonomous sense), but instead aims to create and nurture market-driven media systems that are independent of state support, but dependent on advertising - an emphasis that many scholars would agree is the perfect way to promote lowintensity democracy $(2008$, p. 115).

\subsubsection{Monitoring success of Media Development}

Hand-in-hand with the expanding interest in employing Media Development as a tool to encourage good governance and discourage corruption, goes a call for empirical proof of how media influences or changes the lives of people living in poverty (Norris, 2006). Feek (2006) acknowledges that better data relevant to the 2015 Millennium Development Goals (MDGs) is needed to get a more coherent policy from donors around support for in-country media as an integral and important poverty reduction 
strategy. The Director of the Democratic Governance Group (DGG) of the United Nations Development Programme (UNDP) Pippa Norris, who has studied democratisation and media, calls for case studies on how media works in different developing countries to "flesh out these linkages" (Norris, 2006, p. 75).

Internews, based in New York, is a large well-financed organisation working in the media development area on projects such as Afghanistan ${ }^{10}$. It had the largest OTI grant from USAID of US\$4 million, a sixth of the total spent by OTI on the capacity of the media there, to set up a national network of independent community radio stations (Rohde, 2005, p.20). Internews is working in unison with the World Bank on the Media Map project aimed at giving donors more information on the success or cost effectiveness of putting money into media in developing countries. Oceania is obvious in its absence from all research in this area.

Other investigations trying to make a connection between media growth and economic development have come from very different stances and come up with very different results. A 1990s Latin American investigation into 20 years of media in development analysed data such as life expectancy and GDP in relation to the growth in access to media and press freedom. It yielded less than compelling, even quite diverse, results (Howenstine, 1991). Howenstine discovered that press freedom did not automatically lead to media availability or development in general. His research revealed counties with hard censorship regimes showed markedly different outcomes with, for instance, Argentina progressing in both stakes while Nicaragua declined economically despite growth in media.

Around the same time Fair analysed more than 200 studies, through the 1950s up until the mid to late 1980s, on the impact of mass media (newspapers, magazines, radio and television) in developing countries as agents of behaviour and knowledge change (Fair, 1989). In an excellent overview of how the modernisation ideology stayed strong in this area, Fair accused researchers of ignoring power and class imbalances that would

\footnotetext{
10 See Afghanistan case study above in 2.3.1.
} 
lead to different access to the media and to the messages. Her criticisms would stand today, in that the language of analysis may have changed but the measure of success seems to have remained the same.

A World Bank evaluation of Media Development reveals "a severe lack of donor coordination, and conflicting donor ideologies, result in a distorted dispersal of efforts globally. In the field "local partners are insufficiently involved" (Odugbemi \& Norris, 2010, p. 396). Freille, Haque \& Kneller believe that the media's effectiveness as an anti-corruption tool "may be overstated" (2006, p. 839).

There appears to be a gap in what the development practitioners, media development professionals, donors and academics believe from anecdotal reports, and how that is measured and evaluated. This could be explained on one level because of a long-held view by many in the above groups that the Information and Technology (ICT) era would solve all communication problems in developing countries with speed because the technology would cross cultural, political and geographical boundaries. It didn't live up to its promise of connecting people as cost and disruption have hampered a wholesale uptake.

Nyamnjoh (2005) also challenges the West's faith in the power of the Internet and the 'information superhighway' to connect people in his analysis of the role of the media in democratisation in Africa in the 1990s. He says while the some in the West may see ICT as speeding up globalisation, "their counterparts in the developing world often see it as fostering media and cultural imperialism, and as globalizing poverty above everything else" (2005, p. 2).

\subsection{MEDIA, THE MESSAGE AND THE ELITE}

So far this chapter has talked about the heterogeneity of intentions of donors involved in Media Development throughout the developing world. Added to this are questions around who can access the type of media that is being promoted and who owns, controls or manipulates the messages that come from those different organisations. 
Berger (2010, p. 556) quotes the Zambian scholar Professor Francis Kasoma to highlight how donors might prioritise Media Development in line with their own political and cultural ideologies:

...the French would see state-ownership and control as a basic approach to the press serving a democratic political set-up ... the British would support a privately owned press or at least one owned by a public corporation similar to the British Broadcasting Corporation. The Canadians would support a mixture of private and publicly owned press but not a government owned press, while the Americans would support only a privately owned press (Kasoma, 1999, p. 17).

There is caution around what media model should be supported in developing countries. Herman and Chomsky give their version of the mass media in explaining the thinking behind their 'Propaganda Model'. They conclude the purpose of the Western media is: "...to amuse, entertain, and inform, and to inculcate individuals with the values, beliefs, and codes of behaviour that will integrate them into the institutional structures of the larger society ... to fulfil this role requires systematic propaganda" (2006, p. 257).

It is, after all, the model that has produced the excesses of media magnate Rupert Murdoch and his journalists taking them to new depths of 'reporting' in the News of the World 'phone hacking scandal' (Rush et al, 2011). While the international media has wrung their hands with anxiety and condemned the corrupt practices uncovered in the scandal, in Nigeria journalists such as Sunday Dare, former editor of weekly news magazine The News, are more circumspect:

The preacher has been caught pants down and thus loses the legitimacy to chastise or be preachy. We now know that violation of ethics of the journalism profession is more prevalent in [Western media], and what we have in Africa is nothing compared to the sophisticated and systematic violation of media ethics and individual rights all in the race to make millions... (Rush et al, 2011, para 52).

Curran (2002) adds his voice to those who question the ideology around the power of the media as a public watchdog. He says the idea of a free, 'privatised' news fits nicely into the liberal theorists' view that only a media of the free market can be 
independent enough to question the state. Yet Curran points out this view "derives from the eighteenth century when the 'principal' media were public affairsnewspapers" (2002, p. 219), whereas today, market forces have changed them into vehicles primarily for entertainment.

Papoutsaki narrows that criticism to the Western model of news journalism in the Pacific that she believes concentrates on the voices of the elite and ignores the rest of the population unless they are a part of some sort of catastrophe or violence. She advocates journalism students research their own communities to develop better understandings (Craddock, 2011). Meanwhile Tongan pro-democracy publisher Kalafi Moala decries the impact of globalisation on South Pacific media, with a 'one shoe fits all' approach (Robie, 2008).

\subsubsection{An indigenous media and Pacific ways of knowing}

What we want to do is show our people from our view of people. We know that white people are misrepresenting us. They have been for almost 200 years. We need our information. We need to control our own information. We need to put out the messages that the community needs to hear. (Aboriginal broadcaster in Molnar, 2006, p. 169)

Explorations around an alternative or "indigenous" media model are muted compared to the missionary zeal (Hume, 2004) with which the Western model is being instituted and inculcated in the Pacific and around the globe.

But Eko sees signs of optimism. He avoids labelling what is happening in the African media as 'Americanisation' or 'Westernisation'. He describes the evolving media landscape in Africa as a "vibrant, irreverent and satirical press that is a thorn in the flesh of many an authoritarian government" (2007, p.3). However Angel (2008) uses postcolonial concepts, 'colonialisation of the mind' and 'writing back to the centre', in her research into media and the Aboriginal people of Australia. She suggests the traditional linear storytelling usually favoured by the media ignores indigenous ways of communicating. Meanwhile Ginsburg highlights what she calls the kind of "Faustian dilemma" that indigenous people face (1991, p. 96). She asserts that while the media 
provide platforms for expressing identity, the very same media could be "the final assault on culture, language, imagery, relationship between generations, and respect for traditional knowledge" (1991, p. 96).

And it is that question around different ways of knowing and how the news media may affect that by reflecting the voice of the powerful elite and donors that this research explores with contributors.

Gegeo (2001a) argues that decolonisation in the Solomon Islands has just meant the replacement of white faces by brown. As the provincial and central government people have all been educated in the universities of the former colonial powers, Gegeo says, they are, "... for the most part not different from or maybe even worse than their colonial counterparts. Their worldviews are colonial ... True independence comes from dehegemonization, that is undoing the already established hegemony" (p.493).

Media Development could be seen as another form of hegemony by perpetuating Western-held beliefs about a developing country. For instance several writers on the Pacific have argued there is a discourse coming out of the former colonial powers that misrepresents the Pacific Island peoples. The discourse is informed, they believe, by academics and, more damagingly, by the Western media (Fry \& Kabutaulaka, 2008; Chappell, 2005, p. 78). Chappell (2005) explores the claim by an Australian academic that there is a progressive 'Africanisation' of the South Pacific. He uses the comments of media and politicians and the rants of French geographer François Doumenge to set a scene on a worrying discourse that bears little resemblance to the historical and global impact of colonisation and post-colonial behaviour in Oceania.

Delving into an anthropological view of development in the Pacific, a book bringing together scholars to discuss the writings by influential anthropologist Professor Marshall Sahlins around the role of humiliation in cultural change offers some valuable insights into Melanesia and the influence of Western culture (Robbins \& Wardlow, 2005). The essays are based on a 1992 Sahlins paper which looked at how cultures continuously try to protect their uniqueness in the face of change but then, at a point, 
this 'ruptures'. It is a point Sahlins puts down to 'humiliation' whereby cultures begin to be embarrassed by the very thing they were working to protect. This book analyses these few paragraphs from the perspectives of Melanesian research, placing them into the development world by way of postcolonial theory.

The connection with my research is around the media meta-narrative - the use of such terms as 'broken', 'failed states, 'underdeveloped' or 'least developed nation' to describe a country and how that may be influenced, and in itself, lead to a 'point of rupture' and humiliation.

\subsection{SUMMARY}

To explore the central question of this thesis: how do Media Development programmes contribute to efficient and appropriate development, this chapter plots the emergence of the sector and the attitudes and beliefs that have evolved around it. It shows a beginning as just a part of the replication of Western ideals during the Cold War era, to a strengthening tool for democracy for the transition countries after the fall of the Berlin Wall. As a development programme it fitted nicely into the structural adjustment neoliberal discourse of the $90 \mathrm{~s}$ with its push for private media, and continues today almost in full circle as it slides into an apolitical programme in the donors' state-building and capacity development ideals.

However critics point out the media is political and the use of the Western media model, and surrounding ideology in training and growing media in developing countries, has a political edge to it. Donors and those delivering the programmes seem to view Media Development as above, or apart from, the development discourse around ownership and bottom up, employing Western journalists and mainstream understandings to 'train' and 'upskill' their counterparts in these countries. The language around success appears to hinge on the neoliberal focus of 'globalising' these countries by use of the media to shame and 'out' those not playing by the rules. The question is whose 'watchdog' are the journalists being trained to become? 
There is a huge gap in research on Media Development in the Pacific where programmes are spread out under different donor priority streams. There is a call for more research into the true, as opposed to anecdotally lauded, impact of a free media on development outcomes (Harvey, 2006). There is recognition that there are not enough voices from the developing world in the globalised mass media (Hoffman, 2006). However the discussion and research about a 'different' type, an indigenous media emerging from the developing world is as yet a whisper (Angel, 2008; Eko, 2007).

The next chapter grounds the research in the Melanesian country of the Solomon Islands. To look at how Media Development programmes contribute to appropriate development and influence worldviews in this country, it is important to contextualise the evolving relationship between the Solomon Islands and those that have sought to influence its development from before colonisation until today. 


\title{
CHAPTER THREE: PLACING THE RESEARCH IN THE SOLOMON ISLANDS
}

\begin{abstract}
Our forefathers had their own form of government before the arrival of European traders, blackbirders, missionaries and colonialists. Leaders supervised their followers with strict traditional codes of behaviour. There was no written constitution to blend together the rules of different lines, tribes, clans and islands. No single traditional leader was able to rule over all Solomon Islands (Solomon Islands author Gideon Zolveke as quoted in Alasia, 1989, p.139).
\end{abstract}

\subsection{INTRODUCTION}

Chapter Two outlines how Media Development, supporting the growth of a free and independent news media, has become a tool for donors over the last 30 to 40 years. This has ostensibly been to help strengthen the good governance mandate but it could be argued that more recently it has also been used to encourage citizens of recipient countries to hold their governments accountable while encouraging conditions that will allow them to participate in the global economy. Media Development has been critiqued in its use as part of state-building in post conflict countries, and found lacking in its ability to adapt to local realities.

To investigate the local reality, this research is centred in the Solomon Islands. To place it there this chapter looks at the machinations of the nation's birth under colonisation. It explores the Western discourse around 'failure' that has grown to describe the nation since independence. It looks at the lead up to the 'tensions' between 1998 and 2003, and the motivation behind the Australian-led intervention in 2003. This helps paint a picture of a country struggling with an imposed Westminster system of government (Hameiri, 2007), and heavily dependent on "globalising aid donors" (Firth, 2006, p. 2).

Finally the chapter goes on to give a potted history of the growth of the Solomon Islands news media, and then to link that to donors by investigating how the Regional Assistance Mission Solomon Islands (RAMSI) has instituted change in the media landscape through its Media Development programme. 


\title{
3.2 A BRIEF LOOK AT A COLONY
}

It wasn't until another country showed interest in the more than 900 scattered islands in south-western Pacific in 1893 that that the southern Solomon Islands were hastily claimed as a British protectorate. This was to avoid France expanding north from the New Hebrides and to protect the supply of labour to plantations in Fiji and Queensland. Six years later, after an agreement with Germany, the rest of the islands in the north were subsumed. A colony was founded and divided into four main districts which were run without much local Solomon Island input for the next 50 or so years.

\begin{abstract}
Generally, Solomon Islanders were relegated to being passive subjects of colonial rule. Their opinions were not sought and their wishes ignored ... In addition, the colonial government laid the basis for a centralised government and it did so at the cost of ignoring, and in some instances challenging, traditional leadership systems by appointing headmen from amongst those sympathetic to the araikwa ${ }^{11}$ cause, rather than those held in high regard by the communities involved. (Alasia, 2007).
\end{abstract}

Pacification of the locals was seen as necessary by the British to secure lands for plantations. However it was slow and erratic partially because of the problematic geography of the islands, but also because of the underlying belief that Solomon Islanders were a dying race of people. The imperative to pacify was only where the 'natives' came into contact with Europeans. Missionaries often paved the way for pacification in more remote areas, and plantation managers were also agents in "taming the frontier" (Bennett, 1987, p. 109).

The Europeans struggled with the tradition of a dominant indigenous leadership around the 'big man' model. For the most this was in the form of leadership of clans of kinship, or Wantok, as opposed to the hereditary system of leadership in the minority Polynesian populations found in the islands of Bellona, Rennell, Tikopia, Anuta, Ontong Java, Pileni, and Sikaiana. As Alasia (1997) explains, the chiefly title did not denote a

11 Araikwao (all white expatriate male) 
held ideology as it was about ability to lead, and an understanding and upholding of the cultural mores of the group. "Therefore, in the traditional political systems, there were no alternative parties, but there were alternative individuals. Hence, the power and authority to rule was contested, not between political parties, but between individuals" (Alasia, 1997, p. 1).

While pacification reduced tribal warfare, resistance to the missionaries, government agents, and the big plantations came in the form of isolated attacks. These became more organised by the time of WWII (Allen \& Dinnen, 2010). The loss of land and the growth of missions were weakening the influence of traditional leaders.

At that time the British were trying to find investors for the Solomon Islands in an attempt to make the colony self-supporting. During the first decade of the 20th century plantation development had grown rapidly. Articles in the Sydney Mail and the Melbourne Age talked up the wealth of the colony, " ...[f]or land is cheap... and there are vast areas that might acquired from the native" (Sydney Mail, 12 August 1912 as quoted in Bennett, 1987, p. 139).

WWII shattered any chances of this colonial relationship surviving, both from the point of the Solomon Islanders and from that of the bruised and battered British. Guadalcanal is now famous in Western history for being a brutal theatre of war primarily between the Americans and the Japanese, but the post war impact on the Solomon Islands was a ruined trading economy, a growing rumble from the anti colonialists and a colonial power that was waning (Fraenkel, 2004, p. 31).

Much has been written about the failure of some post-colonial democracies because of the lack of an independence struggle against the 'oppressor' to base a country's self government and national unity on. The British colonial rule was spread thinly across these scattered islands, reaching only pockets of the population and leaving most local polities surviving relatively untouched and disconnected from colonial ideas. 
Bennett (1987) talks of how a handful of the nation's first tertiary graduates began to question the colonial rule in the late 1960s.

Before they could even develop a coherent ideological expression of their intellectual discontent, the Solomons were on a short constitutional journey to independence ... The Solomons were catapulted into independence without any semblance of a great national struggle or even a shared patriotic ideology that might have bound the people together (p. 346).

The Western Province's boycott of the initial independence celebrations in 1978 highlighted this "lack of nationalist consciousness" (Feinberg, 1990, p. 23). This was not a united country celebrating its newfound sovereignty but a group of disparate islands, and groups within those islands, protecting their self-interest under a system of government imposed upon them. The Massina movement, which had its roots on Malaita after WWII, threatened the British and was aggressively put down. ${ }^{12}$ The Weather Coast of Guadalcanal gave birth to the Moro movement and, as has been mentioned, the Western Province showed its resistance not only on the eve of Independence (Allen \& Dinnen, 2010) but also a few years earlier when it proposed the adoption of a federal structure (Scales, 2007). The calls for autonomy were brought up once again during the 1998-2003 tensions.

Westerners ${ }^{13}$ have seen the centralised state as taking too much of their resources without delivering sufficient services in return. They have long wanted to develop the resources themselves and use the profits to provide services more directly. (Scales 2007, p. 188)

Independence for the Solomon Islands had been on the radar since the end of WWII but planning and debate only began in earnest in the 1960s (Bennett, 1987; Fraenkel 2004). A changing world economy with the oil crisis of the late 1970s meant "Britain's gentle amble toward the protectorate's internal self-government rapidly escalated into a breakneck gallop toward independence" (Bennett, 1987, p. 311).

\footnotetext{
12 The Malaita Massina Forum has been in the news in more recent times (SIBC $12^{\text {th }}$ Oct, 2011) over alleged offers of bribes to stop protests over government corruption.

13 Westerners' is a term used to portray people from Western Province.
} 
The speed of Independence and the resistance to a wholesale adoption of the coloniser's preferred systems of government for the Solomon Islands are relevant to this thesis because how the country's 'failings' are framed, both internally and externally, often appears to ignore the historical tensions around sovereignty and choice.

\subsection{INDEPENDENCE AND THE LANGUAGE OF FAILURE}

The Western language and imagery around the Solomon Islands and Melanesia in general was firmly established long before talk of independence. French botanist Bory de Saint Vincent came up with the name Melanesia in the early 1800 s although his fellow explorer Jules-Sébastien-César Durmont D'Urville is more widely credited with dividing Oceania into the groups, Polynesia, Micronesia, and Melanesia. D'Urville spoke of the Melanesians as "almost as black as that of Kaffirs ... living in small tribes, almost never [forming] a nation" (as quoted in Tcherkézoff, 2003, p. 176).

The image-making by the North continued to inform the global imagination around what was now called Melanesia. Fry captures this in his overview of the formation of the South Pacific Commission (SPC) in 1947 where, in a meeting in Canberra, the United States, Britain, the Netherlands, France, Australia and New Zealand drew the boundaries and established the South Pacific Commission (SPC) (Fry, 1997). Fry's sometimes shocking account of the Western intrigue around the first conference of the SPC in Suva in 1950 exposes the novelty and experimental nature with which the organisers and observers viewed this gathering of the South Pacific elite. Fry suggests there was a change in the Australian understanding of the 'native' that they might become a possible equal once fully 'developed'.

True, the bulk of the Pacific natives are still in the 'fuzzy wuzzy' stage; an enormous preponderance are illiterate; the work of raising their standards in prodigious. But the South Pacific Conference was the writing on the wall, the start of better days for these natives whom we would do well to cultivate as our friends as well as our neighbours. What was once a pipe dream-westernized natives in the Pacific-mightn't be far from reality (Sydney journalist David McNicholl as quoted in Fry, 1997, p. 195). 
D'Urville's sentiments about Melanesians persisted widely for more than a century as revealed in a delegate's description of the people from the Solomon Islands and PNG as inferior to the Polynesians, "only just emerging from horizon-bounded village community" (Nancy Robson as quoted in Fry, 1997, p. 191).

By the 1970s the British, in their rush to disentangle themselves from the Pacific including the Solomon Islands, were viewing the process as more one of their establishing independence from the territory, as opposed to the Solomon Islands gaining independence (Bennett 1987). So it was with these firmly placed Western attitudes that the Solomon Islands, almost by default, achieved independence and tried to come to terms with the Westminster system which many argue has no parallel in Pacific cultures. As they and other Pacific governments struggled with this ill-fitting cloak, frustrated postcolonial powers fell into the language of the doomsday scenario and the African state comparison (Fry, 1997; Chappell, 2005).

Hassall believes failures to explore innovative constitutional outcomes for Pacific states during colonial and post-colonial periods restricted their ideological creativeness and ultimately, their effectiveness (Hassall, 2010, p. 4). It was, and is still today, the argument of many that what is seen as the failure of the democratic system is just defective politicians and public servants that need 'fixing', not the system itself. This is relevant to this research in that those perspectives are now being played out by donors in terms of capacity building and communication through the media in the Solomon Islands. The descriptions of how Solomon Islanders fail to adhere to the system of governance placed on them, fit snugly into the rhetoric of explorers and observers over the last 200 years.

However there are contrasting views:

The people are not usually resisting the technologies and 'conveniences' of modernization, nor are they particularly shy of the capitalist relations needed to acquire them. Rather, what they are after is the indigenization of modernity, their own cultural space in the global scheme of things (Sahlins, 1999, p. 410 as quoted in Connell, 2007). 
From another corner Fraenkel, in his book 'The Manipulation of Culture' (2004), is dismissive of analysis that lays the blame for the Solomon Islands' status as a 'failed state' totally on a 'failed colonial-bequeathed state':

What are the policy options if that is accurate? Logically, it would be necessary either to deconstruct the central state, and empower those supposedly crisisengendering 'indigenous power structures', or revert to some form of perpetual overseas control (disavowal of 'neo-colonial' solutions notwithstanding) (Fraenkel, 2004, p. 9).

\subsection{THE TENSIONS}

Experts are divided over the long-term causes that led to what are locally called the tensions' of 1998-2003 (Allen \& Dinnen, 2010) and whether they were the legacy of a Western-style of government that sat uneasily with the culture, or whether they stemmed from the corruption and unequal development within that

The long-standing grievances between Guadalcanal people and the settlers from Malaita were aggravated by an economy that had been rocked by low commodity prices following the Asian financial crisis, forcing cuts to public service (Bennett, 2002, p. 10. Barbara, 2010, p. 129). Before and after independence, Malaitans had become the 'mainstay' of plantation labour and, in some cases, hired muscle. The phenomenon had started in the famous 'blackbirding' of the late 1800s during which young men were taken by force from the island to Queensland and Fiji. This changed to a voluntary movement of labour, as the work became a 'rite of passage' and a source of income for many Malaitans (Moore, 2007; Bennett, 2002; Anderson, 2008). As the plantations expanded locally it also led to disproportionate numbers of Malaitans working on the island of Guadalcanal, and eventually, simmering resentment about the pockets of Malaitans settling on Guale land.

In 1998 the Isatubu Freedom Movement began forcibly evicting Malaitans, who they accused of taking jobs and land. An estimated 20,000 Malaitans left the island under pressure. The Malaitan Eagle Force (MEF) was formed in response and fighting broke 
out between the two groups, often between members of the same family. In 2000 the MEF staged an attempted coup (soon after the Speight coup in Fiji) taking the Prime Minister hostage. By the time the Townsville Peace Agreement (TPA) was brokered in late 2000 the economy was already in a downward spiral and the government was unable to pay wages. The word 'lawlessness' was firmly planted in the country's lexicon over the next two years.

"[O]ne of the militant groups kidnaps someone because they suspect he is a member of the other militant group. Those capturing the suspect beat him very badly even before asking questions. The person is then usually killed, often with cruel torture" (Press Release from the Diocese of Malaita, Church of the Province of Melanesia, 10 July 2000 as reported in Amnesty International 2000 report).

The country was facing bankruptcy and was almost totally dependent on aid, especially from the Republic of China (ROC)/Taiwan (Firth, 2003). However the TPA neglected to address deep-seated issues around governance, corruption and the power of the elite (Barbara 2011) so the economy continued to worsen while outbreaks of violence left the country nervous, and workers unwilling to return to Honiara.

Simplifying the crisis as 'ethnic tension', as some politicians and foreign media have done, is, according to Moore, naïve and more weight needs to be put on the problems of uneven development and distribution of profits. Solutions also needed to be seen in terms of "rethinking economic development ... guided by an understanding of how local cultural practices have articulated with these to date" (Moore, 2007b, p. 211).

Bennett also laments the use of the "jargon of the Balkans" (2002, p. 11) and points out the legacy of the disparities between the artificially imposed capital of Honiara on Guadalcanal, and the rest of the islands.

Identification with place and region is embedded in the Solomon Islanders' worldview, the source of contestation with other regions. Among the causes of the conflict lay the perceived disparities between the provinces and the capital, a centre that had grown fat on the wealth of other provinces (2002, p. 12).

\subsection{A 'FAILED STATE': THE LANGUAGE OF THE INTERVENTION}


The Australians arrived, commando style and heavily armed, and secured the airstrip as though it were Afghanistan. They were met by children, a choir and gifts. (John Roughan, 2008 as quoted in Anderson, 2008, p. 4).

In June 2003 the Australians agreed to accept Solomon Islands Prime Minister Allan Kemakeza's plea for help to sort out the ongoing violence. However by then the economy was in freefall, at least 200 people had died and up to 35,000 more had been forced from their homes (Hameiri, 2007). There is debate over what prompted Australian Prime Minister John Howard to act then, having refused calls for help before. Many have noted how intervention in the Solomon Islands went from being out of the question to a full-scale Australia-led mission within a matter of months in 2003. In a now often-quoted January 2003 address, Australia's Foreign Alexander Downer had ruled out intervention.

Australia is not about to recolonise the South Pacific, nor should it. These are independent sovereign countries ... Sending in Australian troops to occupy Solomon Islands would be folly in the extreme" (Downer 2003a, p. 11).

Those comments were made just six months before the Regional Assistance Mission to Solomon Islands (RAMSI) landed at Henderson Airport.

It was world events that seemed to spur the Australian government's 'flip flop' in foreign policy. With the $9 / 11$ attacks still very much part of the international conversation, and the invasion of Iraq in March of 2003, the discourse around 'statebuilding', sovereignty, and 'failed states' was high on politicians' agendas. A close relationship between Australia and USA had also changed the perspective of the conservative Prime Minister.

The new prism provided by the American-led 'war on terror' served to highlight critical linkages between lack of state capabilities and the generation of transnational security threats. 'Failed' and 'failing' states were now seen as potential incubators for illicit and destabilising activities, including transnational crime and terrorism, thereby posing grave threats to regional and international security (Allen and Dinnen 2010, p. 313).

In 2003, Solomon Islanders welcomed RAMSI ready for an end to the conflict (SIDT survey quoted in Anderson, 2008). While the initial objective was to restore law and 
order, the mandate for the mission was wide: helping government better serve the people, encouraging broad-based economic growth and law and justice (Anderson 2008).

Less than three years after its arrival, RAMSI, and many others, were taken by surprise by the April 2006 riots that left large parts of Honiara's Chinatown destroyed and confidence in RAMSI's progress shaken. The riots came after the election that saw a deputy from the previous government, Snyder Rini, elected as the new Prime Minister when many were hoping for a change to what had been seen as 'dysfunctional' politics of the past (Barbara, 2008). Eventually Rini resigned and was replaced by Mannaseh Sogavare. A war of words between Sogavare and Australia ensued as the head of the government challenged RAMSI's role in the country and Australia's role in the Pacific. Bilateral relations remained tense until Sogavare was replaced as Prime Minister in late 2007. The new government was more supportive of the RAMSI objectives.

In 2009 the Solomon Islands Government and RAMSI signed the Partnership Framework. Its three core pillars support improvements to the machinery of government, law and justice, and economic governance and growth. The Australian government spent just under A\$250 million in the Solomon Islands 2009-10. Around a fifth, A\$45.7 million, came out of AusAID's country programme and the rest through RAMSI, AusAID's regional and global programmes, and other Australian government agencies (McDougall 2010). A report in the Melbourne Age puts the figure spent by Australia at more than a billion dollars over eight years (Dorling, 2011)

RAMSI has many supporters and has been held up as a "model for good practice" by the Development Assistance Committee (DAC) of the OECD (Hamieri, 2009, p.35). However others, such as Solomon Island academic Kabutaulaka, question the "national building objectives" of RAMSI that ignore other power bases in the country (Kabutaulaka, 2005, p. 300). And there are those that see RAMSI's economic governance and growth pillar as working within a "neoliberal vision" (Hamieri, 2009, p. 39), concentrating on "neo-liberal development orthodoxies" such as public sector reform and boosting the private sector (Barbara, 2008, p. 136). Hamieri asserts RAMSI 
and other donors are setting the scene for further conflict as they work on the "trickle down" effect from financial gain through increased markets which he believes will increase poverty at "least in the medium term" (Hamieri, 2007, p. 432).

\subsection{PLACING THE DONORS}

There is not one Pacific

Only one common theme

That development is certain

Though foreign

And coconuts will continue

To fall

The Pacific Ocean will camouflage

superficial dreams

and the faint sound of drums

will still be heard

if we pause a while to listen

(Vaine Rasmussen in Va'ai, 2005, p. 1)

The Solomon Islands ranks well below East Asia and most of the Pacific on the Human Development Index (HDI), placed 123 out of 169 countries (UNDP 2011). Close to a quarter of the population live below the national basic needs poverty line and the Asian Development Bank 2009-13 forecasts increasing pressure on the government budgets due to "complete forest depletion" through unsustainable logging (ADB, 2010, p. xi). The EU forecasts are equally grim as the global economic crisis heightens the economic faltering brought on by the end of logging. The country is heavily dependent on donor funding or "relatively massive donor support" (European Commission, 2008) as development projects are financed by up to $70 \%$ by external resources. ${ }^{14}$ The ADB recommends "recurrent expenditure restraint and prudent monetary policy" (2010, p. xi) including building "the concepts of nationhood, good governance, and affordable public service delivery" (p. xi).

\footnotetext{
14 http://ec.europa.eu/europeaid/where/acp/country-cooperation/solomon-islands/solomonislands_en.htm
} 
The European Union, World Bank, International Monetary Fund (IMF) and the United Nations (UN) plus bilateral partners Australia, New Zealand, Japan, Britain and the Republic of China (ROC) are visible both physically in terms of personnel, signage and logoed cars but also within government departments where the in/out trays are full and labeled 'donors'. Kabutaulaka (2005) points out all are in a position to place conditions around their aid and therefore exert influence. He raises the vital question of who controls the state and says the rhetoric around collaboration belies the fact that Australians have been placed in important revenue dealing line positions, while all donors have influence over policy.

A report by the Independent Expert for the UN Human Rights Council Cephas Lumina has identified challenges around the Solomon Islands' dependency on aid (Lumina, 2011). He suggested the government was unable to cope with the 'massive inflows' of resources. More tellingly he argued the Solomon Islands government was in danger of becoming "more accountable to donors for its actions, rather than to its population" (Lumina, 2011, p. 21). Overall the report is revealing in its muted criticism of Australia's development assistance to the Solomon Islands: its overuse of technical assistance, the problems with irregular harmonisation with other donors, and the lack of a rights-based approach to development.

There are widespread concerns, particularly among civil society organizations in Solomon Islands and Australia, that donors may be advocating reforms, such as reduction of public sector spending, privatization, trade liberalization and financial liberalization. In 2010, for example, the Government received donor budget support linked to the implementation of a number of reforms to improve management of public expenditure. There is evidence that these reforms often have an adverse impact on the enjoyment of human rights, especially by the poorest and most vulnerable. It is therefore important that the effect that these reforms may have on poverty, inequality and the potential for conflict in the country is carefully considered before they are implemented (Lumina, 2011, p. 21).

\subsection{THE PARALLEL HISTORY OF THE MEDIA}

To place Media Development in the present context means looking at its beginnings in 
the Solomon Islands and this is really only recent history with the first private newspaper, the Kakamora Reporter, 1970-75. Pre-independence, it railed against the paternalistic attitude of the British colonial service. It nicknamed the British officials the 'Africa Corps' as many of these people were seconded directly from colonial offices in Africa (Chappell, 2005). Bennett (1987) also remarks on the Kakamora Reporter as the voice of the emerging Western-educated elite during that time.

Moore (2010) has outlined sources for a historical bibliography detailing a government service News Sheet that began in 1954 with different versions in different districts, continuing as late as 1991. The Honiara newsletter morphed into the Solomon News Drum in 1975, and was privatised in 1982 to become the Solomon Star which remains the main newspaper in the Solomon Islands today. Solomons Toktok also published as Melanesian Nius and Kiokio Nius until $1982 .{ }^{15}$

The media landscape has expanded hugely since then to include the national broadcaster SIBC and several Honiara-based FM stations, as well as community radio stations supported by the churches or private interests (such as Gold FM supported by an internationally-owned goldmine). Newspapers include the Solomon Star, Island Sun and National Express, One Television broadcasts to the Honiara area, and the People First Network (PFnet) has 30 sites over nine provinces opening up email for isolated communities. The key players are all members of the Media Association of Solomon Islands (MASI).

During the height of the tensions, the Solomon Islands government imposed what where called 'draconian regulations' ${ }^{16}$ governing coverage of the civil strife. The Emergency Powers Act of 1999 prohibited news reports that 'may incite violence' or were 'likely to cause racial disharmony'. By 2004 the Committee to Protect Journalists

\footnotetext{
15 Moore, C. (2005). Chapter 19. Biography of a nation: Compiling a historical dictionary of the Solomon Islands. Retrieved from http://epress.anu.edu.au/tpl/mobile devices/ch19.html

16 Committee to Protect Journalists (CPJ) protest letter, July 1 1999. Retrieved from http://cpj.org/1999/11/solomon-islands-government-imposes-harsh-media-reg.php\#more
} 
(CPJ) was reporting that media freedom had increased substantially with the arrival of the intervention force RAMSI.

The Solomon Islands is judged to be 'partly free' by the leading media freedom watchdog, Freedom House in its 2011 survey. Freedom House defines a 'partly free' country as,

... one in which there is limited respect for political rights and civil liberties. Partly free states frequently suffer from an environment of corruption, weak rule of law, ethnic and religious strife, and a political landscape in which a single party enjoys dominance despite a certain degree of pluralism (Freedom House, 2011, p. 93).

\subsection{RAMSI AND MEDIA DEVELOPMENT}

A well-functioning media is an integral part of any democratic society that helps builds the demand for good governance. In Solomon Islands, the media plays a key role in holding decision-makers to account. (RAMSI website http://www.ramsi.org/our-work/media-strengthening.html)

This motivation behind the Australian-led intervention and its continued 'entanglement with domestic politics' (Allen and Dinnen, 2010) are relevant to this thesis in that RAMSI is moving from peacekeeping to development. Parts of its statebuilding or strengthening techniques are around the growth of a free and pluralistic media. It is important to understand, therefore, what drives the policies and understandings behind this regional assistance mission and how other donors are mirroring its emphasis on capacity-building, good governance, and anti corruption.

RAMSI's first foray into Media Development in partnership with the Australian Broadcasting Commission ( $A B C)$ was aimed just at the state broadcaster, the SIBC, but came to an abrupt end in 2007. It had caused acrimony with the already suspicious Sogavare government of the time. During that period relationships between Honiara and Canberra were at an all time low illustrated by such incidents as the following.

In a highly provocative move, RAMSI police raided Prime Minister Sogavare's office, in pursuit of documents for their investigation into criminal allegations against Julian Moti, whom Sogavare had appointed Attorney General. It became a test of wills between the two governments, with an unusual show of resistance 
from a Pacific leader (Anderson, 2008, p. 71).

It was within this environment that one of two media trainers from Australia found themselves compromised at a Prime Minister's media conference. They both left the country shortly afterwards. As is explored in Chapter Five, the new Solomon Island Media Assistance Scheme (SOLMAS), launched in 2008, has widened the Media Development brief to all the media.

RAMSI's support, known as the Solomon Islands Media Assistance Scheme provides support and coaching to Solomon Islands journalists, to build their skills in reporting and editing, to ensure they undertake their work efficiently, ethically and with integrity, and to give them the confidence to ask the tough questions. (RAMSI website).

The deep distrust with which some politicians hold RAMSI and, by its association, SOLMAS, may have been prompted in part by the openly neoliberal policies of the intervention force during the first few years of its existence in the Solomon Islands. Anderson (2008) claims that a culture of 'deep interventionism' remains.

\begin{abstract}
Australia's Department of Foreign Affairs and Trade, in its 'medium term priorities' for the Solomons, was urging a standard neoliberal formula: budget cuts ('right sizing'), the privatisation of all state owned enterprises ('as soon as possible') and the registration and commercialisation of land (because 'customary land ownership places serious constraints on the growth of new higher value private sector activities') (DFAT 2004: 135). This line of argument was forced into retreat during the period of the Sogavare Government, through 2006-07 (Anderson, 2008, p. 82).
\end{abstract}

At the time Anderson was writing this, the Special Coordinator of RAMSI, Tim George, was officially launching SOLMAS at RAMSI headquarters (Sireheti, Solomon Times Online, 2008). As was mentioned in Chapter Two, the suspicion with which Media Development is held could be seen as part of the uncomfortable fit of the statebuilding mandate to, on one hand, keep local politicians secure around sovereignty issues while, on the other, work on transformation ideals around good governance (Barbara, 2008). Or it could be more simply based around the elite not understanding the role of the media (Chand, 2007). 
SOLMAS is a more broadly based form of Media Development than would have been found in Eastern Europe in the 90s. It is what Peters (2010) calls a more mature sector now "no longer only focusing on media professionals and setting up new private media companies" (p. 271) but branching out into areas of media law, helping to grow independent media organisations and training others to understand how the media works. It also ticks the boxes for relatively new practices of conducting media audits in an attempt to understand the context before organising the programme (Odugbemi \& Norris, 2010).

Hume (2004) in an online publication, Media Missionaries, gives the 15 commandments of Media Development - no doubt a good indication of some of the thinking behind the programmes being implemented in more than 100 countries in the developing world including the Solomon Islands. On one hand advice to "build from the bottom up, not the top down. Western models don't necessarily work" (p.15), is encouraging as is garnering local "grassroots" support. However the reason given - "so that local politicians can't complain of "Western imperialism" at work" (p.15) - bears similarities to the situation in the Solomon Islands as seen in Chapter Six. Further 'commandments' such as one of accountability - "require them to share the training with their newsrooms. Hold managers accountable, and withhold further aid if these agreements are not fulfilled" (Hume, 2004, p.15) - once again raise questions about donors' role in the sector.

\subsection{SUMMARY}

This chapter has attempted to build a picture of a nation that has struggled to define its own sovereignty under the influence of missionaries and traders, colonisers, then donors, and now a combination of donors and an intervention force largely funded by Australia. It is a people that move between the capital of Honiara and semi subsistence lifestyles, with many scarcely connected to the market-led development ideals of the donors. It is a country that has continually failed to live up to its Western benefactors' standards of success since independence more than 30 years ago and civil unrest over the last decade has added 'failed state' to the list of negative descriptions that 
surround it.

The chapter shows it is into this picture that Media Development has been introduced through the Regional Assistance Mission, RAMSI. And while the RAMSI itself walks a fine line between the transformations of state-building alongside a sovereign state, its media assistance programme, SOLMAS, equally faces a problem of not offending the politicians and elite while working towards a media that can fulfil the 'watchdog' role addressed in Chapter Two.

The next Chapter introduces the methodological theories that have informed, and the challenges that have surrounded, this paper's research in the Solomon Islands. 


\section{CHAPTER FOUR: WAYS OF KNOWING AND THE OBSERVER}

\subsection{INTRODUCTION}

This chapter looks at the methodology and methods used to build the research design while understanding this, and everything else, is guided by questions of paradigm and positionality and, ultimately, by my own perception of truth as a researcher. Having outlined the structure of this research project in Chapter One, presented the theoretical and global understandings through literature in Chapter Two and placed the research in the Solomon Islands in the last chapter, this chapter looks at the very foundation of ideas and beliefs that frame the research. It will look at how the methodological choices have informed the research objectives, philosophy, and ethics.

Guba and Lincoln argue it is crucial researchers sort out their ideas about their place in the world before they start looking at methodology and methods. (Guba \& Lincoln, 1994)

Questions of method are secondary to questions of paradigm, which we define as the basic belief system or worldview that guides the investigator, not only in choices of method but in ontologically and epistemologically fundamental ways (Guba \& Lincoln, 1994, p. 105).

\subsection{KNOWLEDGE AND POSITIONALITY}

$\begin{array}{ll}\text { your way } & \text { my way } \\ \text { objective } & \text { subjective } \\ \text { analytic } & \text { gut-feeling like } \\ \text { always doubting } & \text { always sure } \\ \text { the truth } & \text { of the truth } \\ \text { until proof comes } & \text { the proof } \\ \text { slowly quietly } & \text { is there waiting } \\ \text { and it hurts } & \text { and it hurts }\end{array}$

Our Way (Thaman, 2008, p. 461)

For nearly twenty years of my adult life I worked as a radio journalist. Every working 
day in Radio New Zealand newsrooms I constructed news stories from what I observed, researched and understood to be 'truths'. Even as a young reporter, reducing complex issues down to three-paragraph news bulletin items that would be heard as truth or facts made me uncomfortable. As I got older my uneasiness grew. Truth was becoming for me less substantive-a more shifting concept-and one that was presented and driven by those with interests beyond my understanding. Truth was political, and it was relative.

This has driven my interest in different 'ways of knowing' and the impact of the media on how people, from the journalists to the consumers of news, perceive themselves and others. However it is Development Studies that has opened the door on placing that day-to-day subject into sharp relief. Cross-cultural research in Development Studies offers the biggest challenge in interpreting 'ways of knowing'. There is a constant need to be aware of the impact of different worldviews, and how that influences people, communities and governments coping with the multitude of paradoxes around international development.

There is also the challenge of hegemony. Who holds the power between donors and the developing nation? Where is the fine line of sovereignty breached? Development Studies is a perfect vehicle for this cross discipline research into hegemony and ways of knowing. Development Studies itself has been under attack for being an 'imperialist discourse' supporting neoliberal and ultimately unsustainable economic structures and ideals (Sumner, 2006). However as it evolves as a discipline it retains its focus on social justice and unpicking how that may be achieved.

Denzin, Lincoln, \& Smith (2008) respectfully point to New Zealander Linda Tuhiwai Smith when they repeat her assertion from an indigenous standpoint that the term 'research' in its broadest term is "inextricably linked to European imperialism and colonialism" (2008, p. 2). They go on to say qualitative research can be counterpoised with power and knowledge. Whatever its beginnings in terms of the colonisers, or the motivation behind the early use of qualitative research, it seems too simplistic to condemn all attempts at cross-cultural research and understanding as re-colonisation 
of 'the other'. Scheyvens \& Storey point to the value of cross-cultural research as allowing space for local voices that are not often heard. Also to not step into the developing world as a Western researcher for fear of continuing exploitive practices of the West presupposes those in developing countries have no power (Scheyvens \& Storey, 2003).

Denzin, Lincoln and Smith use a metaphor, when representing qualitative research, of the researcher being the equivalent of the bricoleur. The bricoleur makes do by adapting the bits and pieces of the world to produce bricolage, which is the "poetic making do" or more pragmatically "a pieced together set of representations that is fitted to the specifics of a complex situation" (Denzin, Lincoln, \& Smith, 2008, p. 4). I find this a more fitting introduction to positionality and reflexivity in cross-cultural research as it is a 'piecing together', and the situations are, by their very nature, complex as they are from the worldviews of both the researched and the researcher.

As with all researchers I have my own unique positionality. I come to this research crossing disciplines as a media professional before a development sector professional, a woman, a mother, middle-class and white. My interpretation of my data today will be different from my interpretation as a younger woman. This all drives how I see the world and interpret it. All these factors were instrumental in how I framed my questions and the responses of the interviewees during my research. They, and I, were influenced in our interactions by our race, age, sex and also spatial factors such as issues at hand or "location in time and space" (Mullings, 1999, p. 338). Mullings describes the balancing act of positionality in a piece of research. She found herself drawing on different parts of her identity to produce a form of empathy with her interviewees that "involved a constant shifting of the multiple axes upon which my identity rested" (Mullings, p. 341). Mullings' learning here was, in the end, the positionality of those she interviewed was as 'cross-cutting' as her own.

This was relevant to the answers of the contributors to this research. Journalists responded to my knowledge of newsroom etiquette and jargon. The more we talked about the difficulties of day-to-day news coverage the more relaxed we both became 
in our mutual understandings of the news media, its idiosyncrasies and its contradictions.

It is with that in mind that I took my background as a media professional to this piece of research. There is an optimistic hope that by holding up a mirror to the assumptions of both development officials and media personnel it may create a space for discussion about the impact of the repeated use of certain concepts and how quickly they slip into the lexicon of 'truth'. Also implicit in this is that the role of a journalist to question hegemony in all its forms. This means questioning their own, and the donors', motivations and worldviews, and therefore their influence on, and relevance to, the local realities.

\subsection{RESEARCH PHILOSOPHY}

This research is very much based in the philosophy of critical realism whereby knowledge is 'socially constructed'. "Critical in this context refers to the transcendental realism that rejects methodological individualism and universal claims to truth" (Denzin, Lincoln, \& Smith, 2008, p. 17).

Denzin, Lincoln and Smith (2008) argue against critical realism as assuming knowledge can be constructed without ultimately being a tool for the powerful and the elite. However, while constantly questioning what is truth, whose truth, and for what purpose this truth is being used, this research works on the principle that by bringing more voices to a problem, questioning assumptions and challenging perceptions, knowledge and understanding across ideologies and cultures can still create checks and balances which are crucial to social justice.

\subsection{METHODOLOGY}

This research explores, in part, the meanings of peoples' worlds through their lens on the media they are receiving and their subjective human experience, which makes qualitative methodology a good fit with the topic (Brockington \& Sullivan, 2003; 
Schwandt, 2007).

The academic and political arguments over the legitimacy of qualitative research cross the boundaries of 'truth', bias and positionality. Denzin, Lincoln and Smith talk about the resistance to qualitative studies centring on the feared destablisation of the notion that positivist sciences are the ultimate triumph of Western civilisation, predicated around the assumption that 'truth' can surpass belief and individual partiality or bias (Denzin, Lincoln, \& Smith, 2008).

O'Leary stresses there are ways of reaching credibility with qualitative research and one of these ways is through the relatively new methodology of crystallization (Ellingson, 2009) ${ }^{17}$ which is motivated by more post structural understandings than triangulation. "Building a rich and diverse understanding of one single situation or phenomenon by seeing the world as multi-faceted and accepting that what we see depends on where we look" (O'Leary, 2010, p. 115).

The nature of Masters level research means it can be only a snapshot of an overarching issue. That snapshot for this research was taken between June and July 2011 and looked at media/donor relationships in the Solomon Islands as they were at that point in time. However by using a form of crystallisation-constructing a picture from literature, observation, semi-structured interviews and an overview of news media during that period-the research builds a picture of a way of thinking around Media Development. The aim of crystallisation is to look at an issue from multiple angles to get more depth, but still veers away from seeking a "valid singular truth" (Tracy, 2010, p. 844).

Ideally the methodology for this research project would have woven in the separate discourse of Kaupapa Māori Research (to establish a research method that is tika or appropriate). Kaupapa Māori fits within a larger group of indigenous methodologies,

17 "I came to crystallization out of necessity. I needed a framework, a methodological path that I could follow that would enable me to construct and articulate multiple lived truths, rather than force me to choose among them" (Ellingson, 2009, p.xi). Ellingson developed crystallisation as a way of using different forms of data and analysis... and different genres within interpretive methodology ( $p$. xii). 
which place a group's culture, values and behaviour to the forefront of research (Tuhiwai Smith, 1999, p. 15). I was influenced also by a relatively new methodology, but yet the in the oldest tradition-one of story telling and conversation-Talanoa. Dr. Sitiveni Halapua, Director of the East-West Center's Pacific Islands Development Program, is credited with encouraging the use of Talanoa both for conversations at political level, and for research. "[T] he participants become the experts and our job, as researchers, is to listen, learn from them, and search for the general structural form and coherence of their different ideas and views" (East-West Center, 2002).

While acknowledging these methodologies as influential in my thinking and research design, I am aware that they cannot be claimed as my methodological approach. For instance while I saw every contributor on more than one occasion to introduce and discuss my research questions, and to rewrite and rethink them in a way would be more appropriate and useful to the Solomon Islanders themselves, I was aware that each meeting was yet another imposition by an 'outsider' from the development industry. The restrictions were a two-way street: I was confined by time and finances and, although the contributors to this research were generous with their time, they were also constrained by their obligations elsewhere. The will is there but the practicality of a Western imposed academic paradigm "fatally interrupts the dialogue" (Noblit, 2011, p. 453).

\subsection{RESEARCH METHODS}

The main questions when starting a piece of research is what is the object of enquiry and how can it be enquired into (Hollway \& Jefferson, 2000) so it is important to bring this research back to the main aim. This research seeks to explore development donors' use of Media Development as part of an overall state-building strategy. The way to enquire into this is to find out how journalists in a developing country are interpreting news stories and training from development donors, and how that interpretation is affecting what is being heard or read by the people of that country. Therefore semi-structured interviews are the prime element of the data gathering for this research. 


\subsubsection{Semi-structured interviews}

The post structuralist/post-positivist dialogue around interviewing concentrates on its lack of neutrality and how it is bound by its environment (Fontana \& Frey, 2008). "For researchers using a postmodern conception of interviewing, an underlying assumption is that representations of findings are always partial, arbitrary, and situated, rather than unitary, final, and holistic" (Roulston, 2010, p. 220).

However, having nailed those understandings to the flag, to gain any comprehension of a complex situation from the point of view of the protagonists involved or influenced by that situation, clearly verbal exploration and discussion is essential. Interviews give layers of understanding and "diversity of meaning" but also allow those interviewed a chance to reflect and discuss their experiences (Dunn, 2010, p. 102).

I chose to contact the main contributors by email before I arrived, sending my research information, consent forms, and proposed question line forms in both English and Pidgin (see Appendices one to four). The initial contacts were made using snowballing, or snowball sampling, and the resulting 11 formal interviewees were approached, met with for at least an hour beforehand, and then interviewed on a subsequent day. The twelfth interview was conducted by phone from New Zealand to Honiara.

The NGO and media sectors of Honiara are small so once the first contacts were made, more were suggested (Berg, 2009). The initial contacts and the 30 or so others involved in the sector, who were not interviewed but happy to give thoughts on the research questions, were the gatekeepers of knowledge helping to "pave the way and educate" me during the research journey (Murray \& Overton, 2003, p. 30).

One-on-one semi structured interviews were conducted with the 12 contributors and focus groups held on two consecutive days. I was constantly gratified by the interest in my subject and the time people made for me. The cross section of media 
professionals, civil society, commentators and members of a community interviewed for this research created a suite of lived experiences from which to build a picture. The nature of the interviews meant I could tailor the question line to suit the position the contributor held, but after that it was an organic discourse that was led as much by the interviewee as myself. Fontana \& Frey (2008) call this "a negotiated text ... jointly constructed" (p. 144).

While transcribing I reflected on the interviews and how, on occasion, I had not waited for the 'pause', possibly missing more contemplative answers. However the last question, asking for the contributors to think about any points we may have missed, elicited some insightful replies such as this from one contributor: "We spoke about, is there indigenous-styles of reporting or a new type of media? I want to discuss this more. Whether we realise that or not we tend to develop our own way of reporting on issues".

The journalists and I had some shared realities when approaching the questions around how news media standards can be viewed across cultures. We had faced similar challenges as reporters and observers and our mutual understandings and interests opened the conversation more than I could have hoped for. I have chosen to use my questions in the contributors' quotes when necessary to capture the conversational nature of the interviews in a way that acknowledges the learning from Talanoa.

\subsubsection{Focus groups}

An important part of this research was to get out of the centre of Honiara and experience the villages where more than $80 \%$ of the population of the Solomon Islands lives. To understand how development donors are impacting on the news media and the worldview of the people, it was important to understand the access to news and the priorities that are held in villages outside of the capital. 
Before leaving New Zealand I had identified a village on the Weather Coast of Guadalcanal and a member of that village who could act as my translator and guide. This person lived and worked in Honiara for an International non government organisation (INGO). Her job included guiding and translating for overseas visitors and expatriates working for the organisation. She was also, in her words, "the queen of workshops". Her help, wisdom, and advice were invaluable.

I had intended to do semi-structured interviews in the village but the translator/guide suggested that a workshop/focus group situation would elicit more information as it was something the villagers were used to and more comfortable with. Other development professionals in Honiara also advised this as the preferred way of interacting with communities. Even in the few weeks I had been in Honiara, it was clear to me getting the credibility to gain an insight into the village would be easier and more enlightening in a shared forum. However I had not prepared for this in my research design so it meant some intensive reading and organisation. Indigenous methodologies stress the need for flexibility and awareness of environment, and this was confirmation that listening rather than directing can open doors on ways of knowing (Louis, 2007).

I wanted to understand more about how the villagers interacted with the news from Honiara and how they viewed the donor priorities and language. Chambers (2002) suggests listing and sharing as a way of uncovering what people know. I used that method with two focus groups, the first with the women and the next day with the men of the village. The attendance was obviously voluntary but it was clear there was a good representation of age and status in the village. Although my limited understanding of Pidgin and the local language impeded my ability to monitor the discussions, I observed there were few who did not contribute to the voluble debates in the room.

There is always a risk of getting so tangled in "your own agenda" (Scheyvens, Scheyvens, \& Murray, 2003, p. 177) that you ignore the needs of the contributors. I tried to avoid that by making sure I had gained the appropriate permission to visit the 
village from the village leader, and worked with the translator to find out the most convenient time for the community.

However another factor in fieldwork is managing the expectations of contributors by being clear about your agenda. For instance when travelling by boat along the remote coastline, the translator said we might need to drop into a village to pick up a woman who wanted to come to the workshop. This made me wonder how the focus groups had been explained to the people and we decided it was possible villagers thought they would be learning new skills. These people are hungry for knowledge and I was concerned they would turn up with expectations so once we arrived we sent out messages this was information-gathering and I was the 'learner' or, as one woman helpfully explained in Pidgin, "an over-age pikinini". Despite this there were more than 20 women and 15 men at the focus groups and a lot of interest in the ideas about what news was coming from where and how that was influencing their daily lives.

\subsection{ETHICS}

Every contributor gave their permission for their names and positions to be used and this became a bit of a conundrum for me in the writing up of this research. All my journalism training said the position of these people was vital to give credibility to and understanding of their background, and possible bias. I believed the reader could understand more about how the contributors saw the world by reading vignettes about their lives and experience. However, while data and axial coding, and writing up the interviews, I became more and more uncomfortable with exposing my generous contributors to scrutiny by others in the a small world of development and media that exists in Honiara. I chose not to name the majority of them but assign them to professions: ' $\mathrm{J}$ ' for journalist and 'NGO' for civil society. However, commentators bring their understandings and critique to this research through their professional connections and knowledge so I have continued to name them (see Appendix five for coding list and names of contributors)

At the focus groups in the village we passed around the consent forms in Pidgin to 
those who could read and they relayed the information to the others in the groups. I asked how the village wanted to be known in the research and gave them some options: a remote village in the Solomon Islands; a remote village in Guadalcanal; a remote village on the Weather Coast of Guadalcanal; or the village's actual name? After much discussion they decided they would remain anonymous but be identified as Guale people from the Weather Coast.

The consent process is an interesting one for a former journalist. As Tuhiwai Smith says, "consent is not so much given for a project or specific set of questions but for a person for their credibility" (p. 136). The openness of the contributors in this research was predicated on their trust and belief in me. The only party nervous about that was the General Manager of SOLMAS, Corallie Ferguson, however that can be explained by the political mistrust and debate around the position of RAMSI in the Solomon Islands and therefore the media assistance programme (see Chapter Three p. 20). Also she explained that researchers had come before and not shared their findings despite saying they would. We agreed that SOLMAS would see the research before it was submitted and she would be able to change anything attributed to her. I also fed the analysis chapters back to one of the journalists who had shown an interest in it.

Both these parties fed back just as the final draft was being written. The journalist said he had found the whole project interesting saying "it will definitely help in our plans in the newsroom especially on how best we would like to serve the community in terms of disseminating information". Fergusson made some valid changes to information and quotes around her organisation SOLMAS and, as was agreed, they were changed or additions made as requested.

Finally a situation that made me uncomfortable with my research was the discovery that some people in Honiara had 'research fatigue'. One person I approached said he had done far too many interviews over the last six months and he really was too busy to do more. Another said they were sick of giving their time to university researchers and getting nothing back. The Solomon Islands is heavily researched by Australian universities and more lately by the New Zealand academy. In all the Development 
Studies literature I had read before embarking on my fieldwork, none had suggested finding out how many researchers had been in the area in the recent past. It might well have been good advice.

\subsection{SUMMARY}

This chapter outlines the research journey, framing it with positionality, philosophy, methodology and method. While accepting that research can be yet another hegemonic process, recolonising the ways of knowing or understanding the world, what I discovered was a powerful people who brought intelligence and strength to the project. Almost all the Solomon Islanders I spoke to were keen to discuss and open doors on new ways of looking at news media and donor relationships. The contributors to this research took my seed of an idea and ran with it, expanding it and playing with it to leave me with complex pictures of how relationships in the Solomon Islands develop and where the development sector fits into that. The overarching literature around qualitative research encouraged self-reflexivity and a desire for reciprocity to drive the process at every turn.

The next two chapters present the voices of the contributors under themes that unfolded as the interviewing took place. They make up the analysis of this thesis. 


\section{CHAPTER FIVE: THE PERIPHERY TO THE CENTRE}

\subsection{INTRODUCTION}

This chapter begins by situating the research more squarely in the lives of the majority of the Solomon Island people, those in remote and semi-subsistence environments. These are the people who the development dollar is aimed at, the end recipients of the 'passing parade' of development paradigms (Baker, 1979 as quoted in Connell, 2007b, p. 121).

To begin to understand the influence of the news media on the Solomon Islands as a nation it was necessary to spend some time looking from the outside in, from the village where the news is consumed, to the centre where the media emanates from. This is an attempt to understand the influence of the news from the eyes of the people of the rugged Weather Coast, to understand their views on the donors' words in that news, and the priority the villagers placed on the news in their highly organised communities. It is looking for the context into which the Media Development model is being located (Hume, 2004; Putzel \& van der Zwan, 2005).

These next two chapters present the thoughts and opinions of the contributors. ${ }^{18}$ However it should be stressed this is a snapshot of a very dynamic sector in an even more dynamic environment. It is also based on an understanding and worldview as outlined in the methodology. As such, the stories of the news media, civil society, the consumers, and the donors, are interwoven with the overarching literature and observations as an introduction to the place of the donor in Media Development in the Solomon Islands.

\footnotetext{
18 Direct quotes of contributors are italicised with researcher's question prefaced by initials $A B$ and contributors with their coding - e.g. J1 NGO1 or initials of name when that is given. The use of [brackets] are to indicate the researcher's words.
} 


\subsection{FROM THE VILLAGE}

The field research on the Weather Coast consisted of running two focus groups over two days; first with the women and then the men of the village (see Chapter Four). The focus groups took place during a week-long visit.

This village can only be reached by boat and by foot. It has no cell phone coverage, a couple of working radios and newspapers arrive rarely. Therefore the news is usually received orally from visiting relatives or people passing through on the rough track along the coast. The only way to contact family in Honiara is by cell phone but the nearest coverage is at a mission five hours' walk from the village. There is limited radiotelephone coverage at the medical clinic a half an hour across the river in the other direction.

I was interested in what way news, and the news media, played a part in the day-today life to the village. I wanted to understand what information villagers saw as relevant to their survival and what outlets this came from. I was also interested in finding out what development words reached the villagers and what sort of understanding there was of these words that were liberally spread through news media coming out of Honiara.

The thirty or so women (with lots of children accompanying them) were split into three groups. I began with a Mihi, which was translated. I explained my research aims and asked the groups to discuss three questions and to list some ideas (Chambers, 2002). It took a long time for the first answers to be written and I was concerned I had not made myself clear. Then it was all go as the groups entered into a lot of discussion peppered with outbreaks of laughter. The groups fed back to the gathering with lots of interest and discussion once again. The same format was used for the men. The groups were smaller and split into just two, and the discussion a little more muted.

The questions were as follows:

1. What news do you need to know about here that is important to the village? 
2. What news does the village need or want to know about from Honiara?

3. What words do donors/ development people use in the Solomon Islands that you have heard about? (And which of those words to you feel you understand?)

The results of discussions and the focus groups gave this research a more grounded perspective on the interviews I was conducting in Honiara in so many ways. It gave me a snapshot of the reality of the lives of most of the contributors and a small window on the many positives and negatives that exist in the subsistence communities that dot the shores and mountains of this country (see group lists, Appendices six and seven).

On the first question the men and women's groups came up with much the same list although, in all questions, the prioritising was slightly different.

\section{What news do you need to know about here that is important to the village ${ }^{19}$}

The issues that were raised by all the five groups, both men and women, ranged from weather, planned planting and harvesting, to health, education and commerce. There were commonalities about the need to be apprised about news on how the small school attached to the village was doing, issues of communication and the desire to be more connected through a cell phone tower, concerns about water and fixing the basic pvc piping system that broke frequently (the women felt if they were taught the skills, they could fix the pipes themselves) and both groups were concerned about the illmaintained track through to the nearest settlement which was unable to take the tractors they were hoping to receive through a fund assigned to their local MP. This was crucial to get supplies more easily to and from the local market or to the ships to Honiara. There was a lot of emphasis on finding activities for the young people to keep them educated and out of trouble. They spoke of the 'damaged' children who came home troubled from their time in Honiara. Both groups talked about running their own training centre within the village to share skills that were already there, while taking advantage of workshops on offer from outside. There was recognition of the impact of

19 The following is a synopsis of both the lists and discussions held in the groups. 
climate changes affecting the planning and planting of crops.

\section{What news does the village need or want to know about from Honiara?}

Here the lists differed more between the genders, although the need for news of family, students studying, who had been in trouble, illnesses, depression, successes all figured prominently. Pragmatically both focus groups were interested in the markets, for example what the prices were for the copra and cocoa that was heading to town or the goods that were needed in the village and, related to that, the shipping schedule which was erratic because of the dangerous sea swells on the Weather Coast. Some of this would be available through newspapers but more than likely through family in Honiara. More media-orientated was the news of politics; how their MP was doing, political changes, new laws that might affect them, or changes to currency. The men wanted news from the provincial council, and other islands, plus international news. Everyone was interested in diseases that might break out in Honiara as it turned out that swine flu had caused a lot of worry. Lastly, but not least at all, the football results were sought out by the men.

\section{What words do donors/development people use in the Solomon Islands that you} have heard about?

As far as words that are used by donors or the development people went, the lists were long and detailed but when I asked the groups to tick what words they felt they truly understood they marked only three or four words on each list (see Appendices 6 and 7). ${ }^{20}$ This really was an attempt to see how the language of the donors had pervaded the community, possibly through repetition in the media. However it was clear some words were from international non-government organisations (INGOs) and even the church, so the question had been interpreted as Western words and in this way had little to add to the research, except to say the words were recognised and mainly not understood as they came from a world very much present, but not always

20 Time management came up with the men's groups and when asked about this the chief replied "it is something the donors seem to think is very important so we must get better at it". 
relevant, to their own.

There was one exception to this conclusion. The word 'corruption' came up time and again and it was a word most focus group participants associated with media. Corruption was seen as meaning being let down by politicians but very much also by a political system that didn't work for the local polity. It was a word that seemed to encompass all that was wrong with Honiara, and the reason that frighteningly huge sums of donor money talked about in the media never to reach the communities like theirs, and seemed to "disappear" (see discussion on p. 85).

\begin{tabular}{|c|c|c|}
\hline Women's group 1 & Women's group 2 & Women's group 3 \\
\hline $\begin{array}{ll}\text { - } & \text { poverty } \\
\text { - } & \text { reconciliation } \\
\text { - } & \text { capacity } \\
\text { - } & \text { solar + windmillsv } \\
\text { - } & \text { journalist } \\
\text { - } & \text { satellite } \\
\text { - } & \text { communication } \\
\text { - } & \text { sanitationv } \\
\text { - } & \text { healthv } \\
\text { - } & \text { immunisation (knew injection) } \\
\text { - } & \text { diabetesv } \\
\text { - } & \text { hyper-tension } \\
\text { - } & \text { heart attack } \\
\text { - } & \text { scholarship } \\
\text { - } & \text { yellow fever } \\
\text { - } & \text { literacy } \\
\text { - } & \text { starvation } \\
\text { - } & \text { politics } \\
\text { - } & \text { conservation } \\
\text { - } & \text { environment } \\
\text { - } & \text { tsunami } \\
\text { - } & \text { corruptionv } \\
\text { - } & \text { geology } \\
\text { - } & \text { sensitive } \\
\text { - } & \text { UN } \\
\text { - } & \text { World Bank } \\
\text { - } & \text { AUSAID }\end{array}$ & $\begin{array}{ll}\text { - } & \text { poverty } V \\
\text { - } & \text { uneducated } \\
\text { - } & \text { primitive } \\
\text { - } & \text { virus } \\
\text { - } & \text { theology } \\
\text { - } & \text { technology } \\
\text { - } & \text { hydro } \\
\text { - } & \text { conservation } \\
\text { - } & \text { NGO } \\
\text { - } & \text { NPF } \mathrm{V} \\
\text { - } & \text { UN WHO } \\
\text { - } & \text { UNDP } \\
\text { - } & \text { bachelor } \\
\text { - } & \text { scholarship } \\
\text { - } & \text { degree } \\
\text { - } & \text { universityV } \\
\text { - } & \text { biologist } \\
\text { - } & \text { hypocripe (hypocrite from bible) } \\
\text { - } & \text { crazy } \\
\text { - } & \text { horrible } \\
\text { - } & \text { ugly } \\
\text { - } & \text { chemistry } \\
\text { - } & \text { biblical } \\
\text { - } & \text { physics } \\
\text { - } & \text { toxic } \\
\text { - } & \text { chronic }\end{array}$ & $\begin{array}{ll}\text { - } & \text { sanitationv } \\
\text { - } & \text { migration } \\
\text { - } & \text { HIV } V \\
\text { - } & \text { journalist } \mathrm{V} \\
\text { - } & \text { researchv } \\
\text { - } & \text { vulnerable } \\
\text { - } & \text { electricityv } \\
\text { - } & \text { ethnic } \\
\text { - } & \text { vaccine } \\
\text { - } & \text { vaccination } \\
\text { - } & \text { scholarship } \\
\text { - } & \text { explosion } \\
\text { - } & \text { bias } \\
\text { - } & \text { conflict of interest } \\
\text { - } & \text { gender } \\
\text { - } & \text { violencev } \\
\text { - } & \text { corruptionv } \\
\text { - } & \text { illiterate } \\
\text { - } & \text { dictator } \\
\text { - } & \text { stubborn } \\
\text { - } & \text { eco tourism } \\
\text { - } & \text { short wave } \\
\text { - } & \text { medium wave } \\
\text { - } & \text { poverty } \\
\text { - } & \text { contestant }\end{array}$ \\
\hline
\end{tabular}

Figure 5.1: Women's Focus groups' lists of development words. 


\begin{tabular}{|c|c|c|}
\hline \multicolumn{2}{|c|}{ Men's group 1} & Men's group 2 \\
\hline$\bullet$ & third world & nationals \\
\hline - & primitive & developing nation \\
\hline$\bullet$ & uncivilised & uncivilised \\
\hline - & transparency accountability & social development \\
\hline • & civilisation & social change \\
\hline • & counterparts & economical development \\
\hline • & public servants & economic stability \\
\hline$\bullet$ & international market & IMF \\
\hline • & international trends & global warmingv \\
\hline • & assessment & World Bank project \\
\hline$\bullet$ & conservation & foreign exchange rates \\
\hline • & environmentv & Stabex fund \\
\hline • & trade integration & counterparts \\
\hline • & stratgic partnership & one currency \\
\hline • & instability & new world order \\
\hline • & prosperity & terrorism \\
\hline$\bullet$ & discriminate & inflation \\
\hline • & corruptionV & WHOV \\
\hline
\end{tabular}

Figure 5.2 Men's focus groups' lists of development words.

\subsubsection{From the village: findings}

My time in the village was not long enough to gauge the impact of an increasingly commercialised media coming out of Honiara. It is a difficult point to argue whether it has further isolated the rural population (Rogers, 2006) or marginalised worldviews (Nyamnjoh, 2005) as mainstream news media was accessed only second or third hand. Presently the fact that the media is mostly presented in English, yet English is not spoken widely in the rural areas, would seem to add to the picture of a media primarily aimed at urban audiences, and even more possibly, those that can attract the advertisers (DFID, 2006).

The village was information hungry but at same time the people were quite clear about what it was they needed to know to run their community effectively. The morning I was to leave, one of the women I had got to know had been called away overnight after hearing a fire and destroyed her parents' house some hours' walk down the coast. Someone had passed the news on by foot. The village was neither 
isolated nor ignorant of what was happening in the world, it just got its news differently and was more selective about what it needed because of this.

\subsection{FROM THE CAPITAL}

The capital city of the Solomon Islands could be seen as an example, almost a caricature of development. Honiara, as the centre, is home to less than $20 \%$ of the country's population. However it is estimated that central government and the capital's town council consume almost two-thirds of the country's public revenue (Schindowski, 2004). The façade of development or modernisation-from the bustling port and snaking lines outside the two main ATM machines-continues as the main road, Kukum Highway, runs just 130 kilometres east and west along the coastline either side of the town. After it peters out, access to the villages and settlements is primarily by foot or canoe. Just under a quarter of the villages throughout the 70 inhabited islands of this archipelago are accessible by road-often nothing more than a bush track-about a third only by sea, $40 \%$ by walking tracks and $5 \%$ by river (Fairbairn-Dunlop et al, 2009, p. 54).

Just over 78,000 people reside in Honiara, most drawn there for education and job opportunities. But mixed in with this urban drift are the staff of the numerous aid and development agencies: bilateral, multilateral agencies and INGOs, plus those in business attracted by transnational trading opportunities. The number of expatriates has increased since the intervention of RAMSI in 2003, adding to their visibility on the streets, on the roads (in terms of brand new 4WDs) and on the signage. Foreign nationals stand out by their colour and wealth.

The influence of this population is also evident in the coverage in the newspapers, on the radio and on the sole local television channel - One Television.

However to get a clearer picture or understanding of the rural/urban population of the Solomon Islands it is important to understand its fluidity. Burt describes this phenomenon in his introduction to the biography of Kwara'ae chief and friend, Michael 
Kwa'iola of Malaita. ${ }^{21}$

People in this position are often described as living in 'two worlds' but although Westerners might like to see it in these terms, the Kwara'ae seem to treat their experience of town and rural life, of Western and local culture, as contrasting aspects of a single world, inextricably linked (Kwa'iola \& Burt, 1997, p. 8).

The border between urban/rural, town/country, and kastom/western culture is permeable. This is evidenced by those who come daily and weekly from villages by foot, bus and boat to sell at the Central Market in Honiara. It was highlighted graphically to me when five secondary school students and a couple of offspring in their early twenties returned by outboard, motorised canoe from the capital to the Weather Coast village during my field research. (Photo 1.) This two-day trip, with the associated worrying delays, treacherous seas, and lack of communication, is a normal state of affairs for the village.

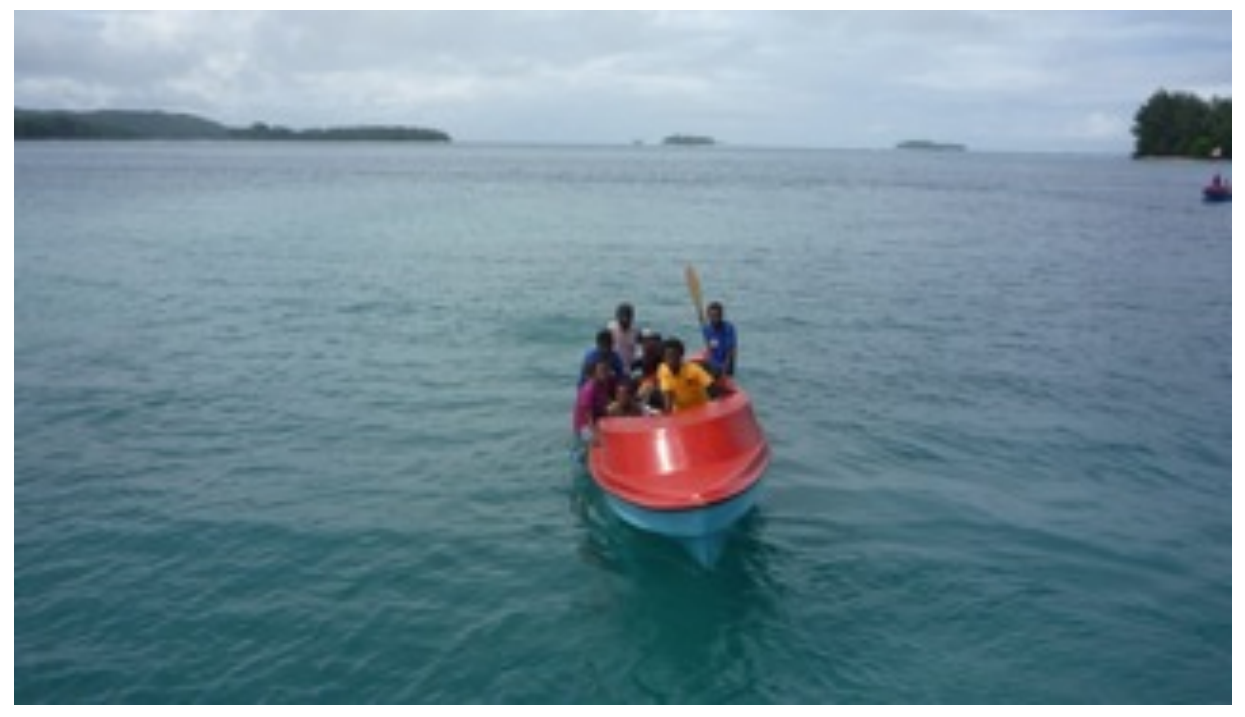

Photo 1. The young members of the village reach some quiet water before heading around into the rough seas on the Weather Coast.

The 'inextricably linked' relationship between rural and town is seen as a strong and sustainable bond (Bennett, 1987; Kwa'iola 1997; Lacey, 2011). That link was also illustrated during the tensions of $1998-2003$ by the ability of people to evacuate Honiara to their villages and begin rebuilding, as one contributor noted:

21 Michael Kwa'iola is a contributor to this thesis and is named at his request. 
NGO 3: [W] hen we had the civil unrest here - most of the aid donors they left the country. Even industries-big industries like we have fishing industry, logging companies and mining industries-oh but they left. And it takes the people the rural people to start the economy again. So people cut copra in the villages, people dry the coca beans. I mean it is sort of the strength of the country, of the society, that brought the country back again - so it builds confidence and people come back.

Understanding this dynamic of Solomon Islands life is important for contextualising the overarching premise of this thesis. All these relationships add to a complex picture of 'ways of knowing' and how that might differ from the development donors and media trainers. It also goes to understanding the reach and influence of donors and the media in this developing nation.

As Bennett (1987) has alluded to, historically Solomon Islanders have proven themselves able to adapt to 'outsiders' and their influence-whether it is from the traders, missionaries or colonisers-while holding firmly onto kinship, kastom, and connections with land. "That the many and varied small societies of the Solomons responded with intelligence and creativity to the challenges of contact with the outside world and a mighty colonial power augurs well for the new nation" (Bennett, 1987, p. 347). The definition of outsiders today extends to development actors with a mandate of statebuilding.

\subsection{WHO KNOWS WHAT}

To investigate the influence of donors through the media and media training it is important to extend what was learnt in the village to an overall understanding of how much information is reaching the more than half million people ${ }^{22}$ that populate this spread-out archipelago.

The village field research gives one perspective; Figure 5.3 (below) gives a more

\footnotetext{
22 This national population figure was stated by the Solomon Islands Government Statistician, Nick Gagahe. B. Hill 2010 'Solomon Islands population census results' ABC Radio Australia online resource: 10.11.10; accessed 23.03.11
} 
national one. Nearly two thirds of the Honiara population is connected to information either by way of radio or mobile phone in contrast with around a fifth of the rural population with mobile phones and less than half with radio.

CENSUS 2010: HOUSEHOLD DURABLES

\begin{tabular}{|c|c|c|c|}
\hline & Total & $\begin{array}{r}\text { Guadalcanal } \\
\text { (excluding } \\
\text { Honiara) }\end{array}$ & Honiara \\
\hline $\begin{array}{l}\text { Number of Private } \\
\text { Households }\end{array}$ & 91,251 & 17,163 & 8,981 \\
\hline \multicolumn{4}{|l|}{ Radio } \\
\hline Households with & 39,756 & 7,470 & 5,500 \\
\hline Households without & 51,495 & 9,693 & 3,481 \\
\hline \multicolumn{4}{|l|}{ Internet connection } \\
\hline Households with & 541 & 291 & 365 \\
\hline Households without & 90,710 & 16,872 & 8,616 \\
\hline \multicolumn{4}{|l|}{ TV } \\
\hline Households with & 10,544 & 1,211 & 4,648 \\
\hline Households without & 80,697 & 15,952 & 4,333 \\
\hline \multicolumn{4}{|l|}{ Mobile Telephone } \\
\hline Households with & 18,799 & 3,240 & 5,500 \\
\hline Households without & 72,452 & 13,923 & 3,481 \\
\hline
\end{tabular}

Figure 5.3 Preliminary figures from the 2010 census.

Other research around consumption of media in the Solomon Islands has been conducted as a project for SOLMAS. The type of audience market research (SOLMAS, 2010) is very much based on a Western model of 'ratings', establishing market share and 'growing' business, which is discussed in the next chapter.

The primary objective of the SOLMAS research is to inform on media access, usage, met and unmet needs, and expectations so as to enable the MASI members to grow their businesses by being relevant to the current and potential audience (SOLMAS, 
p.13). This could be problematic as there is growing concern that market-driven media may start to deliver content that ignores those not engaged fully in the cash economy (Rogers, 2006). In the Solomon Islands that description would encompass the majority of those outside Honiara, and the urban poor.

The SOLMAS General Manager confirmed the commercial motivation of this research is strong saying the mainstream media depend on advertisers to survive.

CF: [F]rom a marketing sales aspect there is a promotions aspect and a sales benefit to some of this information. I did a presentation to all the media individually so they could see the benefit to them and the way the survey was done the data was broken up ... and they all had their own sort of strengths and weaknesses, and they could all use parts of it for their promotion. Whether they do or not is another thing, but they have the capacity to anecdotally pass that information on or, or, ... or not. But it does clarify everyone's position.

She also she emphasised finding out what people wanted from their media was of equal importance in this research.

The SOLMAS research added detail to general census figures by illustrating how access to the media is predicated on a range of factors. For example the high cost of, and irregular access to, diesel and diesel generators means unreliable access to electricity. This is an impediment to habitual radio or television consumption in villages. It is also a factor in the charging of mobile phones and computers.

Although positive about 'new' media such as mobile phones and Internet, the report admits that the "market today is all about radio" (SOLMAS, 2010, p. 23) because of lack of infrastructure and funds to buy the technology to move into the ICT world of connectivity. It also concludes most information is still orally shared.

My limited time in the Weather Coast village backed up this larger research finding, although the village had only one or two working radios. It had one battery and a wind-powered electricity set-up that had been damaged during the tensions. The contributors there, and back in Honiara, pointed out that lack of funds and technology impedes equal access to media. 
NGO 1: Five dollars can buy a Solomon Star - in the provinces [they] don't have that money or access. They listen to radio. But only people with transistor radio can actually hear.

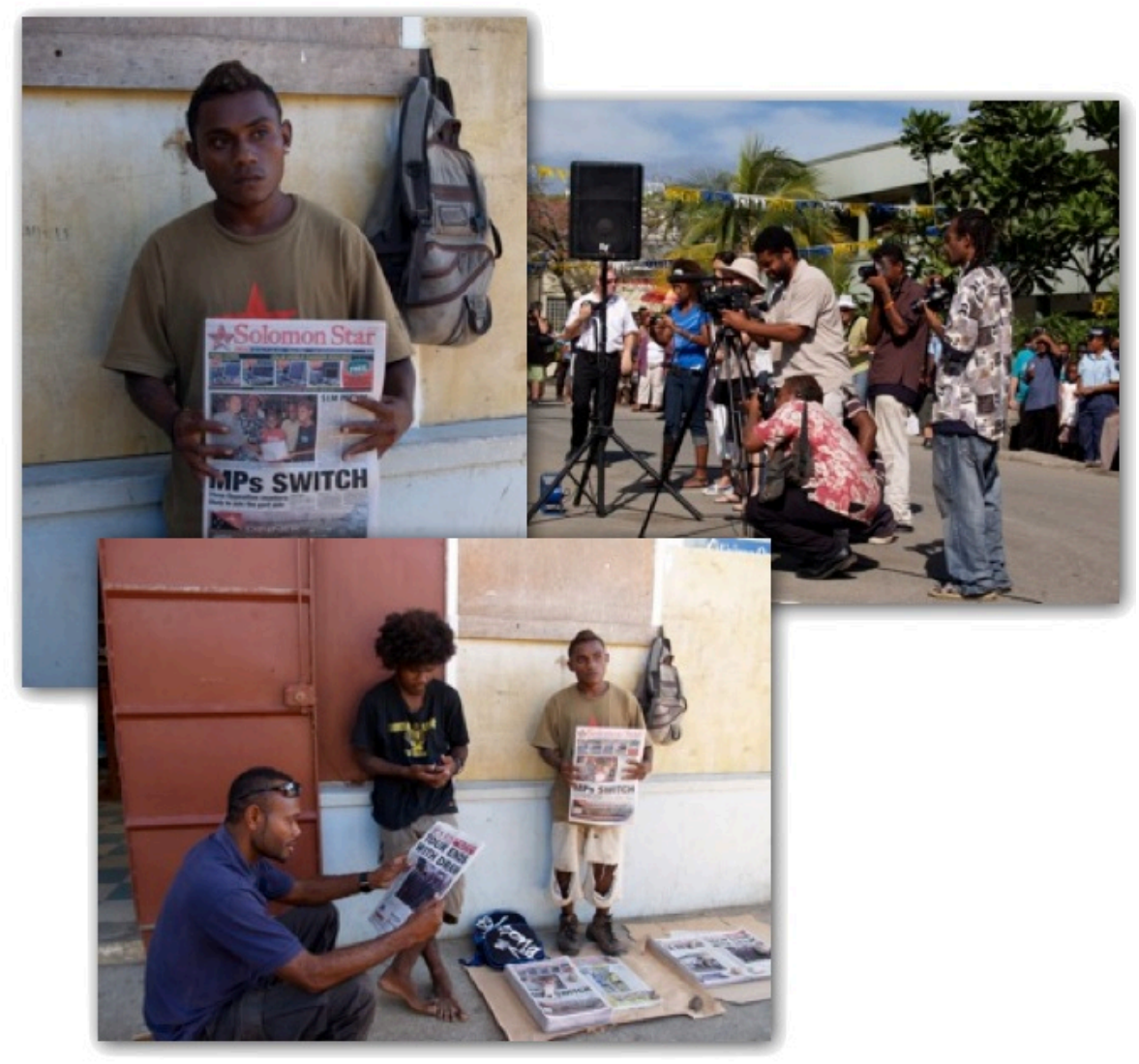

Photo. 2 (left to right.) Solomon Star street seller and customers in Honiara, television crew and journalists at the unveiling of memorial to Solomon Island WWII scouts.

Contributors to this research repeatedly verbalised the concept of an increasingly urban focus for news, often leaving the majority rural population ill served. This follows a trend that is replicated in other developing countries (DFID, 2006). They spoke of the dense, jargonised language used by the Solomon Islands media (and donors themselves). They also talked about the relevance of some of the news to people outside of the 'centre'.

NGO 1: Maybe in a village the boys buy these big stereo tapes. They are listening to music because people bored by talk - too much talk. Or they say all this information that is fed into the radio or newspapers are false. They are cynical or they don't even care to listen to that kind of informations because one of the 
problems is when donors give money that stacks up in Honiara and never reaches the people. So they don't care if they listen to that information or not because it is not to do with them. I don't know, if the media programme is very strong then we could change the minds of the people in the Solomon Islands about listening to the programmes. (NGO 1)

Media standards vary in such an environment. Issues such as gender have a mixed outcome: on one hand, for instance, women are given a platform, yet on the other "an ever-more commercialized and advertising-driven media has increasingly sexualized and objectified women" (DFID, 2006, p. 6). ${ }^{23}$

The explosion of media has its pluses and its minuses. In the Solomon Islands the questions that need to be continually asked are:

1. Is this explosion of information actually resulting in more news directly reaching the rural majority?

2. Is the news that is being generated relevant to the people there, or more weighted to the urban few?

3. How much of it is influenced by the neoliberalist/neostructuralist vision of the donors?

\subsection{IMPACT OF DONORS ON THE DAILY NEWS}

J 2: The fact that they [donors] dominate the society, this is sometimes it is quite hard to try and get our staffs to do, work really independently. You know sometimes they could be, ah, influenced by some people who could be interested in their own - they, they have their own agendas.

There is no escaping the dominance of aid and development actors in the Solomon Islands' political infrastructure and urban environment. International aid accounts for more than $60 \%$ of its development budget. With the intervention of RAMSI following

\footnotetext{
${ }^{23}$ This speaks to another concern from contributors to this thesis who see the westernisation of their media interfering with cultural values of the Solomon Islands. Although this might be seen to be more relevant to overall media, it has also come through in reporting which will be covered under donor influence further in this chapter.
} 
the end to the tensions in 2003, ODA skyrocketed from US\$21 million in 2000 to US\$200 million in 2009 (Lumina, 2011).

Some of the contributors to this research outline how donors are pushing agendas through their communications and using the news media, and media in general. Basically this is known as marketing or public relations or, within the sector, communication for development. There are volumes written on just how to do this by all large bilateral and multilateral donors such as the World Bank, UNESCO, DFID and USAID (see Chapter Two, p. 3). There is an industry behind disseminating information, carrying with it its share of analysts and critics.

However while the link between communication for development and its possible use as a vehicle for propaganda or weighted agendas is well recognised (Roger, 2006), Media Development is seen as something different: a transfer of skills of technology that appears to be unquestionable (Miller, 2009; Berger, 2010).

Communication for development would appear to be working well in the Solomon Islands. In Honiara understaffed, under-trained and under-resourced Solomon Islands newsrooms have a constant supply of media releases from the Honiara-based donor offices. These include the World Bank, Asian Development Bank (ADB), the United Nations (UNDP, UNICEF, WHO and UN Women), European Union, AusAID, the New Zealand Aid Programme (formerly NZAID), JIA, and Taiwan (ROC). The United States has a resident consular agent.

J 3: The newsroom has a lot of times been flooded with $P R$ [public relations] materials that, most times, we have been disrupted from really covering the hard stories.

The contributors were asked what challenges they face in this environment.

J 1: They [the journalists] would put angles that are really not the right type of angles because they want to please people [the donors] and so it happens. 
The journalists seem to feel it is their failure that so much donor/Western jargon is slipping into the news media, however they admit there is also pressure to report it the way the donors want to see it.

AB: So you have never had a donor communications person ring you and say "I sent you that great story what happened - it never made it?' J 1: Yes, sometimes. AB: And you are happy to say back, 'it is my decision?' J 1: Sometimes they call and say we want this photo in, we want this story in, can you put this story on this page or this photo [or] we need two photos in. Yeah um, most of the time the staff will put those people to me and I tell them that we run the show. And even sometimes they'd say we are not going to put our advertisements with you.

Another journalist says there is sometimes pressure from donors to publish material that their organisations have provided. However this journalist believes the good stories and information outweigh the bad.

J 2: I guess so, we do sometimes get that pressure but it is not that much pressure we receive from them. Most of them do a good job of their projects and completed and done so at least when we do report from the good side of the story. And whenever there is a bad side with funds or whatever at least we get that side of the story and report as well.

Some journalists feel the daily influx of press releases get in the way of the real stories. Interestingly this is perceived as a bit of a one-way street with donors happy to pass ready-made media releases to the newsrooms but not so helpful when the questions come the other way.

J 3: A lot of people working in donor offices are always reluctant to talk to us about stories that we want investigated. This is always frustrating reporters.

This was a common theme from journalists. 
J 1: We normally have press releases all the time. They [donors] don't really depend on journalists sometimes to go and cover whatever. They don't normally invite journalists. Normally all they want is for them to put out press releases.

Journalists from other media organisations backed up the view that donors were not always easy to get information out of.

J 3: The issue of public relations materials is one challenge. A lot of times we can't talk to them directly if we see some issues that need to be further investigated.

And another media outlet:

J 2: I think one of the challenges for me as someone looking after the [newsroom], is reporters accessing information of donors or funders who are working on projects in this country, as well as more up-to-date information ... Sometimes we get answers sometimes they don't give much information. Some we can access, sometimes very little.

A journalist who has moved into a different side of the media spoke of the challenges in their newsroom around lack of capacity including staff, equipment, and even fuel, that impact on journalists' ability to follow stories. The interview went on to ask about the numbers of media releases by donors.

AB: Was there a discussion - 'gosh lots of press releases. How many do we cover, can we ignore this one?' J 4: Yeah, yeah we looked and we would have to decide what to do with them - whether we run by [with] them, or get more information from the source, or, if the news part of the story is buried down below, we discuss. We try to tease the story out.

Unlike others, this journalist didn't perceive the donor communications as slick at all.

J 4: I always thought the press releases we got form the donors were never well written. AB: You were cynical? J 4:You are trained as a journalist. You read these press releases. 
All the journalists were adamant they would do their best not to fall into the trap of becoming a daily record for the donors' public relations machines, even when the material is ready-made for publication.

AB: They provide you with a photo as well? J 1: Yes but then that's what we advocate here ... we don't really accept press releases. We have to attend events and see what's in the best interests of the people, the reader. AB: That's your ideal? J 1: Yeah

There was definitely an understanding that healthy questioning and a certain amount of cynicism was needed, not just around politicians but around donors as well. However there was also an admission that lack of training, time and resources often meant the ideal wasn't followed through when the press releases were pouring in.

J1: Then we encourage reporters to look at the press releases and find out what sort of angles they can take. AB: But you are understaffed quite a lot of the time really, in terms of qualified journalists? J 1: Oh yes that's true. AB: If you are understaffed and there are deadlines to meet, are there times when you see things slip through? J 1: Oh it happens quite often. It is our biggest problem especially when stories came in and you see they really [are] not up to what you would like to see and you have to do them again. It is time consuming. And in New Zealand... AB: You would have two or three subs? J 1: Worse still we don't have any sub editors so most of the things slip in.

Journalists believe they are not getting the full story from sources. The problems of understaffed newsrooms and inadequate training continue as a theme in this dialogue. But a repeated explanation for the lack of follow-up on development stories was donors' reluctance to supply information.

AB: Media don't break down the [donor] figures? J 4: Sometimes we discussed this but sometimes when you are trying to develop a story and you hit a brick wall, it dies out. 
This brings up the question of owning information, and how that translates into ways of knowing. One theme that runs through the interviews, and was independently brought up by some contributors, is that donors do not readily 'break down' the huge financial amounts being spoken about in terms of development spending in the Solomon Islands. Equally the contributors feel the news media fails to portray the real story about where the money is going - leaving the country as a whole feeling it has failed in some way.

\subsection{WHO HOLDS THE INFORMATION?}

NGO 3: I think it is overemphasised. It is overboard [donor news]. I mean like you will hear in the media that New Zealand is the biggest donor. The current minister is here now - foreign minister [McCully] $]^{24}$, and they say New Zealand is putting a lot of money into Solomon Islands now. RAMSI is putting a lot of money in too. $A D B$ is putting a lot of money in too. But at the end of the day, if you look at it critically, a lot of that money is going back to the country where it comes from. The number of consultants that are here, a substantial amount of money is paid to them.

The term the contributors repeatedly used on this issue was 'break down'. This was a word they themselves proffered to describe the detail behind the huge figures being tossed around in the media about donor spending. The complaint appears to be that neither the donors nor the media break these figures down. There is concern that this gives a false impression to the growing readership and listenership of the established media in the Solomon Islands about just how much money is available for the development of their country and how much maybe being lost due to corruption or inefficiencies.

\footnotetext{
24 New Zealand's Minister of Foreign Affairs, Murray McCully was on a 24-hour visit to the Solomon Islands in July 2011 when this interview took place.
} 
NGO 1: Many informations come from the radio and I always hear about large sums of money being sent into the country but the question I would raise there is where has the money gone? Who receives the money? How was it spent? And who benefits from the money? If you can listen to these people talking about millions of dollars - they sent the money into the SI in the name of the people of the village but then where does that money go because you see even the villager himself is questioning people. A lot of people would say a sum of money going to the community or to the village - this project costs like this - but if you ask the villager where does it go - people will not tell you where that money goes and they will never answer your question because they know nothing about that money.

There was consternation over this continued coverage of large sums of development money and what was perceived as very little to show for it. But at the same time there was cynicism about just how much was actually reaching the country.

NGO 2: The details, the breakdown yes, and sometime I think as to what comes out in the media. We read a lot of millions coming into this country and why do they want to put those millions when we really do not see the effect? We've got 38 million for the festival, 100 million will be pledged - the figures are crazy. So I think that when you say all these millions are coming in - what really is happening? While the money is coming in? What is the break down? How much really comes down to the people?

One NGO contributor talked about 'the aid triangle' between consultants, the donor and the programme.

NGO 3: Most of the money goes back to consultants. That is why me as a Solomon Islander, I am really critical. Like what really touches the lives of the people in the community? I think there is some aid money just to catch praises. To get the money and to help people travel and to - but it doesn't really go to where it is intended. AB: And the media does not reflect that? NGO 3: No, no the media only covers the-oh 400 something million dollars has come in-but it doesn't go in and say where does the money go to. AB: Doesn't break it down? NGO 3: No. 
Kwa'arae chief Michael Kwa'iola says many feel the same. He feels this reflects badly on the Solomon Islands and gives the wrong impression to the villagers.

MK: That worries me. These people are using these things for their own purpose they say it is big money but you don't know what is the breakdown? What goes to transport, to consultant? What goes to let's say administration? I don't know. This worries me because there you see public fund in the name of the Solomon islands and I am one of the indigenous of my [people] - and so often you saw millions of dollars in the news but we don't know where this money of it goes. This money has been dumped in favour in the project but for them own pockets?

Another NGO contributor felt the emphasis donors put on unachievable aims and timeframes in the media constantly leaves the impression of failure around the country.

NGO 2: It is wonderful that the donors are here and because of the presence of the donors and the weight of what they bring, the country is moving forward. However, sometimes I think the donors have a timeframe which is not realistic to the Solomons because we don't have a base to stand on. There are many things that we take for granted in other countries. Whether it is literacy or the ability to go into another place and state your needs. [Here] You are locked in on [your] own issues and they are not even able to see beyond it.

Lumina (2011) commented on the Australian aid programme saying it was feeding into a needs-based, not strengths-based use of terminology. A contributor backed this up complaining about the use of certain donor-inspired words giving the wrong message about the strengths of the Solomon Islands people.

NGO 3: Capacity building has become a catchphrase people use. [They] must to attract finance from donors. 'We want some money to do capacity building', but what really is capacity building? Is it workshops? To me capacity building can be a two-way process. There are some issues on climate change-although climate change is an issue that is more technical in a sense-but there are people in the community who have been surviving for generations. There might be some 
practices that have been using for generations that can be useful... [I]f you look at capacity-building starting at the base-from the community up-then maybe they can meet at a certain level. It can be more sustainable compared to me putting down. From the ground up.

This brings the conversation around to the jargon, the language used and the power of that language to change how people perceive themselves and the world.

\subsection{SWALLOWED BY THE JARGON}

Among the issues emerging from the contributors is the language of information coming from donors to the news media - and through to the people of the Solomon Islands. The use of language and the ability to translate that jargonised donor world to one that the public can understand is a huge issue for under-resourced media in developing countries. Of course it is not just donors that add to this, but it is the focus of this thesis.

He said the overarching purpose of upgrading this strategy document is to channel all the available donor resources to the national priority areas and to harmonies [sic] mutual collaboration of the Solomon Island government and its development partners to generate substantive tangible result [sic] in line with policy and reform objective [sic] of the government. (Solomon Star, Friday 10 June, 2011:2).

The piece above is a quote from a Solomon Island MP, from an address to a workshop on aid coordination and management strategy attended by government and NGO staff. It was used as an illustration, to my contributors, of development jargon creeping into the news media. The journalists all saw this sort of language slipping through as a result of the newsrooms being pressed for time.

J 4: Sometimes when you were facing very tight deadlines and you were rushing you would have very little time to think of alternative things. One is this word 'stakeholder'. We were getting more and more into using stakeholder, donors and capacity building, sustainable development and sometimes you stop to think - if 
you had the time we would have used another word to explain or express. $\mathbf{A B}$ : Huge pressure? J 4: Yes being understaffed - and the [newsroom] is still understaffed.

In reference to the quote from the newspaper article in the Solomon Star, another journalist had this to say:

J 1: Yes you can't understand it [the quote]... It's a real problem. Um not sure, no I don't think people, especially donors, are taking advantage of the fact that we are understaffed and lots of not qualified professionals. I think they are just putting these things out and at the end of the day it is your problem to look at them. $\mathbf{A B}$ : So they are communications experts? That's their job? J 1: So I would like to think that it is our failure.

In the rural areas, donor words are having an impact - where they are heard.

$A B$ : When you are doing workshops do you see the words used in villages now? The donor language, the development-speak, how prevalent is it? NGO 3: I think some of those words are suppressive in a sense. In the community it all depends on their exposures. In some places where they are exposed to newspapers and people would like to think that way, but in more isolated places people just go about their business and they go fishing and working in the garden.

\subsubsection{Do words affect reality?}

To put this into the context of the Solomon Islands development environment it is useful to go back to Chapter Two. Gegeo \& Watson-Gegeo (2001) argue that the next step of decolonialisation is dehegemonisation - validating indigenous epistemology and "what constitutes truth" (2001, p. 57). They talk about indigenous epistemology focusing on how a cultural group may construct knowledge and how culture itself evolves, "shaped by the dialectic of structure and agency, inherently ideological, and prone to manipulation and distortion by powerful interests" (p. 59). 
Fry (1997) is persuasive in his portrayal of how Australia has viewed its Pacific neighbours, through its policy and through its media. He asserts you cannot "lose sight of outside knowledge as an important influence of the parameters within which societies make choices" (1997, p. 341).

All those interviewed felt the words, concepts and evaluations used by donors are pervading the lexicon and the way of knowing of the Solomon Islands to a lesser or greater degree depending on how exposed people are to the media. To some this is just an evolution of development.

J2: Definitely I would say that it comes in the paper and even the people get used it. I mean even the rural people get used to these words because when you print them it goes down to the rural people and they read it and I mean, they knew about it, they have heard about it and they read about it. Even for us, we rely on the press releases and we are surrounded. So I would say that definitely we would have a words coming into AB: So it is becoming part of the Solomon Islands' language? J 2: Yes, yes because people knew about it-for example the word corruption-it is coming and people know about that.

However others feel the donor language and expectations are negatively weighted, impractical, and often not even connected to the reality at the grassroots of the Solomon Islands.

NGO 2: Now we come in, the donors, and say this has to happen and it has to happen in this timeframe-three to five years-and then we go. In my opinion it is going to take a long time. So when donors see it is not moving in the ways they would like to see it move, it is negative for the country. So [it is] understanding where we stand, and the base on which we are standing.

Journalists again take it as their responsibility to use and interpret the language effectively when they were asked about issues around the power of words to become, or to create, 'truths' in a country. Phrases that were used in the news media during the period of the research included 'lack of capacity', 'poverty', 'governance issues', and 
'fragile state'.

J 2: Yeah this is something that we talk about. We continue see these words popping up in overseas reports and so we omit these words and we change it around sometimes. We try to avoid using these words coming up so this is how we deal [with it]. AB: So it is a discussion you have? J 2: Yes because these are words that were used in the past - now we are recovering and reconstructing so they shouldn't appear. Like lawless society.

And another journalist brought the word corruption into this discussion - where overuse of a term can mean it loses its power or becomes distorted.

J 1: That's something we have to be very careful about and it happens here too. Personally I think corruption is a word that is used all the time and people use it verbally and-[like] a member of parliament is a corrupt person-and it becomes a word that no one associates with.

One NGO contributor highlighted labels such as 'least developed nation', querying how such terms can be referenced by a population that has no experience in the outside world to base their understanding on.

NGO 3: Sometimes we think that we are poor, in equating poverty in relation to money, but when you go abroad and you see people that don't have anything to live on including food-you know people are dying every day on the street-you tend to [realise] we are blessed here. So for me as a Solomon Islander when someone says to me oh you are from a least developed country ... when I went to the States I see beggars on the street you know, just in front of the White House and you think why do they say I am from the least developed country? There are marginalised people and there is different intensity of poverty in every country in the world.

Michael Kwa'iola, the secretary coordinator of the Kwara'rae chiefs of Malaita, says the media is powerful and what is said starts to be believed. He calls the language or jargon used by those in development, "donor dialect" (a term made more relevant 
when it is understood that this country has upwards of 70 dialects) and says the Solomon Islanders are just used as the "machinery" for accessing funding by some in the donor world.

MK: When they are just using that slang language about development of Solomon Islands, [Solomon Island] people don't know what they are talking but it is convincing on the other side for aid donors - it's going that way. Media is a powerful frequency ... and conflicting. $\mathbf{A B}$ : The use of language in paperslawlessness and fragile state. MK: Yes I talk to most of the people and they are thinking that way. When it comes out from departments when we saw it in the paper, it comes out in the paper opposite facts from what we say. Sometimes the politicians make up information and send it outside to donors but it is opposite here ... and [they] use those words - we are the machinery [to attract funding].

And another contributor, poet Jully Makini, ${ }^{25}$ a Solomon Islander well versed on the power of words, also speaks of the descriptions of her country during the tensions versus the reality as she sees it.

$A B$ : When you are writing are there words that come up in the media that you see becoming a way of thinking here? JM: We are 'failed state', 'war-torn'. We are not really war torn. When I flew in here in 2001 [2003?] and RAMSI had just come. Oh boy we were so happy that RAMSI came. But then I had to laugh because when we landed at the airport, the whole airport, one side of it, the might, I mean they had everything, everything. I mean tanks and jeeps and - so to me - where is the fight? There no war here its just two groups of kids playing with pistols I think, and when the real soldiers came, it stopped. I was happy. But I cried. I cried for Honiara. I cried for what I used to have 'cause I lived here and it was good then. And I always say why did we get independence? We are independent from nothing. We are dependent on outside aid. We are just professional beggars.

\footnotetext{
${ }^{25}$ As an independent contributor, and well-known and published poet, Jully Makini agreed to be named for this research.
} 


\subsection{THE ‘CORRUPTION’ AND ‘GOOD GOVERNANCE’ STORY}

"Good governance is not just about government. It is also about political parties, parliament, the judiciary, the media, and civil society. It is about how citizens, leaders and public institutions relate to each other in order to make change happen." Making Governance Work for the Poor. DFID White Paper, 2006, p.20.

One of the objectives of RAMSI is: "The establishment of an effective and cohesive approach to addressing corruption in Solomon Islands". ${ }^{26}$

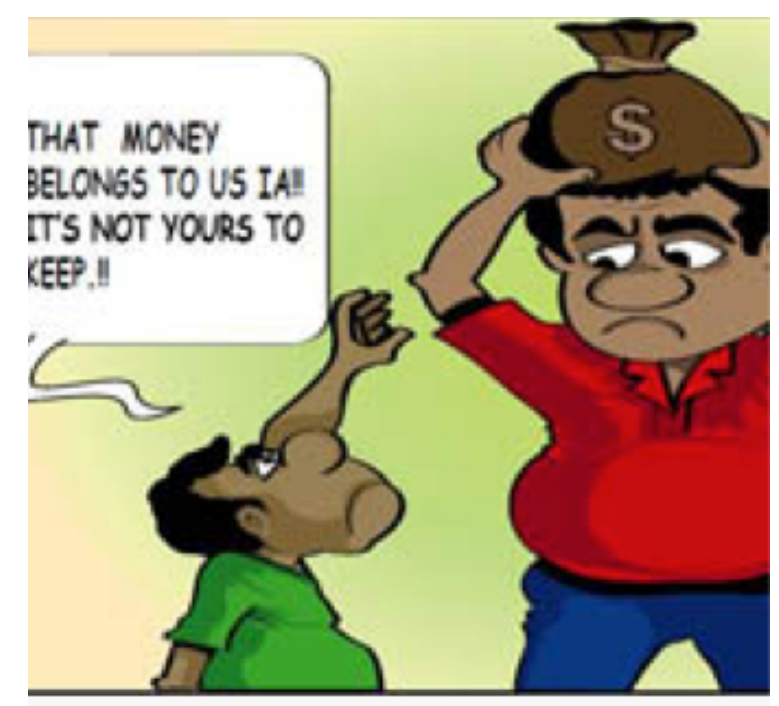

Anti corruption poster in Honiara.

The website describes the motivation behind placing corruption so high on the mandate by quoting figures from ten special audits into government departments and agencies after RAMSI arrived in 2003 - "[i]t was found that SBD \$433 million had been lost or foregone through corruption or maladministration." ${ }^{27}$

\footnotetext{
26 http://www.ramsi.org/our-work/anti-corruption.html

27 An Auditor-General's Insights into Corruption in Solomon Islands Government, 2007 as quoted in the RAMSI website http://www.ramsi.org/our-work/anti-corruption.html
} 


\section{EXAMPLES OF DONOR PROGRAMMES' EMPHASIS ON CORRUPTION}

\begin{tabular}{|c|c|}
\hline $\begin{array}{l}\text { NZ } \\
\text { AID } \\
\text { PROGRA } \\
\text { MME }\end{array}$ & $\begin{array}{l}\text { \{Solomon Islands\} Fisheries, plantation and small-holder agriculture, mining and tourism } \\
\text { are all currently under-exploited potential sources of economic growth, but as noted } \\
\text { above, growth in these sectors will be heavily dependent on improved governance, } \\
\text { infrastructure development, ongoing improvements in the business environment, and a } \\
\text { reduction of corruption. } \\
\text { http://www.mfat.govt.nz/Countries/Pacific/Solomon-Islands.php }\end{array}$ \\
\hline AUSAID & $\begin{array}{l}\text { Australia has consistently sought through its aid program to help partner governments } \\
\text { strengthen governance and reduce corruption. But more needs to be done. Corruption } \\
\text { has a substantial negative impact on economic growth and development and weakens } \\
\text { institutions. The costs of corruption fall disproportionately on poor people. } \\
\text { www.ausaid.gov.au/makediff/anticorruption.cfm }\end{array}$ \\
\hline $\begin{array}{l}\text { WORLD } \\
\text { BANK }\end{array}$ & $\begin{array}{l}\text { Fighting corruption has become a policy priority for the development community over } \\
\text { the past two decades and extensive reform efforts have been launched. These reforms } \\
\text { build on the idea that corruption is a dysfunction of public administration that emerges } \\
\text { in the presence of monopoly and discretion, which in turn can be curbed by promoting } \\
\text { accountability and transparency. Corruption undermines policies and programs that aim } \\
\text { to reduce poverty, so attacking corruption is critical to the achievement of the Bank's } \\
\text { overarching mission of poverty reduction. } \\
\text { http://web.worldbank.org/WBSITE/EXTERNAL/TOPICS/EXTPUBLICSECTORANDGOVERNA } \\
\text { NCE/EXTANTICORRUPTION/ }\end{array}$ \\
\hline$A D B$ & $\begin{array}{l}\text { ADB defines corruption as the abuse of public or private office for personal gain. This } \\
\text { means any behavior in which people in the public or private sectors improperly and } \\
\text { unlawfully enrich themselves or those close to them, or induce others to do so, by } \\
\text { misusing their position. The purpose of ADB's Anticorruption Policy, approved in July } \\
\text { 1998, is to reduce the burden corruption exacts from the governments and economies of } \\
\text { the region. http://beta.adb.org/documents/anticorruption-policy }\end{array}$ \\
\hline
\end{tabular}

Figure 5.4. Examples of donor's policy language around corruption in the Solomon Islands 


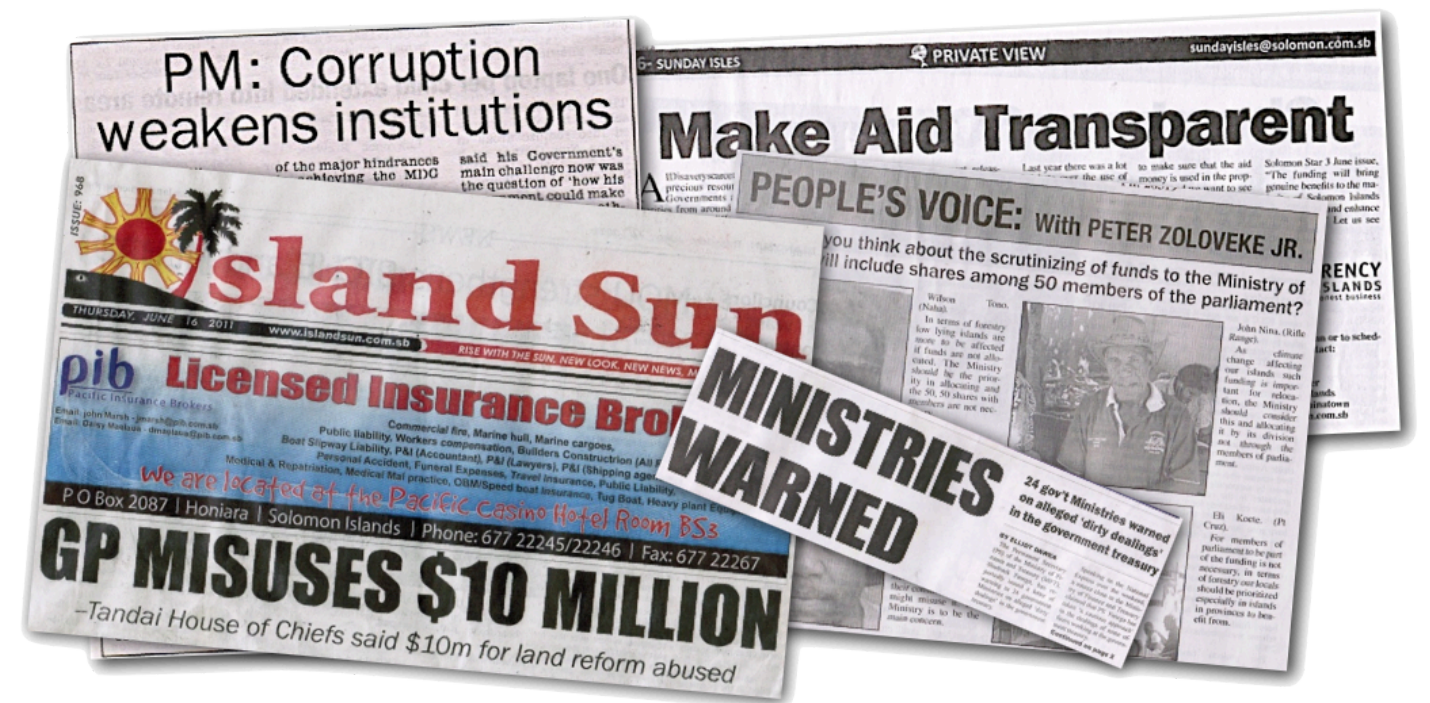

Photo 3. Headlines montage.

However it is the meaning of the word and its application that is difficult to translate into Solomon Islands culture.

$A B$ : Corruption - is that word used? MK: It is the main principle in this country and bring poverty in this country.

One NGO that does a lot of outreach communication into rural Solomon Islands often paid for by donors says people are confused by who can be corrupt. Often it is seen as just a Honiara problem.

NGO 1: We talked about corruption on our programme but it is a very difficult word to describe. Corruption is a big word to describe because our village people when they hear the word corruption they always refer back to the politicians misusing funds given by donors or some people or some sort of government-togovernment funding programme. So when you talk about corruption people think that it happens in Honiara to the people who are there but they do not understand that also happens at the community - in their village, everywhere - within a family. AB: And you talk about that? NGO 1: We always talk about that because it is one of those words which we would like to eradicate from the minds of people but maybe it is too difficult to take out from the minds of people because it has 
been here and the word connects to the financial situation of the country and then it has been done by the Solomon Islander or someone else here. [This] makes the people always talk about it.

Another NGO contributor saw corruption as being understood as a government problem when village chiefs and others are involved as well.

NGO 3: That's the general consensus of the people that the money has ended up in Honiara and ended up in the hands of officials. If you look at it on the other hand as well, say for example we worked on two provinces that logging is the number one issue, people come and log tribal lands and the chiefs and the elders come in to Honiara to get the money yeah? And it didn't end up in the community, I mean in the hands of the tribe. So to me that is corruption as well at the village level. Like you would have seen the Solomon Star thing last week they usually come up every Saturday, Transparency International. Churches talk about corruption as well and schools ... But it happens everywhere - yeah?

Below is an example of a script that was used to introduce corruption as a topic on a privately funded community media slot on SIBC, the state-owned broadcaster. ${ }^{28}$

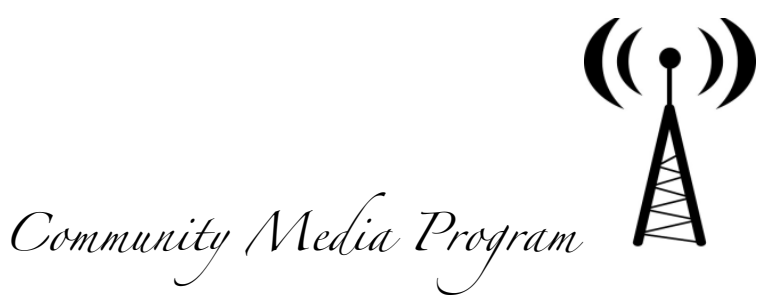

We at SIDT as good community citizens of Solomon Islands understand corruption is a word that breaks up every development in country. I want as to look at few questions which I am going as ask you good citizens of Solomon Islands about corruption. You and I are Solomon islanders; Let us put our self as Solomon islanders and what we can do with this question. And can we make this Christmas free corruption Christmas.

1: Do we want corruption in our country Solomon Islands. And if say no what are we going to do fight corruption as people who owns this country Solomon islands

28 Reproduced as it was written and broadcast, and provided to this researcher. 
2: Do we have medication to treat corruption, if you have any can you help other people to know this medication so that we eradicate this sick corruption in our country.

3: What are some of the development that we know that brings corruption or that we directly see corruption it.

4: Transparent and Accountability, Bribery and Corruption. Four big words, which of this word s are best words for a small country as Solomon Islands to work on.

Editorially newspapers regularly take a stand on corruption.

AB: Your paper took a very strong line pushing for an independent corruption investigation body recently. Is that you taking the lead, almost a lobby role, as a paper? J 2: I think that is part of our role that we play in this country, in the society, in the community, in the Solomon Islands. I think ... these are the same issues that are raised over and over again. People have said this and that but nothing has changed. So I think one of the roles we play in the Solomon Islands in trying to address this corruption. AB: What do your readers tell you about fighting corruption? Do they applaud your role? J 2: Yeah they support them in what we are trying to do when we report on issues relating to corruption, relating to ministers or leading officers. When we report on that they appreciate that. A lot of people support 100 percent with what we have done. The problem is in prosecuting them. AB: Chicken or egg, are you leading the community or reflecting? J 2: I think we are reflecting what the people want to fight against corruption in this country.

However there is also awkwardness about the challenging or shaming of officials in such a small population and with the added complication of the close-knit relationships through the wantok system.

$\boldsymbol{A B}$ : Is there a point when challenging corruption and officials face-to-face is culturally inappropriate? Does the wantok system challenge the way you can report things? J 2: That's an interesting challenge especially with the wantok system and how we report it. [Long pause] It is quite eh, it is difficult.

This challenge around the wantok system and a possible indigenous way of reporting is addressed in Chapter Six of this thesis. However here it is brought up here to point out 
that it is a very vexing issue for journalists. Clouding the scene further is the question of how corruption is portrayed by donors and the media. Tom Woods is a New Zealander who has worked in the Solomon Islands for many years as a legal adviser and then on constitutional matters with the Prime Minister's department. He is used in this thesis as an observer with a deep understanding of the historically difficult road the political landscape has emerged from.

TW: The whole corruption angle, the very institutions that are promoting noncorruption in this country are basically down the liberalist institutionalist path the liberal peace path - and they are doing it by strengthening the anti-corruption institutions in the country, but nothing is changing. In fact the political institutions in this country are so adept that they are actually using these reforms to their advantage ... For example they use the fact that they are adopting these anticorruption reforms, a few people may be caught, but they use it to say that the system is working, we are changing, where in fact nothing has changed at all. And then what is corruption is something that is very open to debate. What are the limits of corruption? What are the parameters of corruption that they are talking about? We have all these issues and these parameters have never been discussed.

Meanwhile others see the emphasis on corruption just encouraging the practice. This can be seen as a reflection of the power of the news media to create realities.

NGO 2: The journalist, and the media for that matter, has to be very careful about what is the message that that youngster is getting from that news article or story that comes out. How often is it being repeated? Is it good? Is it true? Has the message gone across? And I think these are things that have to be dealt with. Because if we are bringing up the youngster with a positive story, it is much better than the negative. Like the issues of corruption - are they bringing about lesser corruption or only increasing the corruption? Do we have a system in place to control what has been done and corrected or just bringing it out into the open? That gives people knowledge of what can be done and get away with it. Certainly there are few prosecutions because we don't have a system in place to say this is wrong and this will be corrected. If you bring out a story, five days later what is the result to correct that wrong? That is where we need to look. If not [the media 
is] giving, especially the youngsters, the wrong message.

Standing back from this, Woods says right from the time RAMSI entered the country in 2003 the media message began to change substantially. He believes RAMSI, through the media, is propping up the myth that the failure is with the people and not the system, which means necessary changes are being thwarted. He says the ideology of the donors is apparent in the media.

TW: Absolutely. When RAMSI first arrived you couldn't miss it. Terminologies appeared on the airwaves, good governance, law and order, a rule of law, corruption - expressed in different ways. And they all sound good and they all led to expectations that things were going to get better and reinforced perceptions that the government is bad. AB: That other clan? TW: That other clan's bad ... but no one has any idea what the change is - and of course that was the problem. Basically what I am saying is that RAMSI and the support of media, what I call the foreign-funded media message, were advocating constitutional reform, which was quite different from what the people wanted. And they did it quite pervasively. From 2003 they dominated the airwaves at the critical hours from 5 to $7 p m$ RAMSI was the dedicated programme. They captured certain Solomon Islanders who were paid to speak the 'right' message, to re-educate people, of what is happening, what is going to happen, and what is bad, and what is good. It was like revaluing the minds of the people.

Therefore the media could be seen to be adding to the country's humiliation (Robbins \& Wardlow, 2005) and buying into the Western discourse of failure (Fry \& Kabutaulaka, 2008; Chappell, 2005).

TW: What the donors, and I'll just say the RAMSI group have done, they've done their best to destroy politics in this country. They perceive ... it is just a matter of disruptive political behaviour - dysfunctional political behaviour that can be corrected and if we have strong corruption measures in place and a bit of retraining things will come right. You know it's that message. It's just reinforcing the democratisation - these words and in fact the whole, the international community is now looking the other way. They realise that after 50 years this 
system has not worked.

Once again the issue of the media as a watchdog comes up. If that is such an outdated idea in the market-driven economies of today as Curran (2002) suspects, then the whole premise behind Media Development being an effective donor programme comes into question.

\subsection{SUMMARY}

This chapter began to weave together the responses of those interviewed into a series of findings that paint a picture, still just a passing glance, of the influence of donors on the news media of the Solomon Islands. It introduced the 'inextricably linked' lives of the rural and urban population of the Solomon Islands but also found, running parallel, the perplexing disconnection between the modernised centre of Honiara and the rest of the country. It began to unveil a growing gap between the majority of the population and what is portrayed in the media emanating from the centre, dominated by English, donor jargon and imperatives, with an agenda of globalisation and neoliberal values.

The chapter investigated the direct influence of donors on newsrooms around Honiara but also explored the frustration of journalists and civil society around the superficial nature of the donor information and how that reflects on the country in general. It looked at the how the meta narrative, the use or overuse of terms or value-laden words, can change a way a population might view itself. The contributors talked about how certain concepts begin to pervade and possibly influence the understandings of those removed from the machinations of the country by challenges of literacy or geography. Finally it used the language around anti-corruption and good governance to explore these issues further with the contributors.

The next chapter looks at the direct influence of donors by bringing in the voices of those doing the Media Development. It asks questions of those involved in Media Development from the trainer to those 'in-training'. It looks at the use of English and Pidgin in the media and opens the discussion about alternative models. 


\section{CHAPTER SIX: LOCAL REALITY AND THE DONOR MODEL}

\subsection{INTRODUCTION}

The last chapter began by looking at the accessibility and importance of the news from the perspective of the majority of Solomon Islanders living semi subsistence existences in often-isolated villages. Through the eyes of Solomon Islands journalists, civil society and commentators it looked at how the rural and urban areas are inextricably linked by 'wantok', yet worlds apart in language and worldview from the donor community. It investigated the influence of the donors on daily news media in terms of the flood of media releases and jargon, or as one contributor wryly put it, 'donor dialect'. And finally it used the donor rhetoric of anti-corruption and good governance to look at how these issues are dealt with, interpreted and perceived in the islands themselves.

This chapter will look at the direct influence of donors on the news media in the form of Media Development. It will give voice to the people running the Solomon Islands Media Assistance Scheme (SOLMAS), its supporters and its critics. It also explores the problem of English versus Pidgin in terms of the language used in the news media. In addition this part of the analysis investigates a concept that brought a spark to the eyes of the Solomon Island journalists, the idea of an indigenous way of doing news, reporting and interviewing that may be more appropriate, and even more effective, than the model imported from the West.

\subsection{THE SOLMAS STORY}

The SOLMAS office is up the stairs from the Ministry of Education in a Honiara building that houses just the Ministry and a few small businesses. There is very low-key signage - just a $30 \mathrm{~cm}$ square placard on the door. Behind the misted glass and reception area sit a staff made up of a general manager, two trainers (Australians) and two local staff members - a project officer and an administrative assistant. 


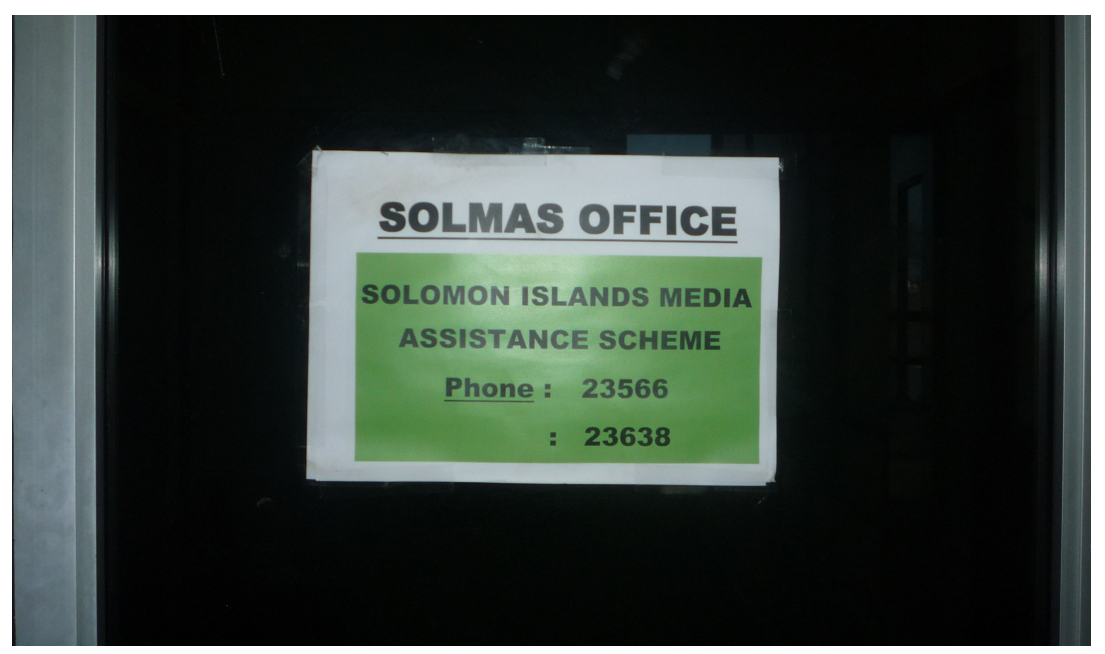

Photo 4. Signage on SOLMAS door.

As mentioned in Chapter Three of this thesis, SOLMAS, which is funded through partnership between RAMSI and the Australian Broadcasting Corporation (ABC), has its reasons for seeking a low profile and being cautious about how its mandate is perceived. It sits in an uncomfortable position of being mostly financed by the intervention force RAMSI which is treading its own careful path and has been the centre of plaudits but also ongoing criticism over the nine years it has been in the country (Anderson, 2008). This can be seen in part as tension between its transformative role while stepping delicately around issues of sovereignty (Barbara, 2008).

SOLMAS is, by its very nature, in league with a news media that is viewed with suspicion and hostility by some politicians who are wary of the media's power, and, in part, unskilled in how to deal with it (Chand, 2007).

SOLMAS was cautious of publicity. ${ }^{29}$ It became clear as the interview progressed that RAMSI's first attempt at instituting Media Development, aimed then only at the state broadcaster, the SIBC, had caused acrimony with the already suspicious Sogavare government of 2007 (see Chapter Three, p. 19). So SOLMAS is keen to keep its head

29 The General Manager of SOLMAS Corallie Ferguson was wary about SOLMAS participating in this Masters research project. There was a suspicion about how the research would be used, and whether it would be shared back with the organisation. Ms Ferguson required a written question-line and a signed undertaking that she could view the material from SOLMAS before it was printed. 
below the parapet.

CF: We are not here to be promoted; we are here to do good work with MASI ${ }^{30}$. They are wonderful to work with. A media reported in the paper about [a] training session not a word mentioned about SOLMAS. So they kind of protect us. AB: Otherwise you become a political football, is that a good way of putting it? CF: Yes I think so, yes definitely. I mean I don't think Derek Sikua ${ }^{31}$ knew who we were. I shared the floor with him at the media awards because the PM [Prime Minister] is the patron of the Media Awards and MASI ... so they are aware of us. They probably don't know what we do specifically and we certainly do not get involved in the political life.

\subsubsection{SOLMAS - a wide brief}

SOLMAS is working in many areas and most of them have no direct impact on the politicians of the Solomon Islands. Working with the Solomon Islands journalists around the elections in 2010 could, potentially, have led to tension however there were no incidents and SOLMAS was pleased with the outcomes for the Media Development programme.

CF: The whole election period, it was about voter awareness, voter education and covering the election and making sure they had the capacity to do so. AB: That's a time that a disgruntled MP could have started pointing fingers but you got none of that? CF: No. No it's about fairness and balance and impartiality and all of those things and that's what we drive. We are not here to favour one or the other. Our work is with the media.

However at least one senior journalist was circumspect about how SOLMAS approached journalism training leading up to the 2010 elections. This contributor felt

\footnotetext{
30 Media Association of the Solomon Islands

31 Prime Minister at the time of the media awards.
} 
SOLMAS 'fed the media' an agenda during the elections although SOLMAS says journalist were always asked by their trainers to come up with their own questions.

J 1: They will organise this forum, and then hide under MASI, the Media Association of Solomon Islands - and get these people [the candidates] yeah then they would go and hide in the glass room and feed us with ah questions and what we are supposed to ask these people. AB: They fed you questions? J 1: Yeah they prepared the questions and then, but then it is not closed I mean, 'these were some of the questions you might want to ask but we would like you to ask these questions'. [Or] 'these are very good one'. Its open to journalists to ah reporters to ask whatever questions they like. Yeah so actually they are running the show behind the curtain. AB: SOLMAS said they stand behind MASI? J 1: I think that is why they are worried and they don't want to have a profile and I think it's reasonable. AB: It is reasonable that they do that? I 1: I mean the fact that they don't want to have politicians to have to really see that they are directly involved? But then... [LAUGHTER]

This journalist articulates an uncomfortable feeling that the news media is being coached to ask the questions the donors want answering, or the donors want the country to ask. It is a theme that Allen and Stremlau (2005) raise about experts from the donor countries setting standards for 'truth' and 'justice' while ignoring local realities. The contributor goes on to recommend Solomon Islands media may need to adapt a model to suit their own worldview and culture.

$\mathrm{J} 1$ This is our country - this is our people. What is effective for us is what we should apply here. Not only in media. It is not because we are saying it is our country - it is because we want to put effective measures in place where the country can develop. So in terms of media um definitely I think we should look at ways that we can disseminate information effectively to people. It's good to adapt the Western style but then is it going to work is the big question? So we should really look at ways that we can reorganise how we can do it and really should get the message down with people. 
In Honiara, just five $\mathrm{f}^{32}$ of the $30-40$ journalists had tertiary-level training. Most came straight from school. The newsrooms are understaffed and lack adequate equipment. Often even the fuel to get journalists to cover events is too expensive. Despite that, the media is vibrant and challenging. It has its own quirkiness that tells the story differently from how you would hear or read it in New Zealand or Australia. It is the story that is important in the culture of this country. Some journalists seem a little confused by the intensity of training offered by the donors. Mostly there is an awkward embarrassment that they are not performing 'adequately' yet underlying that I sensed a pride in what had been achieved and a belief that they, not people from other countries, probably know more about what their readers, viewers and listeners respond to.

SOLMAS' Corallie Ferguson is positive about the way her organisation has felt-out the environment in the Solomon Islands and stuck to the mandate set down by RAMSI.

CF: Fairly early in the piece after we had done quite a bit of consultation with the media and we had these components that we agreed on with RAMSI; strengthening the media was one of the main areas, and that was the whole media system not just the SIBC. AB: When we talk media here are we talking news media? Community media? CF: Community media is very strong here ... [the following was added after it this chapter had been reviewed by SOLMAS]. We are just as involved with Community media as with commercial media. We have completed media training with the 8 FM stations and PFnet operators in Isabel, and also with PFnet in the Western Province to bring stories back to the mainstream media from the villages. We assist others like Vois Blong Mere (advocacy and media training for the Provincial members), Guid News Radio, Don Bosco, SIDT (assisting them with their setup for a new FM service).

SOLMAS certainly has its supporters and, in lieu of other news media training within the country, it is seen to have a place. There is a new Certificate in Media and Journalism Studies at SICHE (Solomon Islands College for Higher Education), from which the first students were graduating while this research was taking place (in 2011)

\footnotetext{
32 Information given to the researcher by SOLMAS from capacity survey.
} 
but unfortunately the college did not respond to requests for an interview. There are also a few courses available from the University of the South Pacific's (USP) small Honiara campus. There is an understanding that there is a need for building capacity immediately in Honiara and Western-trained journalists are the ones to provide that.

J: 4: I think the media still needs to develop and we still don't know how to do that and there is a place for SOLMAS. But in terms of building private media I am not sure if that is the way to go. But training young journalists to give them the training that they need. Even young graduates [out of USP] I am starting to question the degree programme that we have at the USP - if the lecturers impart the right knowledge to young. For our young reporters as well I think SOLMAS, they have done quite a good job in trying to teach our young reporters how to write a good lead, how to develop a nose for a story, that sort of thing. I am not sure where the problem lies really. Is it with us not wanting to learn? Journalists do need to learn the hard way [on the job].

There was a great deal of support for the skills training.

J 3: At $S I B C$, donors send in specialists on short-term basis to do training and capacity building. These short-term trainers do get us to improve on our work. The people have come to realise the importance of journalists' work, and therefore their expectations are high.

One journalist made the distinction between donors having influence in training but not in directing the news media.

J 2: I think we are getting ... donors' influence from coming in and training local journalists...

This journalist also related the case of a senior journalist from outside the country causing some consternation because of the way he tried to get the newsroom to treat specific stories. 
J 2: Also came across those situations in the past when we have one la New Zealand journalist ${ }^{33}$... here we have some things on that when we are going to report on-cultural sensitive issues- and he says go and report on that and we say we can't report on this, it is a quite sensitive issue. Very cultural, so yes sometimes we come across that.

SOLMAS is adamant the programme is listening to what the journalists and news organisations want and need.

$A B$ : How much is your work driven by the needs of the local news media and how much by the imperatives of the donors and the MDGS, RAMSI etc? CF: It is all driven by local media because while the standard of journalism is the same worldwide in terms of what it should be, you know the 'who what where when why', that's our basis for starting any training - and we repeat, and we always do feedback at the end of every session to look for anything else that is needed by that particular group. And we do group work, one-on-one mentoring and all of that sort of thing. So they both [SOLMAS trainers] go into the work place and do editorial meetings with their editors. They are doing newsroom management right now, formulating best ways to do that top down. So we are doing everything we can bottom up - top down - one, two groups, and big groups sessions - whatever is best for them.

SOLMAS has wide-ranging objectives and is reactive to need. This is highlighted in its move into communications for development.

CF: We discovered the media training as we were going along - how people just needed it ... We also work with the institutions like the leadership code commission, the ombudsman, the auditor general, the DPP, legal people. AB: Once again are they telling you what they think they need? CF: Yes we are always do that - always ask what they want first but we also will approach them if we hear 'no comment, no comment, no comment' or they are misquoted, or there is something not right about a story we would approach them and offer them media

33 This person's name is not relevant to this research so it has been omitted. 
training. That's one of our real success stories I think and working with NGOs, with people working away but they don't think about communications for development sort of the things. So that's where we are going into phase three working with not all NGOs but a certain number of them to find out if they need any help.

This could be seen as a conflict of interest with SOLMAS working with the 'spin doctors' (as in the communications/public relations people) and at the same time training those trying to decipher the 'spin', but Corallie Ferguson says their primary work is still with the news media. Journalists spoke about problems with the politicians, and others, not understanding how the media works, which suggests SOLMAS is reading the signs well. The journalists say they struggle to achieve balance on stories as they are blocked from getting comment or chasing angles as interviewees duck for cover.

J1: The main thing we really need to have in the media industry in the Solomon Islands to make sure it is effective and whereby people can really know our job, is we need awareness about the work of the media in the Solomon Islands. Most of the Solomon Islanders do not understand the work of the media - that's why there is a big challenge sometimes. When we go to places to get stories we face difficulties. People do not understand what we are doing so the work of the media in the Solomon Islands needs to be boosted. I mean education on the work of the media. At the moment journalists are really struggling to get by. It is difficult... and then another problem is these untrained people in the media.

\subsection{A CULTURE CLASH}

An example of issues where the Western media model clashes with the culture and kastom of the Solomon Islands is in terms of compensation by way of shell money or pigs divided up by the community. "The reconciliation ceremonies act as public acknowledgement that negotiation has taken place and that the restoration of relationships can now proceed in earnest. They serve as a confidence building measure, a healing mechanism, and a public declaration" (Maebuta \& Spence, 2009, p. 12). 
Compensation ceremonies, including those that continue today to settle disputes from the tensions some eleven years ago, are seen as an unresolved legal pluralism whereby kastom runs up against Western-imposed government and rules of law. Menzies (2007) put it that the custom of paying compensation to settle disputes also doesn't cross the boundary well into business and cross-cultural situations.

"[G]iven societal change there are issues which traditional mechanisms may not be equipped to deal with (e.g. resource disputes involving outsiders) and modernisation has distorted customary governance (e.g. in the misuse of compensation) (Wairiu and Tabo, 2003). The most blatant forms of extortion have been couched in terms of customary claims for compensation (Fraenkel, 2004) (Menzies, 2007, p. 11).

This is an area where media have come under attack during the tensions and also more recently. Soon after the research fieldwork for this thesis was completed, a Solomon Islands newspaper received an NZ\$8,000 (\$75,000 SBD) compensation claim over a story it had published. It referred the matter to the police. MASI has denounced the claim saying it is "inappropriate and disrespectful to media freedom in Solomon Islands" (Solomon Star, 2011) while a regional media monitoring network, the Pacific Freedom Forum $(\mathrm{PFF})^{34}$, slammed the claim as extortion rather than a custom arrangement. PFF co-chair Monica Miller has urged Pacific Island journalists to report actions of this kind, recognising these are issues that are continually being faced. "As Pacific journalists, it's important to understand that elements of culture are always going to be a point of contention in our work, but the bottom line is culture should make us better not worse, at doing the best job for our communities" (Pacific Freedom Forum, 2011).

\footnotetext{
34 Pacific Freedom Forum (PFF) is a regional network of journalists, academics and friends committed to the defence and implementation of Article 19 of the UNDHR in the Pacific. http://www.pacificfreedomforum.org
} 
A journalist recounted what he described as a "very scary" incident earlier in 2011 when one aggrieved group invaded a newsroom.

J1: They thought it [the story that was published] was culturally insensitive and we were saying all of them are bad people. They came in three loads of vehicles and everyone ran to the back because most of them [the assailants] were drunk. They came to the front desk so I have to go and face them and talk to them ... No they didn't hit me, no but I told them we take these figures from [a donor report], it's not our own making. But they didn't understand. They say 'but you put it out to the people saying it was us'... They came back the next day and we ended up at the police station and the police asked us if we could settle the matter by agreeing with them to give compensation. AB: Did you? J 1: No I told police that this is our job and it would be under threat if we do this because people will expect it in future time. New reports will come out and people will expect compensation. I have to protect the media and we will not give compensation. So the police told them they will not give you guys' compensation. They say threatening words -' watch your steps'. I told them to open a legal case if they are not happy and take us to court but they didn't want to. They don't understand the media. Most of the people in the Solomon Islands don't understand the media.

One NGO has a different solution to the problem of the community and politicians understanding the media's role. It is to turn the system on its head and to encourage the community to drive the media rather than the other way around.

NGO 1: Like to look at SOLMAS and try and get [it] to the community. Try to work with people find out what they know about the media and work from there. It is not from them [the donor/media] to the village but the village to them. Just like the FM stations working in Isabel $\left.\right|^{35}$ if we get a kind of university lecture down to

\footnotetext{
${ }^{35}$ UNDP funded the setting up of eight FM radio stations on the island of Isabel in 2006. However there was a problem with ongoing maintenance of the equipment and training of the people. Seven of the stations broadcast for just two to three hours a day depending on solar power as they are in remote rural areas Early expectations that the stations would be self sustaining, met by local revenue, proved overly optimistic. There were disagreements over who had ownership of the stations and ultimately the funding has had to continue from outside sources. RAMSI has provided funds for digital media equipment. In 2011 there has been a concerted effort to sort some of the governance issues out with the communities and the Isabel Provincial Government.

(http://communitymediasolomons.wordpress.com/isabel-learning-network/)
} 
the people in the community they lose their way 'cause they have not been to broadcasting place or school - so [we should] get down there ask what they intend to do and help these people ... The other way is what they have done in Isabel where they [the staff of the stations] were just picked from families.

How the donor world is represented (or misrepresented) to the people of the Solomon Islands is an ongoing debate for all the contributors. An NGO that spends a lot of time working with donors to get their messages into understandable language and concepts for the majority who live out of the urban areas believes the majority of the people in the Solomon Islands are left out of the donor/government loop and the media isn't helping that.

NGO 1: Because [from a] long time ago donors had been donating money to the Solomon Islands people. Millions and millions of dollars have been given to the people and the people lower down have never seen that money in their possessions and they were questioning where all the money gone. So that's why [we are] interested in some people talking to the donors because when they come in here they always choose the upper people to do talk to and not the community people and when that money given to the people that money had not even reached the poor level of people down in the village. That is a big gap that we have so we are educating the donor about use of language and interpreting language doing that. We are doing our best as an organisation to help the people and help the donors to get together to see what changes would be like in the near future so the money that gets sent in - or what materials or what assistance they have is seen - as a very important thing for the people of the Solomon islands.

Woods believes by using the media as a corruption watchdog, often highlighting government inadequacies, donors are damaging the very fabric of the country. He worries that the messages are further distorted as they are disseminated second hand, often with limited explanation, to those outside the centre of Honiara. 
TW: An important issue is that when you consider a province like Isabel where $38 \%$ of the people are not literate - you have got to think about how people interpret and internalise these messages coming from overseas. What type of expectations does it raise, or does it? It is an open question. How are these messages received and how does that message correlate to their own government? Do they understand how their government works? No they don't, and RAMSI have never done a thing. The people get frustrated why there is no change and the negative press [doesn't help this].

\subsubsection{Adapting to the wantok}

During a discussion with one journalist I was asked if I had ever found myself in a situation of having to report on my extended family during my twenty years as a news journalist. In a country of four million I acknowledged that was less likely to happen than in a country of half a million. However wantok is more than just family in the Solomon Islands.

Walter Malau of Transparency International Solomon Islands puts the issue of wantok and how it impacts on the Western news model down to the concept of 'conflict of interest'.

WM: The wantok system is sort of like interchanged with the words conflict of interest. We understand that part of corruption is the chances where you could not avoid conflict of interest of wantok issues ... given the smallness of the population and the concentration of the commercial activities which is in Honiara itself ... So there is times when we can link corruption related to - corruption increases because of the conflict of interest because of the wantok issue... so we can apply that when we move to the role of journalism in a small society like ours that is prevalent with wantok issues. So you can tell this from reading the media whereby sometimes things that are highlighted and sometimes you expect things to be highlighted but - they were not. Because of things and you have no proof but I think there is a danger of this. 
Journalists say they have ways of coping with the problems of reporting on their own village, or even province.

J1: It is a big challenge here especially when the Melanesian society is very good at extended family and the wantok system. Personally I did drop a few stories during my time as a reporter as a result of that. $\mathbf{A B}$ : You dropped them or passed them on? J 1: I passed them on. I said look I don't want to do this story it is something to do with people I know and are related to so and I encourage the reporters to really understand that issue if they come across something that is of interest to them - if it's a conflict of interest they have to pass it on ... it is a problem with us it is a problem --- even if it is not your wantok sometimes these people they know really well someone who is related to you and they will come and talk to them and they will say can you talk to him.

J 2: I think sometimes I would I just give it to another reporter. AB: Is that a discussion you have in the open or is something that you just know to do? $\mathbf{J} 2$ : It is something that we just know to do and you just give it to another reporter and another might come to me with a story about their wantok and say it you might like to do this. I mean because sometimes you don't want to get caught up in that thing-yeah sometimes it is sensitive.

It is exceedingly difficult to get the contributors to define wantok or even talk about its impact. It is variously described as describing kin or cultural group, while wantokism is giving preference to your kin (Moore, 2007a, p. 149).

J 2: It is my family, my extended family. Even island yes. AB: Because you are here in Honiara? That's right yeah ... When the reporters they report on some officials or top people for instance when they are being sentenced or being charged with corruption and some of the relatives would sometimes threaten or call some of the reporters so that is one of the things. The wantok system is so strong, second cousins and so forth, so connected so if you said something about the island or village, all of them would be really angry.

Balancing responsibilities as an editor and keeping the peace in your village or even 
island wantok is tricky.

J 2: Sometimes I mean we have some issues on that. But most of the time when I go down I used to do some good stories about them before that. [laughter]. But I do have some close supporters of Ministers [MPs] and even some Ministers who call me up and have me on about some of the reports we have written. AB: So sometimes you are put in awkward situations? J 2: Sometimes. I just say I didn't write the story in the end.

So there is no doubt that pressure is put on journalists not to report on close members of their wantok, and it would be seen in the West as impinging on media freedom. However as the explanation goes on the journalist stresses that there are ways of coping with this - it just takes time. This journalist gives me an example where the news organisation backed off in the first instance.

J 2: They are close wantoks with the guy who was implicated in that is close associated wantok of the Minister. They call me up and say sue. This is what happens. AB: So are you sitting on the story and hoping to run it later or will you drop it? J 2: We will hopefully run it later but ... yes that is the point I am raising [It] takes time. AB: Because of the wantok is so strong? J 2: Yes.

One NGO contributor who publicly challenged a relative in government over what they believed were incorrect practices found there was a change to their relationship following the news media reports.

NGO 3: We [have] a different, severe relationship now. And it affects the family as well. His mother came to me and was crying and said how did you do this and now it is blown out in the media. We have been talking about it for months.

However this contributor believes the Solomon Island population is becoming more media savvy.

NGO 3: People are more open but I believe if people are more educated [for example] I should not take things personally. My position being representative of 
the people is an open position and anyone can say what he would like about it.

In a country with no social security or safety net for the less able members of the community or those that suffer misfortune, the wantok provides a vital insurance. This is a security that cannot be underestimated.

NGO 3: It has its positive and negative parts too it but ah wantok system - comes down to the bottom - it is likely family. It is my insurance that I can fall back on.

\subsubsection{A place for Pidgin}

NGO 1: One of the biggest problems we have is you always hear people speaking in English when they speak to our people in the community rather than speaking Pidgin and making everything clear for our people to understand what they are talking about. So [all] people being interviewed or speaking on radio, in Star, speaking in English. More difficult and boring of information. People would like to hear the content but speaking in English - they couldn't understand.

There are more than 70 living languages in the Solomon Islands with Pidgin being the lingua franca ${ }^{36}$. Figures from the 2010 census are still being processed however it is clear that outside of Honiara, a mixture of English, Pidgin and other languages is used with the older people often only speaking the dialect unique to their area. This was also the case on the Weather Coast where the older women spoke a broken Pidgin and no English. Their knowledge of the world outside their village came from their wantok and visitors passing through. However, one of the older Aunties who told me she could not read nor write, also told me how she would be travelling to Honiara soon to Skype with her son who is studying medicine in Cuba. So to box this community as cut off, illiterate or unable to function with new technology would be to ignore the permeability of the rural/urban environments in the Solomon Islands. But it is also true that this generation of the village would not benefit from regular newspapers as they do not speak English and none of the newspapers are printed in anything but English.

\footnotetext{
362011 Human Rights Council report to the UN General Assembly http://www.ohchr.org/EN/countries/AsiaRegion/Pages/SBIndex.aspx
} 
As mentioned the SIBC does run a few news bulletins a day in Pidgin but there are difficulties and time constraints on this.

J 3: Pidgin is not a standardised language and therefore there are times journalists find it difficult to translate such words into Pidgin. It will take a full sentence at times to translate a word from a donor language into Pidgin, if it is to be understood by the people, especially those in rural areas most of whom don't understand or speak English.

And translating concepts such as governance and capacity building into Pidgin create problems for the time hungry journalists.

J 4: Sometimes we just say governance and capacity building because our fresh news bulletin goes out at 10 o'clock in the morning the English version then translated for the Pidgin to go out at 11, and sometimes in that hour you have other distractions. You have another story to write or some people come to see you...[there are] distractions.

Newspapers face the same problem.

J 1: We know really good that 80 percent of Solomon Islanders live in the rural areas and most of them are illiterate but then as you say we stick to the Western style and but we do encourage reporters to use simple English to really break down big words. But again sometimes it comes down to time and then most of them do not have the experience and so they will just go with what they got... yeah. But yeah I do not think many of the villagers would understand what's in it.

As the SIBC has the largest reach of any news organisation they recognise the difficulties faced by the population.

J1: I have not come across any written policy on the use of Pidgin for news. I guess the perception [is] that the majority of Solomon Islanders, mostly in the rural areas do not speak English (let alone understanding it). If there are people who 
understand \& speak English, it's less than half the population. The fact that SIBC broadcasts to the entire country, we will continue to use Pidgin in our news bulletins.

\subsection{AN ALTERNATIVE MEDIA MODEL?}

News stories are never written or broadcast in a vacuum, for they are always written and told within the framework of cultural, social, and historical contexts. (Kalafi Moala, 2007, p. 241).

A few of the journalists I spoke to were interested in the concept that news reporting might develop differently in different countries (Allen \& Stremlau, 2005; Craddock, 2011; Nyamnjoh, 2005). There was almost a tired resignation from the senior journalists about the perception that they didn't measure up to the standards of their Western counterparts. They saw their handling of some issues as 'failings' in their ability to report issues in their country. Some of this was put down, once again, to the Solomon Islands people not understanding how the news media works.

J 1: I think it boils down to politicians, and leaders understanding the work of the media most of the time. This is compared to what I understand from New Zealand and Australia. Most of the time in New Zealand when I call someone from the local government to say 'look there is a story I need to talk to you about to make balance and fair' - they would really understand and know it was important I talk to these people and say look come and see me and it is important we get this right'. But here when you try to talk to people about these things you call someone and say look someone is accusing you of misusing some money and can I talk to you about it' ... 'sorry no, no I am too busy, I am at a meeting'. So they are trying to put out the media and they just don't want to talk to the media. AB: So you are often getting one side and not the other? I 1: Yeah and so sometimes I would say that is one reason why most of the time he would not want to comment ... he is available, he has just told his secretary to say he is not in. AB: So what would happen after you print? J 1: They would call the next day and scream at you. I always tell the reporters as long as you have tried your best to talk to them and 
they have put you off, then tell them you have given them a chance to talk AB: Not just a style thing? J 1: No understanding the work of the media.

However this same journalist also spoke of the length of news stories, as the result of the interviews often having to be translated from Pidgin to English. He says that means a lot more description. And another journalist saw there being a 'Solomon Islands style' of reporting but wasn't sure if that was by necessity or even a good outcome.

\begin{abstract}
$A B$ : Is there an indigenous way or beginning to be a Solomon Islands style of reporting? J 4: Whether we realise it or not we tend to develop our own way of reporting on issues. Like sometimes you just go with one side of story and then you don't think it is right or your duty to go for the other side. So on one day you do one side and the next day you try to chase the other guy to say his other side. Whether we do it knowingly or it is the way that we do it, and I think it is the way that we do it ... We don't see it as unbiased. I don't think it is lack of training. We just - that person is unavailable - I am not sure - do you have to wait or [push]?
\end{abstract}

It is not just the lack of comment that is an issue. There are difficulties around challenging people directly, and sensitivity around the church, that also present challenges for the journalists.

J 3: One of the challenges we have is the cultural differences in the two worlds. Local journalists are culturally sensitive especially when reporting on leaders. The question of relatives also comes into play. There are also religious attachments in our communities that at times hold us back in reporting.

Walter Malau, the executive director of Transparency International Solomon Islands, says the reach of the Western media, and globalisation in general, is too strong for the news to be reported differently or to different standards in his country. He says with the high rates of corruption in the Solomon Islands, the country needs a strong news media.

WM: You have a situation where the Solomon Islands is a very corrupt country and you have a media that is not that in-depth, investigative-type of reporting. That 
really gets down to the root of our expectations of reporting on corruption. So you will see people who might be tertiary trained ... and if there are currently interested journalists in the pipeline they will definitely be thinking about the way they will be transforming the reporting style. There is no model to adopt within the Solomon Islands and then given globalisation, given lack of models, given transparency - they will have to attend and try to adapt to the civilised way of reporting.

Malau says the lack of a Freedom of Information Act (FIA) in the country means the journalists need to work even harder to get to the bottom of stories. So would an FIA make a big difference? Malau isn't totally convinced when he looks at countries with FIAs.

WM: England is a country with a Freedom of Information act - why do journalists continue to tap phones to access private information?

However he thinks the lack of legislation in the Solomon Islands goes some way towards explaining problems the country's journalists face.

WM: We haven't reached the stage of getting a Freedom of Information Act but currently other donors which I have already spoken to indicated that they are working on a process to get it through. But given we don't have that, people will try and get the same level of access of information as expected from other countries that already have a FIA. So you can imagine if you are a journalist working in the Solomon Islands in a country with that high-end corruption - what would you expect? (WM)

The lack of an FIA, a fear of offending advertisers and the constraints created by defamation laws are all problems for the media and the public facing a flood of multimedia pouring into the country. The issue of inadequate legislation to control media has been brought up by Media Development researchers who believe in post conflict countries an explosion of private media can lead to more tension. (Putzel \& van der Zwan, 2007, Hume, 2004). 
An NGO making some inroads into educating young people about the impact of the media believes there are problems with the lack of legal infrastructure around the growing media environment.

NGO 2: I think every person is born with an innate sense of values and everyone has ... to be given an outline to say fine, these are the possibilities the ultimate choice is yours. But if people are not aware that they can be manipulated through the media, then they drink in whatever. For example laws of advertisements within the country do not exist. Now this should be in place and who's there to question it? No one. Laws of defamation are not really fully in place despite the fact that they could be. Now there are things that people do and say it is my freedom to do - yes it is your freedom to do within a certain context with limitations.

However journalists do believe they adapt their reporting to allow for cultural aspects of their society.

J: Whether we realise it or not we tend to develop our own way of reporting.

And to echo a theme referred to earlier, thoughts from a journalist who believes an appropriate way of reporting for the country should not just evolve but should perhaps be more widely sought by the news media there.

J 3: I think we should look at ways that we can disseminate information effectively to people and it's good to adapt the Western style but then is it going to work is the big question. So we should really look at ways that we can reorganise how we can do it and really should get the message down with people.

\subsection{SUMMARY}

This second analysis chapter opened the conversation with contributors around Media Development and whether it can be seen simply a technological tool, or could be seen as a political tool championing donor priorities. It explored the tension around a media 
assistance programme working to a mandate from RAMSI but seeking to maintain neutrality that sets it apart from the politics of the country and its partnership with donors. It appears the majority of the contributors see this as either acceptable or inevitable while a few question where the boundaries should be. This particular Media Development programme is charged with, and appears to be, responding to the local media environment and working closely within it. Its challenge is to be constantly open to local alternatives and the possibility that different standards are acceptable or even to be encouraged (Allen \& Stremlau 2005). The personnel may be willing but the structure and ideology of the Media Development programme may be restrictive.

This chapter attempted to look at the Western media model's fit in a developing country. There appear to be clashes of culture in issues around reporting wantok and other areas of kastom. There also appears to be an uneasy fit between donor imperatives around good governance and anti-corruption and the mixed messages coming from that, as highlighted in Chapter Five. Some contributors were keen to discuss alternatives such as more community-based and driven media. It was recognised that the use of English in the media alienated a great deal of the rural audience.

The discussion here around indigenous media left no real solutions and mirrors the discussion worldwide on these issues, which is new and at this point disjointed. However there was recognition that within the media system inherited under colonialisation and perpetuated today, there may be room for a style that is distinctly and uniquely Solomon Islands. 


\section{CHAPTER SEVEN: CONCLUSION}

This vertical approach to knowledge in development echoes the vertical approach to development in general, whereby knowledge is perceived as an ingredient of the technical assistance given by those who have it to those who do not. However, no organisation can offer social transformation or knowledge sharing if it is not itself engaged in an internal learning process that systematically questions certainties, authorities, and decision-making (Dragon, 2006, p. 593).

\subsection{INTRODUCTION}

This thesis has sought to explore development donors' use of Media Development as part of an overall state-building strategy. It has attempted investigate this by looking at the history and contemporary experience of the growing Media Development sector heralded as supporting a free and pluralistic media to aid good governance and democracy. It has uncovered a parallel emergence of caution around this model. There are charges that its religious adherence to the commercialised neoliberal model threatens to ignore the "issues affecting the rural and urban poor" (Rogers, 2006, p. 184). There are concerns that Media Development is seen by donors as a way of training the media 'watchdog' to oversee the funds that they no longer have control over in the new aid modality. At the same time there are warnings that the Western model of media being transferred in to developing countries is so market driven that the public affairs watchdog has been subsumed by the commercial drive to entertain (Curran, 2002). There is also caution about Media Development being perceived as apolitical and "even altruistic" when it has political overtones (Miller, 2009, p. 10).

The thesis has grounded its research in the Solomon Islands. It explores the factors of history and culture that have led to today's local reality in this Melanesian nation. This is a country where the majority of the population live semi-subsistence lifestyles while the capital Honiara is flush with development donors and the elite. It plots the rush to independence in 1978 and the build-up to the civil unrest that gave the Solomon Islands the title of a 'failed state' just two decades later. It is in this setting that the research localises a Media Development programme as part of the state-building project under RAMSI, the regional assistance mission. 


\subsection{KEY FINDINGS}

The interviews with the contributors reveal a complex picture of interactions between the Solomon Islands media and donors. Into this comes a Western-driven Media Development project with a particular set of assumptions about what media should look like. The relationship is across multiple levels; donors as providers of news, trainers of newsrooms and consumers of news, while journalists are variously engaged in, frustrated by, or mistrustful of the process.

The Solomon Islands media is often struggling under the amount of donor material flooding its newsrooms with their own agendas. Despite this, the members of understaffed newsrooms talked about their determination to work on their own 'angles' on most stories and not be directed by outside influences. There is pressure from donors for more investigative reporting from local media as part of the 'watchdog' role. However civil society and the media both felt the donors themselves aren't always compliant when it comes to responding to media questions, especially about how money is being spent in their country. Sometimes stories like this hit a "brick wall" 37.

Meanwhile contributors were aware that the majority of rural people in the Solomon Islands are still isolated from the media either by way of geography, literacy issues, or the predominant use of English by media outlets. NGOs were concerned that despite the fact that less than a fifth of the population live in Honiara, the news is dominated by issues from there and not from other communities. Contributors saw problems with negative language which some believed was emanating from donors. They felt overuse of terms such as corruption threatened to become meaningless, " $a$ word that no one associates with".

37 Italicised words are direct quotes from contributors. 
Culturally specific challenges were recognised as creating problems, for example the expectations of the wantok, which were "sensitive" and "challenging", and how that had to be balanced with the expectations of the donor media model. However the Media Development programme in the Solomon Islands was seen as reactive to the needs of the local media within the restrictions of its outcomes-based approach.

The research found a Solomon Islands media generally supportive of the Media Development programme "there is a place for SOLMAS", with reservations in some areas: "this is our country - this is our people" and "what is effective for us is what we should apply here". There appeared to be room to open a discussion around a local media style having space and encouragement to develop: "it's good to adapt the Western style but then is it going to work is the big question?" and "whether we realise it or not we tend to develop our own way of reporting".

Alternatives to the homogenised Western media model being imported by donors involve opening the conversation so that issues around wantok and kastom, for instance, are not seen as obstacles but engaged with in meaningful ways. It means the use of Pidgin, rather than seen as too hard, is explored with input from those most isolated and marginalised by the market-driven commercial model of media presently being encouraged.

There is a growing call for more research around the efficacy of Media Development (Harvey et al; Odugbemi \& Norris, 2010), but it is still restricted to a discourse with the lens firmly aimed at Eastern Europe, Africa, and parts of Latin America and Asia. There is little to no activity on this front in the Pacific. Also, the existing international research seems to be based more around the efficiency of Media Development in a neoliberal sense of 'growing' economies rather than in terms of culturally appropriate or evolving media, or 'growing' resilient communities.

To move to a locally 'owned' media that relates to all levels of a country rather than a market-based homogenous Media Development model may be too restrictive and be driven too closely by Western ideals. If donors accept that a strong local media is 
important in overall development, and if they also buy into the 'ownership' rhetoric in the contemporary aid modality, then they must apply it to the media sector of the developing countries within which they are working. This means opening spaces for a heterogeneous, indigenised media model that can be explored and developed to engage local realities in an informed and critical way.

This research has been limited in breadth and aimed only to hold a mirror up to an area of development that is seen internationally as ill-researched. It seems clear that while Media Development is viewed as skills and technology transfer, it is a political project that can be seen to challenge, or attempt to change, local realities. The questions that need to be asked are whether donors should be part of this area in developing countries and whether more can be done to open spaces for indigenised community-based media to grow and develop in its own way. 


\section{REFERENCES}

Ashcroft, B., \& Ahluwalia, D.P. (2001). Edward Said. London: Routledge.

Alasia, S., \& Laracy, H. (1989). Ples blong lumi: Solomon Islands, the past four thousand years. Suva: University of the South Pacific. Institute of Pacific Studies.

Alasia, S. (1997). Party politics and the government in Solomon Islands. Paper presented at the State, Society and Governance in Melanesia Project, Australian National University. Retrieved Aug, 2010 http://www.vanuatu.usp.ac.fj/sol_adobe_documents/usp\%20only/pacific\%20g eneral/Alasia.htm

Alasia, S. (2007). Rainbows across the mountains. The Journal of Pacific History, 42(2), 165-186.

Allen, M., \& Dinnen, S. (2010). The North down under: Antimonies of conflict and intervention in the Solomon Islands, Conflict, Security \& Development, 10(3), 299-327.

Allen, T., \& Stremlau, N. (2005). Media policy, peace and state reconstruction. Discussion Paper no.8. Crisis States Research Centre. LSE. Retrieved Sept, 2011 http//http://www.global.asc.upenn.edu/.../conference_Ise05_session3_allenst remlau,

Altaiconsulting. (2010). Afghan media in 2010 - Executive Summary. Retrieved March 2011 http: //www.altaiconsulting.com/docs/media/

Amnesty International. (2000). Solomon Islands: A forgotten conflict. Retrieved Sept, 2011 www.amnesty.org/en/library/asset/.../005/.../asa430052000en.pd

Anderson, T. (2008). The limits of RAMSI. AID/WATCH. Retrieved April, 2011 http://apo.org.au/?q=node/3769

Angel, S. (2008). Radio writes back: Challenging media stereotypes of race identity. Pacific Journalism Review, 14(2). 123-140.

ANU Enterprise. (2010). People's survey 2010 final report. Canberra: ANU. Retrieved Feb, 2011 http://www.ramsi.org/solomon-islands/peoples-survey.html 
Arsenault, A., \& Powers, S. (2010). The Media Map Project. A resource on the impact of media development worldwide. Review of Literature. Retrieved March, 2011 http://www.internews.org/global/mediadev/mm_research.shtm

Asian Development Bank (ADB). (2010). Solomon Islands: 2010 Economic Report. Mandaluyong City, Philippines. Retrieved Aug, 2011 http://www.adb.org/documents/reports/sol-economic-report-2010

AUSAID. (2011). Anti-Corruption and Australian aid. Retrieved Oct, 2011 http://www.ausaid.gov.au/makediff/anticorruption.cfm

Baaz, M. (2005). The paternalism of partnership: A postcolonial reading of identity in development aid. London: Zed Books.

Banks, G., Murray, W. E., Overton, J., \& Scheyvens, R. (2011). Paddling on one side of the canoe? The changing nature of New Zealand's development assistance programme. NZADDS Working Paper. Retrieved Jan, 2012 http://www.nzadds.org.nz

Barbara, J. (2008a). Antipodean statebuilding: The Regional Assistance Mission to Solomon Islands and Australian intervention in the South Pacific. Journal of Intervention and Statebuilding, 2(2), 123-149.

Barbara, J. (2008b). Rethinking neo-liberal state building: Building post-conflict development states. Development in Practice, 18(3), 307-318.

Barker, M. (2008). Democracy or polyarchy? US-funded media developments in Afghanistan and Iraq post 9/11. Media, Culture Society, 30, 109-130.

Becker, L. B., Vlad, T., \& Nusser, N. (2007). An Evaluation of press freedom Indicators. International Communication Gazette, 69(1), 5-28.

Bennett, J. A. (1987). Wealth of the Solomons: a history of a Pacific archipelago, 18001978. University of Hawaii Press.

Bennett, J. (2002). Roots of conflict in Solomon Islands. Though much is taken, much abides: Legacies of tradition and colonialism. Discussion Paper 2002/5, State, Society and Governance in Melanesia, Research School of Pacific and Asian 
Studies, Australian National University. Retrieved Dec, 2010

https://digitalcollections.anu.edu.au/handle/1885/41835

Berg, B. L. (2009). Qualitative research methods for the social sciences. Boston: Allyn \& Bacon.

Berger, G. (2010). Problematizing 'media development' as a bandwagon gets rolling. International Communication Gazette, 17(7), 547-565.

Blankson, I. A., \& Murphy, P. D. (2007). Negotiating democracy: media transformations in emerging democracies. New York: State University of New York Press.

Bowden, K. (2010). Pacific press freedom under constant attack - Kalafi Moala. Pacific Media Centre item: 7049. Retrieved Nov, 2010 http://www.pmc.aut.ac.nz/pacific-media-watch/2010-10-01/region-pacificpress-freedom-under-constant-attack-kalafi-moala

Brockington, D., \& Sullivan, S. (2003). Qualitative Research. In R. Scheyvens \& D. Storey (Eds.), Development fieldwork: A practical guide (pp. 57-74). London: Sage.

Browne, S. (2006). Aid \& influence: Do donors help or hinder. London: Earthscan.

Chand, A. (2007). Book Review: David Robie - Mekim Nius: South Pacific media, politics, and education. The University of South Pacific Book Centre, Fiji Islands, Global Media Journal, Australian Edition. 1:1

Chappell, D. (2005). "Africanization" in the Pacific: Blaming others for disorder in the periphery? Comparative Studies in Society and History, 47(2), 286-317.

Chambers, R. (2002). Participatory workshops: a sourcebook of 21 sets of ideas and activities. London: Earthscan.

Connell, J. (2007a). The Fiji Times and the good citizen: Constructing modernity and nationhood in Fiji. The Contemporary Pacific, 19(1), 85-901.

Connell, J. (2007b). Islands, idylls and the detours of development. Singapore Journal of Tropical Geography, 28, 116-135.

Connell, J. (2010). Pacific Islands in the global economy: Paradoxes of migration and culture. Singapore Journal of Tropical Geography 31, 115-129. 
Coronel, S. (2008). The Media as a watchdog. Harvard-World Bank Workshop. May 2331. Paper 3.1. Retrieved Nov, 2010 http://www.hks.harvard.edu/fs/pnorris/Conference/Conference\%20papers/Co ronel\%20Watchdog.pdf).

Cotton, J. (2004). Peacebuilding in the Pacific: the Australian military experience. Journal of Peace, Conflict and Development, 14.

Craddock, P. (2011). Western media 'elite'models challenged by PNG research. Review of the book, Communication, culture and society in Papua New Guinea, Yu Tok Wanem? E. Papoutsaki, M. McManus \& P. Matbob. (Eds.). Pacific Journalism Review, 17(2): 210-213.

Curran, J. (2002). Media and power. London: Routledge.

Davison, J. (2009). Media in development - where's the gap? . In the 'Director's Blog' Polis Journalism and Society. (Polis is a joint initiative from LSE and the London College of Communication.). Retrieved Oct, 2010 http://www.charliebeckett.org/?cat=12\&paged=2

Deane, J. (2006). Why the Media Matters: The relevance of the media to tackling global poverty. In M. Harvey (Ed.), Media Matters; Perspectives on advancing governance \& development. Retrieved Aug, 2010 http://www.internews.fr/Media-Matters-publication

Denzin, N. K., Lincoln, Y. S., \& Smith, L. T. (2008). Handbook of critical and indigenous methodologies: CA: Sage.

DFID. (2006). Making governance work for the poor: A White Paper on International Development. Retrieved Aug, 2011 www.dfid.gov.uk/R4D/Output/173973/Default.aspx

DFID. (2008). Media and good governance: A DFID practice paper. Department for International Development, London. Retrieved Aug, 2011 www.gsdrc.org/docs/open/innovations-in-accountability/IA5.pdf

Dinnen, S. (2007). A comment on state-building in the Solomon Islands. The Journal of Pacific History, 42(2), 255-263. 
Dinnen, S., \& McLeod, A. (2009). Policing Melanesia - international expectations and local realities, Policing and Society, 19(4), 333-353.

Dorling, P. (2011). Diplomatic cables claim Australia has failed to stabilise 'fragile' Solomons. The Melbourne Age, August 30. Retrieved Sept, 2011 http://www.theage.com.au/world/diplomatic-cables-claim-australia-has-failedto-stabilise-fragile-solomons-20110829-1jih7.html

Doughton, S. (2011). Gates Foundation gives $\$ 20 M$ to BBC charity arm, Local News I Gates Foundation gives $\$ 20 \mathrm{M}$ to BBC charity. Seattle Times. Retrieved Sept, 2011 http://seattletimes.nwsource.com/html/localnews/201439313

Dragon, A. G. (2006). Knowledge, communication, development: A Perspective from Latin America. Development in Practice, 16(6), 593-602.

Dunn, K. (2010). Interviewing. In I. Hay (Ed.), Qualitative research methods in human geography (pp 101-137). 3rd ed. Ontario: Oxford University Press.

East-West Center. (2002). Transportation and security workshop attempts 'Talanoa'. Pacific Islands Report. University of Hawaii. Retrieved Nov, 2011 http://166.122.164.43/archive/2002/November/11-19-01.htm

Eko, L. (2007). Africa: Life in the margins of globalisation. In L. Artz \& Y.R. Kamalipour (Eds.). The media globe: Trends in international mass media. Lanham (pp 7-32), Maryland: Rowman \& Littlefield.

Ellingson, L. (2009). Engaging crystallization in qualitative research: An Introduction. Thousand Oaks, CA: Sage.

Escobar, A. (1992). Reflections on development: grassroots approaches and alternative politics in the Third World. Futures, 24(5), 411-36.

Escobar, A. (1995). Encountering Development: The making and unmaking of the third world. Princeton, NJ. Princeton University Press.

European Community. (2008). Country strategy paper and National Indicative Programme for period 2008- 2013. 
Eyben, R., \& Ferguson, C. (2005). How can donors become more accountable to poor people. In R. Groves \& L. Hinton (Eds.), Inclusive Aid: Changing power and relationships in International Development (pp. 108-122). London: Earthscan.

Fair, J. E. (1989). 29 years of theory and research on media and development: the dominant paradigm impact. International Communication Gazette 44(2), 129150.

Fairbairn-Dunlop, P., Mason, N., Reid, E., \& Waring, M. (2009). Pacific gender and aid effectiveness case study report 5. For New Zealand Agency for International Development (NZAID) Nga Hoe Tuputupu Mai-tawhiti and Australian Agency for International Development (AusAID). Retrieved May, 2011 http://www.ipp.aut.ac.nz/_data/assets/pdf_file/0013/110443/pacific-genderand-aid-effectiveness.pdf

Feek, W. (2006). Moving media: The case for the role of communications in meeting the MDGs. In M. Harvey (Ed.), Media Matters; Perspectives on advancing governance \& development (pp. 59-66). Internews Europe on behalf of the Global Forum on Media Development (GFMD). Retrieved Aug, 2010 http://www.internews.fr/Media-Matters-publication.

Feinberg, R. (1990). The Solomon Islands' tenth anniversary of Independence: Problems of national symbolism and national integration. Pacific Studies, 13(2), 19-40.

Field, M. (2010). Commentary: Journalists at risk: News media perspectives. The seduction of war - and when to take one step back. Pacific Journalism Review, 16(1), 49-67.

Finin, G., \& Wesley-Smith, T. (2001). Coups, conflicts and crises: The new Pacific way? Race \& Class 42, 1-16.

Firth, S. (2003). Future directions for Pacific studies. The Contemporary Pacific 15(1), 139-148.

Firth, S. (2006). Introduction. In S. Firth (Ed.), Globalisation and governance in the Pacific Islands (pp 1-6). ANU E Press. Retrieved Jan, 2011 http://epress.anu.edu.au?p=55871 
Firth, S. (2011). Culture and context in the teaching of Pacific history and politics. The Journal of Pacific History, 46(2), 207-213.

Fontana, A., \& Frey, H. (2008). The interview. In N. K. Denzin \& Y. S. Lincoln (Eds.), Collecting and interpreting qualitative materials (pp 61-81) (3rd ed). London: Sage.

Fraenkel, J. (2004). The manipulation of custom: From uprising to intervention in the Solomon Islands. Wellington: Victoria University Press.

Freille, S., Haque, M.E., \& Kneller, R. (2006). Contribution to the empirics of press freedom and corruption. European Journal of Political Economy, 23, 838-862.

Fry, G. (1997). Framing the islands: Knowledge and power in changing Australian images of "the South Pacific". The Contemporary Pacific, 9(2), 305-339.

Fry, G., \& Kabutaulaka, T. T. (2008). Intervention and state-building in the Pacific: The legitimacy of 'co-operative intervention'. Manchester: Manchester University Press.

Gallagher, P., Gounder, R., \& Lee, J. (2009). Trade policy capacity development for non state actors in the Pacific: Programme design. (NZAID Contract for services). Retrieved Aug, 2010 http://www.nzaid.govt.nz/programmes/r-pac-trade.html

Gegeo, D. (2001a). Cultural rupture and indigeneity: The challenge of (re)visioning "place" in the Pacific. The Contemporary Pacific, 13(2), 491-506.

Gegeo, D. (2001b). (Re)visioning knowledge transformation in the Pacific: A response to Subramani's "The Oceanic Imaginary". The Contemporary Pacific, 13(1), 178183.

Gegeo, D., \& Watson-Gegeo, A. (2001). “How we know”: Kwara'ae rural villagers doing indigenous epistemology, The Contemporary Pacific, 13(1), 55-88.

Ginsburg, F. (1991). Indigenous media: Faustian contract or global village? Cultural Anthropology, 6(1), 92-112.

Groves, L., \& Hinton, R. (2004). Inclusive aid: Changing power relationships in international development. London: Earthscan. 
Guba, E. G., \& Lincoln, Y. S. (1994). Competing paradigms in qualitative research. In N. K. Denzin \& Y. S. Lincoln (Eds.), Handbook of qualitative research. (105-117). Thousand Oaks, CA: Sage.

Hacket, R.A. (1984). Decline of a paradigm: Bias and objectivity in news media studies. Critical Studies in Media Communication, 1(3), 1984, 229-259.

Hameiri, S. (2007). The trouble with RAMSI: Reexamining the roots of conflict in Solomon Islands. The Contemporary Pacific, 19(2), Fall, 409-441.

Hameiri, S. (2009). State-building or crisis management? A critical analysis of the social and political implications of the Regional Assistance Mission to Solomon Islands. Third World Quarterly, 30(1), 35-52.

Harvey, M. (2006). Media Matters; Perspectives on advancing governance \& development. Internews Europe on behalf of the Global Forum on Media Development (GFMD). Retrieved Aug, 2010 http://www.internews.fr/MediaMatters-publication.

Hassall, G. (2010). Public leadership, political parties, and parliamentary performance in the Pacific Islands. Paper presented at the Institute of Policy Studies, Wellington.

Herman, E. S., \& Chomsky, N. (2006). A Propaganda Model. In M. Durham \& D. Kellner (Eds.), Media and Cultural Studies (pp 280-317). Revised Edition. Oxford: Blackwell Publishing.

Hoffman, D. (2006). Why media matters: Global perspectives. Information equality: The third revolution. In M. Harvey (Ed.), Media Matters; Perspectives on advancing governance \& development (pp 19-22). Internews Europe on behalf of the Global Forum on Media Development (GFMD). Retrieved Aug, 2010 http://www.internews.fr/Media-Matters-publication

Hollway, W., \& Jefferson, T. (2000). Doing qualitative research differently: Free association, narrative and the interview method. London: Sage.

Howard, R. (2003). International media assistance. A review of donor activities and lessons learned. Working Paper 19. Netherlands Institute of International 
relations. Retrieved Nov, 2010

http://gmc.sagepub.com/content/3/3/352.extract

Howell, J., \& Lind, J. (2009). Changing donor policy and practice in civil society in the post-9/11 aid context. Third World Quarterly 30, 1279-96.

Howenstine, E. (1991). 20 years of media and development in Latin America: Trajectories by canonical correlation. International Communication Gazette, 47(2), 107-120.

Hudock, A. (2003). Hearing the voices of the poor: Encouraging good governance and poverty reduction through media sector support. Retrieved Nov, 2010 unpan1.un.org/intradoc/groups/public/.../UNPAN027616.pdf

Hume, E. (2004). Media Missionaries: American support for journalism excellence and press freedom around the globe. John S. and James L. Knight Foundation. Miami, Fla. Retrieved Aug, 2010 http://www.ellenhume.org/articles/missionaries.html

Hume, E. (2006). Media Development: Mapping the media assistance sector. In M. Harvey (Ed.), Media Matters; Perspectives on advancing governance \& development (pp. 195-201). Internews Europe on behalf of the Global Forum on Media Development. Retrieved Aug, 2010 http://www.internews.fr/MediaMatters-publication.

Hviding, E. (2003). Between knowledges: Pacific Studies and academic disciplines. The Contemporary Pacific, 15(1), 43-73.

IMS. (2011). Report: International partnerships in progress. Retrieved Jan, 2012 http://www.i-m-s.dk/article/international-partnerships-progress-new-report

Kabutaulaka, T. (2005). Australian foreign policy and the RAMSI intervention in Solomon Islands. The Contemporary Pacific 17(2): 283-308.

Kabutaulaka, T. (2006). Parties, constitutional engineering and governance in Solomon Islands. In R. Rich (Ed.), Political Parties in the Pacific Islands (pp 103-116). Canberra: Pandanus Books, ANU. 
Kabutaulaka, T. (2008). Westminster meets Solomons in the Honiara riots. In S. Dinnen \& S. Firth (Eds.), Politics and state building in Solomon Islands (pp 96-118). Canberra: ANU Press.

Kaufmann, D. (2005). 10 myths about governance and corruption. World Bank Institute. Retrieved Oct, 2011 blogs.worldbank.org/psd/ten-myths-aboutgovernance-and-corruption.

Kilman, L. (2006). The role of the press in sustainable economic development. Paper presented at the UNESCO World Press Freedom Day conference, Colombo, Sri Lanka. Retrieved Oct, 2011 http//www.unesco.org/new/fileadmin/.../wpfd2006_WAN+Kilman.doc

Kwa'ioloa, M., \& Burt, B. (1997). Living tradition: a changing life in Solomon Islands. London: British Museum Press.

Lacey, A. (2011). Shifting the gaze, shifting the agenda: sustainable livelihoods in urban Honiara. Society for International Development, 54(3), 368-375.

Lacey, A. (2011b). Honiara, Solomon Islands: new urbanization challenges, a new development imagination? In UoA Centre for Development Studies Working Paper No. 4 June 2011. Retrieved Oct, 2011 http://www.palgravejournals.com/development/journal/v54/n3/full/dev201154a.html

Larmour, P. (2007). International action against corruption in the Pacific Islands: Policy transfer, coercion and effectiveness. Asian Journal of Political Science, 15(1), 116.

Lines, K. (2009). Governance and the media - A survey of policy opinion. Prepared for the BBC World Service Trust by the Fuse Group. Retrieved Aug, 2011 www.bbc.co.uk/worldservice/trust/.../governance_media_survey

Linton, R. (1936). The study of man. New York: Appleton Century Crofts.

Locksley, G. (2008). The media and development. What's the story? World Bank working paper; no. 158. Retrieved Aug, 2010 worldbank.org/INFORMATIONANDCOMMUNICATIONANDTECHNOLOGIES/Reso urces 
Louis, R. (2007). Can you hear us now? Voices from the margin: Using indigenous methodologies in geographic research. Geographical Research, 45(2), 130-139.

Lumina, C. (2011). Report of the Independent Expert on the effects of foreign debt and other related international financial obligations of States on the full enjoyment of all human rights, particularly economic, social and cultural rights. Mission to Australia and Solomon Islands: United Nations Human Rights Office of the High Commissioner for Human Rights. Retrieved Nov, 2011 ww.ohchr.org/EN/Issues/Development/IEDebt/Pages/AnnualReports.aspx

McCormack, T. (2011). Human security and the separation of security and development. Conflict, Security \& Development, 11(2), 235-260.

Mcloughlin, C., \& Scott, Z. (2010). Topic Guide on Communications and Governance. Birmingham: University of Birmingham.

McKinnon, K., Gibson, K., \& Malam, L. (2008). Introduction: Critical and hopeful area studies - Emerging work in Asia and the Pacific. Asia Pacific Viewpoint, 49(3), 273-280.

Maebuta. J., \& Spence, R. (2009). Reflection on peace practice project. Cumulative impact case study. Attempts at building peace in the Solomon Islands: disconnected layers. CDA Collaborative Learning Projects in Cambridge, Massachusetts. Retrieved Dec, 2011 www.cdainc.com

Mansell, R., \& Nordenstreng, K. (2006). Great media and communication debates: WSIS and the MacBride Report. Information technologies and international development, 3(4), 15-36.

Moala, K. (2007). Media as a tool for national development. In E. Wood-Ellem (Ed.), Tonga and the Tongans: Heritage and identity (pp.235-248). Alphington: Tonga Research Association.

Melkote, S., \& Steeves, H. L. (2001). Communication for development in the third world. Theory and practice for empowerment (2nd ed.). Thousand Oaks: Sage.

MFAT. (2011). Solomon Islands overview. Retrieved Sept, 2011 http://www.mfat.govt.nz/Countries/Pacific/Solomon-Islands.php 
Mikkelsen, B. (2005). Methods for development work and research: A new guide for practitioners. New Delhi: SAGE Publications.

Miller, N. (2003). Media assistance post the Taliban regime and the implications for transforming the Afghan social system. Retrieved Jan, 2011 www.stanhopecentre.org/research/mdps_afghanistan.doc

Miller, J. (2009). NGOs and 'modernization' and 'democratization' of media. Global Media and Communication, 5(1), 9-33.

Molnar, H. (1995). Indigenous media development in Australia: A product of struggle and opposition. Cultural Studies, 9(1), 169-190.

Moore, C. (2007a). Helpem Fren. The Journal of Pacific History, 42(2), 141-164.

Moore, C. (2007b). The misappropriation of Malaitan labour. The Journal of Pacific History, 42(2), 211-232.

Moore, C. (2007). External Intervention: The Solomon Islands beyond RAMSI. In A. M. Brown (Ed.), Security and Development in the Pacific Islands: Social Resilience in Emerging States (pp. 169-196). Boulder, Colorado: Lynne Rienner

Moore, C. (2008). Biography of a nation: compiling a historical dictionary of the Solomon Islands. In V. Luker \& B. Lal (Eds.), Telling Pacific lives: prisms of process (pp. 277-292). Canberra ACT, Australia: ANU E Press.

Mullings, B. (1999). Insider or outsider, both or neither: some dilemmas of interviewing in a cross-cultural setting. Geoforum, 30(4), 337-350.

Murray, W. E., \& Storey, D. (2003). Political conflict in postcolonial Oceania. Asia Pacific Viewpoint, 44(3), 213-224.

Murray, W., \& Overton, J. (2003). Designing development research. In R. Scheyvens \& D. Story (Eds.), Development fieldwork: A practical guide (pp 17-35). London: Sage Publications.

Mutu, M. (2004). Researching the Pacific. In T. Baba, O. Mahina, N. Williams \& U. Nabobo-Baba (Eds.). Researching Pacific and indigenous peoples: issues and perspective (pp 186 - 200). Auckland: University of Auckland. 
Myers, M. (2009). Funding for Media Development by major donors outside the United States. Center for International Media Assistance and National Endowment for Democracy. Retrieved Aug, 2010 cima.ned.org/research-reports/fundingmedia-devlopement

Nabobo-Baba, U. (2004). Research and Pacific indigenous peoples: Silenced parts and challenged futures. In T. Baba, O. Mahina, N. Williams \& U. Nabobo-Baba (Eds.), Researching Pacific and indigenous peoples: issues and perspectives (pp 17-32). Auckland: University of Auckland.

Naidu, V. (1995). Whose sea of islands? In E. Waddell, V. Naidu \& E. Hau'ofa (Eds.), A new Oceania: Rediscovering our sea of islands ( $\mathrm{pp}$ 49-55). Suva: University of the South Pacific.

Noblit, G. (2011). Book Review: Engaging crystallization in qualitative research: An introduction. Qualitative Research, 11(4). 453-454.

Norris, P. (2006). The role of the free Press in promoting democratization, good governance and human development. In M. Harvey (Ed.), Media Matters; Perspectives on advancing governance \& development (pp. 66-76): Internews Europe on behalf of the Global Forum on Media Development (GFMD). Retrieved Aug, 2010 www.internews.fr/Media-Matters-publication. .

Nyamnjoh, F. B. (2005). Africa's media, democracy and the politics of belonging. London: Zed Books.

Odugbemi, S., \& Norris, P. (2010). Policy recommendations. In P. Norris (Ed.), Public Sentinel: News media \& governance reform. The International Bank for Reconstruction and Development / The World Bank. Retrieved Nov, 2011 issuu.com/world.bank.publications/docs/9780821382004

OECD. (2008). Part 2: Enhancing the Delivery of Justice and Security, OECD Journal on Development, 8(3), 107-177.

OECD. (2009). DAC Peer Review of Australia. OECD Journal on Development, 10(2), 147-260. 
O'Leary, Z. (2010). The essential guide to doing your research project (2nd ed.) Los Angeles; London: Sage

Overton, J., \& Murray, W. (2011). Neoliberalism is dead, long live neoliberalism? Progress in Development Studies 11(4), 307-19.

Owusu, C. (2004). An international NGO's staff reflections of power, procedure and relationships. In R. Groves \& L. Hinton (Eds.), Inclusive aid: Changing power and relationships in international development (pp. 108-122). London: Earthscan.

Pacific Freedom Forum. (2011). Solomon Islands: Police action urged on 75,000 compensation demand. Retrieved Nov, 2011 http://www.pacificfreedomforum.org/2011/09/no-place-for-compensationthreats.html

Peters, B. (2010). The future of journalism and challenges for media development. Journalism Practice, 4(3), 268-273.

Petras, J. F., \& Veltmeyer, H. (2005). Empire with imperialism: The globalizing dynamics of neo-liberal capitalism. London: Zed Books.

Pieterse, J. (1996). The development of development theory: Towards critical globalism. Review of International Political Economy, 3(4), 541-564.

Pieterse, J. (2009). Development theory. Deconstruction/Reconstruction. London: Sage Publication.

Plimmer, N. (2009). Policies to our Pacific neighbours' need to take a long view. [Editorial]. Future Times, 3, 2-3.

Putzel, J., \& van der Zwan, J. (2007). Why Templates for Media Development do not work in Crisis States: Defining and understanding media development strategies in post-war and crisis states. LSE Crisis States Research Centre (CSRC), London. Retrieved April, 2011 http://eprints.Ise.ac.uk/837/

Pye, L. (1963). Communication and Political Development. Princeton: Princeton University Press.

Robie, D. (2008). Frontline reporting, ethos and perception: Media challenges in the South Pacific. Asia Pacific Viewpoint, 49, 213-227. 
Robbins, J., \& Wardlow, H. (2005). The making of global and local modernities in Melanesia: humiliation, transformation and the nature of cultural change: Aldershot: Ashgate.

Rogers, A. (2006). Participatory diffusion or semantic confusion? In M. Harvey (Ed.), Media Matters; Perspectives on advancing governance \& development (pp. 180-201). Internews Europe on behalf of the Global Forum on Media Development. Retrieved Aug, 2010 http://www.internews.fr/Media-Matterspublication.

Rohde, D. (2005). All successful democracies need freedom of speech: American efforts to create a vibrant free press in Iraq and Afghanistan. Retrieved Aug, 2010 http://www.ksg.harvard.edu/presspol/Research_Publications/ Papers/Working_Papers/2005_6.pdf

Rose-Ackerman, S. (2006). International handbook on the economics of corruption. Cheltenham: Edward Elgar Publishing.

Rosser, A. (2008). Neo-liberalism and the politics of Australian aid policy-making. Australian Journal of International Affairs, 62(3), 372--385.

Rostow, W. W. (1971). The stages of economic growth. A non-communist manifesto (2nd ed.). Cambridge: Cambridge University Press.

Roulston, K. (2010). Considering quality in qualitative interviewing. Qualitative Research 10(2), 199-228.

Rush, D. et al. (2011, July 22). Phone hacking: how NoW scandal has changed UK's image in the world. The Guardian. Retrieved Aug, 2011 http://www.guardian.co.uk/media/2011/jul/22/phone-hacking-scandal-rupertmurdoch

Sachs, W. (1997). The development dictionary: A guide to knowledge as power. Johannesburg: Witwatersrand University Press.

Sahlins, M. (2005). On the anthropology of modernity, or some triumphs of culture over despondency theory. In A. Hooper (Ed.), Culture and Sustainable Development in the Pacific (pp 44-61). Canberra: ANU E Press. 
Scales, I. (2007). The coup nobody noticed. The Journal of Pacific History, 42(2), 187209.

Scheyvens, R., \& Storey, D. (2003). Development fieldwork: a practical guide. London: Sage.

Scheyvens, R., Scheyvens, H., \& Murray, W. (2003). Working with marginalised, vulnerable or privileged groups. In R. Scheyvens \& D. Storey (Eds.), Development fieldwork: A practical guide (pp 167-194). London: Sage.

Schindowski, D. (2004). The implications of the constitutional reform from an economic point of view. United Nations Development Programme (UNDP) consultancy. Retrieved Sept, 2011 www.vanuatu.usp.ac.fj/library/Paclaw/Solomonlslands/SIConstitutionDraftIMP .pdf

Schwandt, T. A. (2007). The Sage Dictionary of Qualitative Inquiry (3rd ed.). London: Sage.

Sen, A.K. (1994). Liberty and poverty: Political rights and economics. The New Republic, (210), 31-37.

Sen, A. K. (1999). Development as freedom. Oxford: Oxford University Press.

Shome, R., \& Hegde, R. S. (2002). Postcolonial Approaches to communication: Charting the terrain, engaging the intersections. Communication Theory, 12(3), 249-270.

Silverman, D. (2009). Doing Qualitative Research. London: Sage.

Sipolo, J. (1986). Praying Parents. Honiara: Aruligo Book Centre.

Sireheti, J. (2008). Solomon Islands Media Assistance Scheme Launched. Dec 8. Solomon Times Online . Retrieved Aug, 2011 http://www.solomontimes.com/news.aspx?nwID=3174

Slatter, C. (2006). Neo-liberalism and the disciplining of Pacific Island states-The dual challenge of a global economic creed and a changed geopolitical order. In M. Powles, (Ed.) Pacific Futures (pp 91-110). Canberra: Pandanus Books. 
SOLMAS. (2010). Audience Market Research in Solomon Islands. Qualitative and Quantitative Research Report. Retrieved Nov, 2011 www.ausaid.gov.au/foi/pdf/solmas-report.pdf

Solomon Star (2011). Finalisation workshop held. Published Friday 10 June 2011 p. 2. Solomon Star (2011). MASI denounced compensation demand on Island Sun. Retrieved Oct, 2011 http://www.solomonstarnews.com/news/national/12355-masidenounced-compensation-demand-on-island-sun-newspaper

Steeves, J. (2011). "Unbounded politics" and the democratic model in Solomon Islands: the 2010 national elections, Commonwealth \& Comparative Politics, 49(3), 342-358.

Storey, D., Bulloch, H., \& Overton, J. (2005). The poverty consensus: some limitations of the 'popular agenda'. Progress in Development Studies, 5(1), 30-44.

Sullivan, S., \& Brockington, D. (2004). Qualitative methods in globalisation studies: or, saying something about the world without counting or inventing it. CSGR Working Paper No 139/04. Warwick: University of Warwick.

Sumner, A. (2006). What is Development Studies? Development in Practice, 16(6), 644650.

Tcherkezoff, S. (2003). A long and unfortunate voyage towards the 'invention' of the Melanesia/Polynesia distinction 1595-1832. The Journal of Pacific History, 38(2), 175-196.

Thomas, S. (2004). "Euphoria in the Pacific?" Regional economic partnership agreements - Implications for the Pacific. Paper presented at the New Zealand Asia Pacific European Studies Association Conference, Christchurch Arts Centre. Retrieved April, 2011 www.europe.canterbury.ac.nz/conferences/apeu2004/papers/thomas

Thaman, K. (2008). Nurturing relationships and honouring responsibilities: A Pacific Perspective. International Review Of Education / Internationale Zeitschrift Für Erziehungswissenschaft, 54(3/4), 459-473. 
Tracy, S. (2010). Qualitative quality: Eight "Big-Tent" criteria for excellent qualitative research. Qualitative Inquiry, 16(10), 837-851.

Tuhiwai Smith, L. (1999). Decolonizing methodologies research and indigenous people. Dunedin: University of Otago Press.

Tuhiwai Smith, L. (2004). Building research capability in the Pacific, for the Pacific and by Pacific peoples. In T. Baba, O. Mahina, N. Williams, U. Nabobo-Baba (Eds.), Researching Pacific and indigenous peoples: issues and perspectives (pp. 4-16). Centre for Pacific Studies. Auckland: University of Auckland.

Ulrich, O. (1997). Technology. In W. Sachs (Ed.), The development dictionary: A guide to knowledge as power (pp 275-287) (7th ed.). Johannesburg: Witwatersrand University Press.

UNDP. (1997). Governance for sustainable human development. A UNDP policy document. Retrieved Nov, 2010 http://mirror.undp.org/magnet/policy/chapter1.htm

UNDP. (2012). Solomon Islands: Retrieved Jan, 2011 data.un.org/countryprofile.aspx?Solomon Islands\#Summary

UNESCO. (2005). E-governance capacity. Good Governance. Retrieved April, 2011 http://portal.unesco.org/ci/en/ev.phpURL_ID=5205\&URL_DO=DO_TOPIC\&URL_SECTION=201.html

UNESCO. (2007). Model curricula for journalism education for developing countries \& emerging democracies. Retrieved March, 2011 http://unesdoc.unesco.org/images/0015/001512/151209E.pdf

UNHCR. (2004). Committee to protect journalists: Attacks on the press in 2003 Solomon Islands. Retrieved Sept, 2011 http://www.unhcr.org/refworld/docid/47c566b833.html

Urwin, G. (2007). Keynote address Pasifika Project. Paper presented at the Secretary General. Pacific Islands Forum Secretariat, Auckland, New Zealand. Retrieved March, 2011 ps.ac.nz/publications/files/6e752be83cb.pdf 
Va'ai, S. (2005). Pacific utopias and national Identities in the twenty-first century. Portal Journal of Multidisciplinary International Studies, 2(2), 1-23.

Wainwright, E. (2003). Our failing neighbour: Australia and the future of Solomon Islands. Canberra: Australian Strategic Policy Institute. Retrieved April, 2011 www.foreignminister.gov.au/speeches/.../030610_solomonislands.ht

Wainwright, E. (2003b). Responding to state failure-the case of Australia and Solomon Islands, Australian Journal of International Affairs, 57(3), 485-498.

Wolfensohn, J. D. (1999, Nov 10). Voices for the Poor. Washington Post. Retrieved from http://chora.virtualave.net/voicesofthepoor.htm

World Bank. (2011). Solomon Islands: Providing short-term employment for Honiara's urban poor. Retrieved Oct, 2011 http://web.worldbank.org/WBSITE/EXTERNAL/NEWS/0,,contentMDK.html. 


\title{
APPENDIX ONE: PARTICIPANTS' INFORMATION ON RESEARCH
}

\section{(ENGLISH)}

\author{
Title of project: Power, Media and Development \\ Researcher: Adele Broadbent, School of Geography, Environment and Earth Sciences, \\ Victoria University of Wellington
}

\section{Greetings.}

My name is Adele and I am completing my Masters in Development Studies at Victoria University of Wellington. As part of this degree I am undertaking a research project leading to a thesis. The project is examining the influence of donors (i.e. countries giving financial aid and development to countries) on the news media and the people of that country.

As this research requires talking to people in the Solomon Islands, the University requires that ethics approval be obtained.

I will be talking to journalists, editors, members of Civil Society (as in advocacy Non Government organisations), and the public about the above subject. Participants will be asked to speak with me on tape so I can later transcribe and make research notes from what I learn. Interviews should take no longer than three hours. Participation is voluntary and participants do not have to answer all questions and can stop interviews at any stage.

Should any participants feel the need to withdraw from the project, they may do so without question at any time before the data is analysed. Just let me know at the time.

Responses collected will form the basis of my research project and will be put into a written report by April 2012. I would like to name the media professionals although they may remain anonymous if they prefer. Members of the public will remain anonymous. Professionals will be given the choice of confidentiality.

The thesis will be submitted for marking to the School of Geography, Environment and Earth Sciences, and deposited in the University Library. It is intended that one or more articles will be submitted for publication in scholarly journals. Tapes and research notes will be destroyed five years after the end of the project.

If you have any questions or would like to receive further information about the project, please contact me, Adele Broadbent, at the School of Geography, Environment and Earth Sciences, Victoria University of Wellington, Office phone: 04 4635233 Extn 8916, Mobile: 027576 4644, broadbadel@myvuw.ac.nz or my supervisor, Dr John Overton, at the School of Geography, Environment and Earth Sciences, Victoria University, P O Box 600, Wellington, ph: 044635281.

Yours sincerely.

Adele Broadbent 


\title{
APPENDIX TWO: PARTICIPANTS' INFORMATION ON RESEARCH (PIDGIN)
}

\author{
Title of project: Power Media and Development \\ Researcher: $\quad$ Adele Broadbent, School of Geography, Environment and Earth \\ Sciences, Victoria University of Wellington
}

Halo olketa

Nem blong mi Adele. Mi wanfala student blong Victoria University long Wellington long New Zealand. Distaem mi waka long Masters long Development Studies. Masters hem kaen pepa wea iu save duim afta iu finisim degree blong iu long university. Fo mi finism Masters blong $\mathrm{mi}$, mi nid fo duim nao wanfala research project wea long end blong hem bae mi raetim wanfala bigfala ripot. Disfala project hem lukluk long paoa blong olketa donors (olsem olketa kantri wea gigivim seleni for helpim eni narafala kantri). Hem lukluk long paoa wea olketa karem long nius long pepa an long TV an long olketa pipol wea stay long kantri tu olsem olketa pipol long Solomon Islands.

Fo duim disfala research mi nid fo stori wetem samfala pipol long Solomon Islands so mi nid fo askim approval blong ethics committee long University. Waka blong ethics committee hem fo mek sua dat mi duim gudfala research an mi tritim gud olketa pipol wea helpim mi long research blong $\mathrm{mi}$.

Bae mi tok abaotim research blong mi wetem olketa waka man long niuspepa an TV wea olketa raetim olketa nius stori an bae mi tok wetem ota waka man blong Civil Society (olsem olketa man wea waka fo ota bisnis wea no blong gavman but helpem olketa pipol blong kantri). Bae mi tok tu wetem olketa nomal pipol blong Solomon Islands wea no duim eni kaen waka olsem. Bae mi tok long olketa evriwan abaotim research blong mi. Bae mi askim evriwan sapos hem oraet sapos mi ricodim olketa long masini mekim mi save herim bak stori blong olketa bihaen an raetim samfala notes abaotim wat mi lanem. Sapos eniwan laek fo stori wetem $\mathrm{mi}$ abaotim research blong mi hem tiois (choice) blong hem seleva nomoa. Sapos olketa man willing fo tok but samfala questions olketa les fo ansam hem oraet nomoa. Olketa save stopim stori blong mi enitaem nomoa an no nid fo givim eni rison long $\mathrm{mi}$.

Sapos eniwan wea helpim mi long disfala research disaed hem no laek fo tek part long research bae hem save talem mi lo eni taem bifo mi stat fo waka long olketa information. Bae hem no need fo givim eni rison nomoa.

Olketa information wea bae mi tekim long olketa stori bae hem mekim up ripot blong mi bifo April long 2012. Mi laek fo talem long report blong mi olketa nem blong olketa man waka long niuspepa an TV but sapos olketa les fo mi talem aot nem blong olketa bae mi no talem. Olketa pipol wea no duim kaen waka olsem bae mi no talem nem blong olketa. Olketa professional pipol bae save chus nomoa fo mi talem nem blong olketa or nomoa. 


\title{
APPENDIX THREE: CONSENT TO PARTICIPATION IN RESEARCH (ENGLISH)
}

Title of project: Power Media and Development

Researcher: $\quad$ Adele Broadbent, School of Geography, Environment and Earth Sciences, Victoria University of Wellington

\begin{abstract}
+ I have read the Participant Information Sheet and understand the purpose of this research project.

+ I understand the interview will be electronically recorded and any notes or recorded material from interviews will be destroyed at the end of the research process.

+ I understand I can choose not to be electronically recorded.

+ I understand I have the right not to answer any question put to me.

+ I understand that all information I provide will be safely stored accessed only by the researcher and research supervisor.

+ I understand I will have an opportunity to see a summary of the research.

+ I understand I may withdraw myself, and any information I have provided, from this research project without explanation during the interview or at any time before 1 December 2010.

+ I understand the results of this research will be included in a thesis and may be used for publication in academic or professional journals, and for dissemination at academic or professional conferences.
\end{abstract}

I agree to take part in this research.

Please tick as appropriate:

I would like to receive a summary of the results of this research when it is completed.

I consent to my name being used when my comments or opinions are used in this research.

or

I request that my name be omitted and a pseudonym assigned by the researcher be used if my comments or opinions are included in this research.

I consent to the name of the organisation I work for being used in this research.

or

I request the name of the organisation I work for to be omitted from this research.

Name:

Date:

Organisation:

Email:

Signed: 


\title{
APPENDIX FOUR: CONSENT TO PARTICIPATION IN RESEARCH (PIDGIN)
}

Title of project: $\quad$ Power Media and Development

Researcher:

Adele Broadbent, School of Geography, Environment and Earth Sciences, Victoria University of Wellington

\begin{abstract}
+ Mi ridim finis Information Sheet blong olketa Participant an mi undastandim gud wat nao reason fo duim disfala research project.

+ Mi minim dat disfala interview bae iu ricodim lo masini an long pepa an olketa notes wea iu raetim an recordim bae iu putim long rabis taem research hem finis.

+ Mi minim dat mi save talem iu sapos mi no laek fo iu ricodim toktok blon mi long masini.

+ Mi minim dat mi save talem iu mi no laek ansam eni question wea iu askim kam long mi.

+ Mi minim dat evri information wea bae mi givim long iu bae iu kipim gud an bae iutufala boss blo iu long research nao bae save lukim.

+ Mi minim dat bae mi karem tians (chance) fo lukim wanfala summary blong disfala research

+ Mi minim dat bae mi save talem iu dat mi no laek fo join in long disfala research an mi no laek fo iu usim eni information or toktok wea mi bin talem long iu. Sapos mi laek fo duim datwan mi minim tu dat bae mi no nid fo givim eni rison long iu an mi save duim long taem wea iumitufala stori or eni taem gogo kasem namba wan Disema 2011

+ Mi minim dat olketa tings wea iu findim out taem iu duim disfala research bae iu usim fo pepa blong iu an mebi bae hem bikam part lo eni journal blo olketa professionals an academics. Mi minim tu dat mebi bae iu sharim olketa result tu wetem olketa nara pipol lo eni conference or miting blong iufala professionals long disfala area.
\end{abstract}

Mi hapi fo tek part long disfala research an mi aloim iu fo usim toktok an information wea bae mi givim long iu

Plis mekim mak sapos iu laekim eniting long hea:

Mi laek fo iu givim long mi wanfala summary blong olketa result blong disfala research

Mi hapi fo iu usim nem blong mi taem iu shoim eni toktok blong mi long disfala research or sapos nomoa

Mi no laek fo iu usim nem blong mi taem iu shoim eni toktok blong mi long disfala research. lu save shoim eni nem wea no ril nem blong mi but no can usim ril nem blong $\mathrm{mi}$.

Mi hapi fo iu usim nem blong waka blong mi tu long disfala research or sapos nomoa

Mi no laek fo iu usim nem blong waka blong mi long disfala research

Date:

Nem blong mi: Email:

Waka blong mi:

lu nid fo saenim nem blong iu long hea 


\section{APPENDIX FIVE: CODING FOR CONTRIBUTORS}

\begin{tabular}{|c|c|c|c|}
\hline CONTRIBUTOR & $\begin{array}{l}\text { NAME OR } \\
\text { PROFESSIONAL } \\
\text { GROUP }\end{array}$ & ORGANISATION & $\begin{array}{l}\text { AREA OF } \\
\text { KNOWLEDGE }\end{array}$ \\
\hline $\mathrm{J} 1$ & Journalist & & \\
\hline $\mathrm{J} 2$ & Journalist & & \\
\hline $\mathrm{J} 3$ & Journalist & & \\
\hline $\mathrm{J} 4$ & Journalist & & \\
\hline NGO 1 & $\begin{array}{l}\text { Non government } \\
\text { organisation }\end{array}$ & & \\
\hline NGO 2 & $\begin{array}{l}\text { Non government } \\
\text { organisation }\end{array}$ & & \\
\hline NGO 3 & $\begin{array}{l}\text { Non government } \\
\text { organisation }\end{array}$ & & \\
\hline NGO 4 & $\begin{array}{l}\text { Non government } \\
\text { organisation }\end{array}$ & & \\
\hline $\mathrm{JM}$ & Jully Makini & & Published poet \\
\hline TW & Tom Woods & & $\begin{array}{l}\text { Former } \\
\text { Constitutional } \\
\text { adviser to the } \\
\text { Solomon Islands } \\
\text { government }\end{array}$ \\
\hline $\mathrm{CF}$ & Coralie Ferguson & $\begin{array}{l}\text { General Manager - } \\
\text { SOLMAS }\end{array}$ & \\
\hline $\mathrm{WN}$ & Walter Malau & $\begin{array}{l}\text { Executive Officer } \\
\text { Transparency } \\
\text { Solomon Islands }\end{array}$ & \\
\hline $\mathrm{MK}$ & Michael Kwa'iola & & $\begin{array}{l}\text { Chief and Kastom } \\
\text { commentator - } \\
\text { Michael Kwa'iola }\end{array}$ \\
\hline
\end{tabular}




\section{APPLENDIX SIX: WOMEN'S FOCUS GROUPS}

\section{GROUP ONE \\ Q. 1. WHAT NEWS DO YOU NEED TO KNOW ABOUT THAT IS IMPORTANT TO THE VILLAGE?}

1. COMMUNICATION - cell phone tower coming and cell phones generally as the clinic has coverage sometimes and the mission five hours walk to the south 2. ROADS - is the road clear for tractors (four tractors have been bought for the area but not delivered). Also rivers, as they rise to unpassable.

3. WATER SUPPLY AND SANITATION - aware not good to use the beach heads as toilets but only three or four flush toilets in village of upwards 40 leaf houses.

4. EDUCATION

5. HEALTH - doctors come infrequently so important to know simple knowledge.

6. TRAINING CENTRE FOR COMMUNITY, TRAINING MATERIALS - there is a lot of knowledge held in the village, men and women know a lot but need a venue or a community hall and resources to give talks.

7. GENERATING INCOME ACTIVITIES FOR YOUTHS - when youths in the village are not occupied they produce homebrews and trouble so need activities to make money.

8. ENVIRONMENTAL EFFECT - high-level seas, rain, flooding rivers. Things are changing and we have to keep watching.

\section{Q.2. WHAT NEWS DOES THE VILLAGE WANT OR NEED TO KNOW ABOUT FROM HONIARA?}

1. OUR CHILDREN IN TOWN - education, school fees, how are they doing, are they sick?

2. NEWS ABOUT EARTHQUAKES FOR EXAMPLE TE MOTU - listen to radio news from Honiara for problems here

3. REPRESENTATIVES IN PARLIAMENT - especially planning and development at ward level.

4. SHIPING SCHEDULE - problem with ships not coming, waiting with harvested food.

5. CHURCH NEWS/PROGRAM - when is the pastor is coming?

6. RESOURCE PEOPLE e.g AGRICULTURE - want to know when trainers are coming.

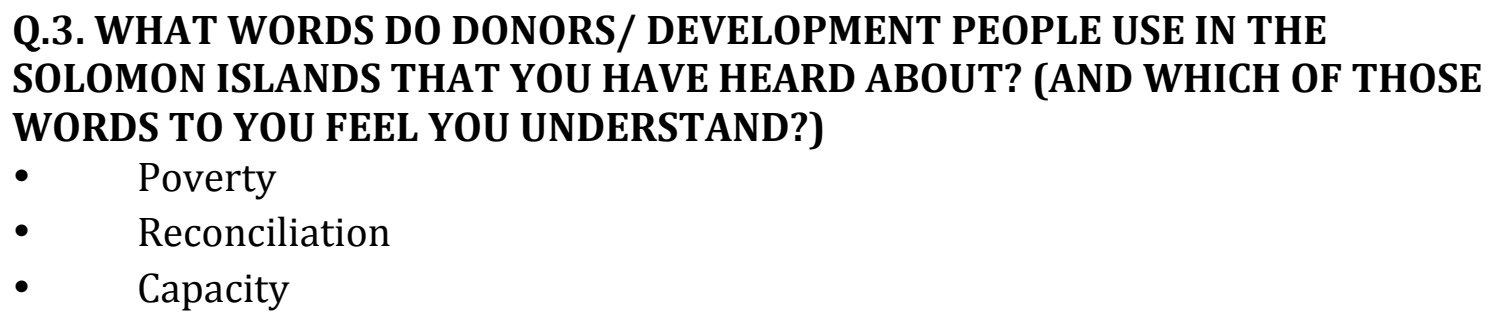


- Solar + windmills $\sqrt{ }$

- Journalist

- $\quad$ Satellite

- Communication

- Sanitationv

- Health $\sqrt{ }$

- Immunisation (knew injection)

- Diabetes $\sqrt{ }$

- Hyper-tension

- Heart attack

- Scholarship

- Yellow fever

- $\quad$ Literacy

- Starvation

- Politics

- Conservation

- Environment

- Tsunami

- Corruption $\sqrt{ }$

- Geology

- $\quad$ Sensitive

- UN

- World Bank

- $\quad$ NZAID

- $\quad$ AUSAID

\section{GROUP TWO}

Q.1.

1. HEALTH - to know that they have to be health and the types of food for different ages.

2. GOOD ROAD - cleared for tractors to make it to market in Marau and export

3. GOOD SANITATION

4. GOOD COMMUNICATION - CELLPHONE TOWER

5. GOOD WATER SUPPLY - ways to improve. Only men do plumbing women should also on pipes.

6. GOOD COUNSELLING FOR YOUNG

7. GOOD PEOPLE - know who is depressed and stressed, marijuana causing mental illness/instability.

8. GOOD HOUSING - know skills to build and be good carpenters.

9. GOOD EDUCATIONPLANNING FOR RAINY SEASONS - a lot of thinking and planning because seasons are quite hard --- kastom gardens need to prepared in the dry season from Sept - March- 


\section{Q.2.}

1. WANTOK - illnesses and news about the children and their holidays.

2. POLITICS CURRENT MEETINGS - who's in power and what are they doing.

3. CURRENCY - changes in case have to get rid of old money.

4. COPRA AND COCA PRICES - when the price is down.

5. CRIMINAL ACTION - what's going on, any children in trouble, new penalties?

6. SPORTS - many boys in soccer.

7. SHIPPING INFORMATION - when the ships are going to come.

8. MARKETING REPORTS - price of vegetables and crops.

9. PROVINCIAL GOVERNMENT- what did the representative in Guadalcanal do for the people?

10. WEATHER REPORT WHAT HAPPENS AT THE OTHER ISLANDS - cyclone report, tsunami.

11. DISEASE BREAK OUT - prevention and news of relatives.

12. NEW POLICIES / LAWS - many policies and laws, property law and domestic violence.

13. VOLUNTEERS FLYING BUILDERS IN SCHOOLS CLINIC ETC - overseas volunteers and when they come so can prepare.

Q.3.

- $\quad$ POVERTY $\sqrt{ }$ (people don't have water or food or clothes but not here)

- UNEDUCATED

- $\quad$ PRIMITIVE

- VIRUS

- THEOLOGY (from pastors)

- TECHNOLOGY

- ?

- HYDRO

- CONSERVATION

- NGO - NPF NATIONAL PROVIDENT FUNDV

- UN WHO

- UNDP

- $\quad$ BACHELOR knew something to do with university

- SCHOLARSHIP

- DECREE DEGREE

- UNIVERSITY $\sqrt{ }$

- BIOLOGIST

- $\quad$ HYPOCRIPE (hypocrite from bible)

- $\quad$ CRAZY

- HORRIBLE

- UGLY

- $\quad$ CHEMISTRY 
- $\quad$ BIBLICAL

- $\quad$ PYSICS (physics)

- TOXIC

- $\quad$ CHRONIC

\section{GROUP THREE}

Q.1.

1. WATER SUPPLY - makes things easier for women and children for cooking and cleaning.

2. ROAD - tractors coming and track needs to be kept clear.

3. SCHOOL - education in village.

4. HEALTH - to be safe from diseases.

5. COMMUNICATION - access to mobiles through cell phone tower..

6. FISHING - protein for villagers.

7. HALL - meeting for discussion and workshops.

8. GOOD HOUSE - build and repair houses.

9. CLEANLINESS - keep safe from sickness.

10. GARDENING - need to know how to plan for wet and dry seasons so food doesn't run out. People cannot live without food.

\section{Q.2.}

1. SCHOOL CHILDREN

2. MONEY (COPRA, COCOA)

3. FIGHTING - heard a lot of fighting in Honiara, who kills someone who diedworried some of the children involved

4. GOVERNMENT

5. MARKET

6. SOCCER

7. NEWS

Q.3.

$\begin{array}{ll}\text { - } & \text { SANITATION } \sqrt{ } \\ \text { - } & \text { MIGRATION } \\ \text { - } & \text { HIVUS } \\ \text { - } & \text { JOURNALIST } \sqrt{ } \\ \text { - } & \text { RESEARCH } \sqrt{ } \\ \text { - } & \text { VULNERABLE } \\ \text { - } & \text { ELECTRICITY } \sqrt{ } \\ \text { - } & \text { ETHNIC } \\ \text { - } & \text { VACCINE } \\ \text { - } & \text { VACINATION }\end{array}$


- $\quad$ SCHOLARSHIP

- EXPLOSION

- BIAS

- $\quad$ CONFLICT OF INTEREST

- GENDER

- VIOLENCEV

- CORRUPTIONV

- ILLETERATE

- DICTATOR

- STUBBORN

- $\quad$ ECO TOURISM

- $\quad$ SHORT WAVE

- $\quad$ MEDIUM WAVE

- POVERTY

- $\quad$ CONTESTANT 


\section{APPENDIX SEVEN: MEN'S FOCUS GORUPS}

\section{GROUP ONE}

\section{Q. 1. WHAT NEWS DO YOU NEED TO KNOW ABOUT THAT IS IMPORTANT TO} THE VILLAGE?

1. ACCIDENTS

2. PRICE FLACTUATING IN HONIARA

3. POLITICS - instability both provincial and parliament.

4. SHIPPING INFORMATION

5. SCHOOL CHILDREN - living with guidance.

6. SPORT NEWS

7. WHAT IS HAPPENING - around the country around the world on TV.

8. SICKNESS /AIDS - number of people affected.

9. DO ANY NEW SICKNESSES ARRIVE IN THE COUNTRY?

10. TOWN BOUNDARY

11. ECONOMY IN THE COUNTRY

12. SOCIAL PROBLEMS IN URBAN - often might affect family members /relatives.

13. CURRENCY

14. WE NEED TO KNOW ABOUT RELATIVES LIVING IN HONIARA

15. LAND ISSUES IN HONIARA

16. POPULATION IN HONIARA

17. HOW GOVERNOR PARDONS PRISONERS

\section{Q.2. WHAT NEWS DOES THE VILLAGE WANT OR NEED TO KNOW ABOUT}

\section{FROM HONIARA?}

1. CLIMATE CHANGE

2. POPULATION INCRASE

3. LANGUAGE CHANGES

4. TRANSPORT BY LAND AND SEA

5. DEVELOPMENT

6. EDUCATION

7. HEALTH

8. ECONOMY

9. DISASTER

10. SPORT

11. TIME MANAGEMENT

12. FOOD SHORTAGE

13. SOCIAL SECURITY'

14. LIFE STYLE CHANGES 
15. DRUG ABUSE

16. COMMUNCIATION

17. POOR SANITATION AND WATER SUPPLY

18. STANDARD OF LIVING POOR

19. AGRICULTURAL IMPROVEMENT

20. TEENAGE PREGNANCE AND MARRIAGE

21. CULTUAL VALUES

\section{Q.3. WHAT WORDS DO DONORS/ DEVELOPMENT PEOPLE USE IN THE} SOLOMON ISLANDS THAT YOU HAVE HEARD ABOUT? (AND WHICH OF THOSE WORDS TO YOU FEEL YOU UNDERSTAND?)

- THIRD WORLD COUNTRY

- $\quad$ PRIMITIVE

- UNCIVILISED

- $\quad$ TRANSPARENCY AND ACCOUNTABILITY

- CIVILISATION

- COUNTERPARTS

- $\quad$ PUBLIC SERVANTS

- INTERNATIONAL MARKET

- INTERNATIONAL TRENDS

- ASSESSMENT

- CONSERVATION

- ENVIRONMENTV

- TRADE INTEGRATION

- $\quad$ STRATGIC PARTNERSHIP

- INSTABILITY

- $\quad$ PROSPERITY

- DISCRIMATE

- CORRUPTION $\sqrt{ }$

\section{GROUP TWO}

Q.1.

1. WEATHER - day to day.

2. TYPES OF SICKNESS - out in our environment.

3. HOW TO CONTROL POPULATION IN OUR AREA - i.e. land problems.

4. HOW TO MANAGE OUR LIVLIHOOD - in terms of resource and development.

5. INTERNATIONAL NEWS AND LOCAL NEWS - about things that would affect our living both contemporary and in the future.

6. HOW TO MANAGE TIME AND ITS IMPORTANCE

7. WE WANT TO KNOW BETTER ABOUT AID DONORS ROLE IN OUR

COMMUNITY - some of their representatives and how they function in our society. 
8. NEED PROPER COMMUNICATION - to know of disaster or hazards that are about to affect us.

9. HOW TO MANAGE HEALTHY LIVING - i.e. general hygiene.

10. LAW AND ORDER CONTROL IN OUR COMMUNITY - e.g. drinking/disorderly / stealing property etc.

11. ADULT EDUCATION - i.e. community leadership for our chiefs /elders etc.

12. AWARENESS OF HAPPENINGS - in other countries, in the world that relate to us.

13. PRICE CONTROL FOR COMMODIES - local produce sold in Honiara markets for exports i.e. copra cocoa, timber, and fish etc. Updates now and again.

14. TRANSPORT PROBLEMS - i.e. shipping problems on conditions unsafe both unhealthy and uncomfortable with high fares.

15. THIRD WORLD AND POOREST - country to be aware of and know how to make improvements to livelihood.?

Q.2.

1. ACCIDENTS HAPPENING

2. PRICES OF GOODS IN THE LCOAL STORES

3. PRISONERS

4. SHIPPING INFORMATION

5. WHEN OUR RCDF (RURAL CONSTITUENCY DEVELOPMENT FUND) IS IN HAND

6. WHAT HAPPENS WITH OUR KIDS STUDYING IN HONIARA

7. W HAT S HAPPENING INSIDE THE PARLIAMENT HOUSE - e.g. our parliament members and government information.

8. WE NEED TO KNOW DIFFERENT SCHOOLS IN AND AROUND THE COUNTRY

9. WE WANT TO KNOW DIFFERENT PRIVATE DENTAL CLINIC IN HONIARA

10. DIFFERENT SICKNESS HAPPENING

11. DIFFERENT WARDS IN THE HOSPITAL

12. DIRECTIONS INSIDE TOWN

13. BUS FARES

14. DUMPING SITES

15. NEED TO KNOW WHETHER HONIARA IS CLEAN OR NOT

16. DAY TO DAY SITUATION IN HONIARA

17. NEED TO KNOW WHETHER HONIARA WATER SYSTEM IS HYGIENIC OR NOT

18. CHURCHES - number of different churches around Honiara.

Q.3.

- $\quad$ NATIONALS

- DEVELOPING NATION

- UNCIVILISED 
- $\quad$ SOCIAL DEVELOPMENT

- $\quad$ SOCIAL CHANGE

- $\quad$ ECONOMICAL DEVELOPMENT

- $\quad$ ECONOMIC STABILITY

- $\quad$ INTERNATIONAL MONETARY FUND

- GLOBAL WARMING $\sqrt{ }$

- WORLD BANK PROJECT

- FOREIIGN EXCHANGE RATES

- $\quad$ STABEX FUND

- COUNTERPARTS

- ONE CURRENCY

- NEW WORLD ORDER

- TERRORISM

- INFLATION

- WHOV 